




TH E

\title{
RECENT PROGRESS
}

\author{
OF \\ A S T R 0 N 0 M Y
}

ESPECLALLY

IN THE UNITED STATES.

\author{
BY ELIAS LOOMIS, \\ PROFESSOR OF MATHEMATICS AND NATURAL PHILOSOPHY IN THE \\ UNIVERSITY OF THE CITY OF NEW YORK, AND AUTHOR \\ OF A COURSE OP MATHEMATICS.
}

NEW YORK:

HARPER \& BROTHERS.

1850 . 


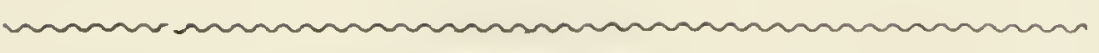
Entered, according to Act of Congress, in the year 1850, B Y -HARPER \& BROTHERS,

In the Clerk's Office for the Southern District of New York. (1)

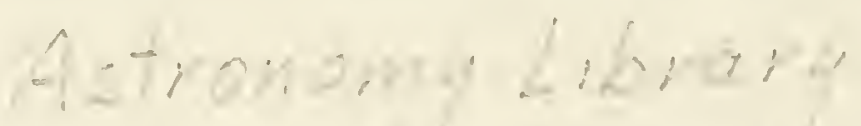




\section{P R E F A C E.}

This little volume is designed to exhibit in a popular form the most important astronomical discoveries of the past ten years. It does not profess even to enumerate all the discoreries of this period. Such an enumeration would have swelled the volume much beyond its present size. Those topics have been selected in which it was supposed the public generally would feel the deepest interest. The book was designed, not for astronomers, but for the public; and I have accordingly aimed to exhibit results in common language, as free as possible from technical terms. It is hoped that the book may be read with profit by those who have never made Astronomy a subject of special study; and that it may be found an appropriate supplement to the popular treatises on this science, most of which are very deficient in their notice of recent discoveries. It is hoped that the fourth chapter, which exhibits the progress of Astronomy in the United States, may be found to have a special interest for American readers. They may here see how far we are deserving of the compliment recently bestowed by 
the Astronomer Royal of Great Britain; "The Americuns of the United States, although late in the field of astronomical enterprise, have now taken up that science with their characteristic energy, and have already shown their ability to instruct their former masters."

I have endeavored to award equal and exact justice to all American astronomers; and if any individual should feel that his labors in this department have not been fairly represented, he is requested to furnish me in writing a minute account of the same, and I will endeavor to make amends in a second edition of the work. 


\section{0 N T E N T S.}

\section{CHAPTER I.}

RECENT ADDITIONS TO OUR KNOWLEDGE OF THE PLANETARY SYSTEM.

\section{SECTION I.}

Page

THE DISCOVERY OF THE PLANET NEPTUNE, • . . . 9

Irregularities in the Motion of Uranus, . . . . 10

Labors of Mr. Adams, . . . . . . . 16

Labors of M. Le Verrier, . . . . . . . 17

Discovery of the Planet by Dr. Galle, . . . . 24

Search for old Obserrations, . . . . . . 28

True Orbit of the Planet, . . . . . . 33

Name given to the Planet, . . . . . . . 35

Is Neptune surrounded by a Ring? . . . . . 40

Discovery of a Satellite, . . . . . . . . 43

Will Neptune account for the Anomalies of Uranus? . 45

Is Neptune the Planet predicted by Le Verrier? . . . 48

Why was not the Planet sooner discorered? . . . 56

SECTION II.

THE DISCOVERY OF SETFRAL ASTEROIDS, . . . . . 60

Six new Asteroids, . . . . . . . . 63

Are they all Fragments of a single Body ? . . . . 66

SECTION III.

DISCOVERY OF AN゙ EIGHTH SATELLITE OF SATURX;, . . . 72

SECTION IV.

NETT OBSERVATJONS OF THE SATELLITES OF URARUS, 


\section{CHAPTER II.}

RECENT ADDITIONS TO OUR FNOWLEDGE OF COMETS.

\section{SECTION I.}

TIIE GREAT COMET OF 1843, Page

Seen at Noon-day, . . . . . . . . . 80

Orbit of this Comet, . . . . . . . . 84

Has this Comet been seen before? . . . . . 88

\section{SECTION II.}

FAYE'S COMET OF 1843 ,

SECTION III.

DE VICO'S COMET OF 1844,

\section{SECTION IV.}

THE RETURN OF BIELA'S COMET IN 1846, . . . . . 99

Double Appearance of this Comet, . . . . . 100

Relation of these two Bodies, . . . . . 102

Cause of the Separation, . . . . . . 105

MISS MTCHELL's CONET, . $\quad$. . . . . . 109

SECTION VI.

EXPECTED RETUR: OF TIE COMET OF 1264, .

\section{CHAP'TER III.}

ADDITIONS TO OUR KNOWLENGE OF FIXED STARS AND NEBULE.

\section{SECTION I.}

DETERMINATIOY OF THE PARALLAX OF FIXED STARS, . . 116

Labors of Bessel, . . . . . . 118

Parallax of 61 Cygni and other Stars, . . . . . 120 


\section{SECTION II.}

OBSERVATIONS OF NEW AND VARIABLE STARS, • • . 122

The Star Eta Argus, . . . . . . . . 123

Hind's Star of 1848, . . . . . . . . 124.

Kepler's Star of 1604, • . . . . . . . 125

\section{SECTION III.}

DISTRIBUTION OF THE STARS IN SPACE, . • • • • 128

Herschel's View of the Milky Way, . . . . . 128

Abandoned by its Author in 1817, . . . . . 132

Struve's Researches on the Milky Way, . . . . 133

Sir J. Herschel's Observations in the Southern Hemisphere, 137

\section{SECTION IV.}

MOTION OF THE SUN AND FIXED STARS, . . . . . 144

Point of Space toward which the Sun is moving, . . 145

Mädler's Speculations respecting the Central Sun, . . 147

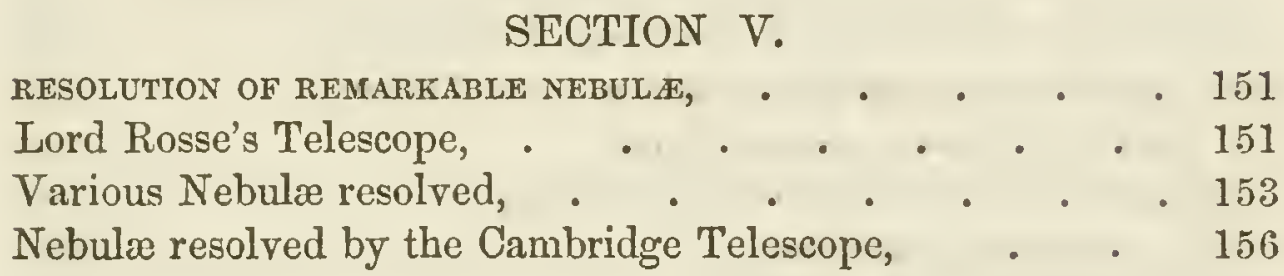

\section{CHAPTER IV.}

PROGRESS OF ASTRONOMY IN THE UNITED STATES.

\section{SECTION I.}

HISTORY OF AMERICAN OBSERVATORIES, • • • . 158

Transit of Venus in 1769, . . . . . . . 158

Yale College Observatory, . . . . . . 160

Williams College Observatory, . . . . . . 162

Western Reserve College Observatory, . . . . 163

Philadelphia High School Observatory, . . . . 165

West Point Observatory, . . . . . . . 168

National Observatory at Washington, . . . . . 171

Georgetown Observatory, D. C., . . . 179 
Cincinnati Observatory, . . . . . . . 182

Cambridge Observatory, . . . . . . . 184

Sharon Observatory, near Philadelphia, . . . . 194

Tuscaloosa (Alabama) Observatory, . • . • . 196

Mr. Rutherford's Observatory, N. Y., . . . . 196

Dartmouth College Observatory, . . . . . 198

Amherst College Observatory, . . . . . 200

Brooklyn Observatory, . . . . . . . 200

\section{SECTION II.}

ASTRONOMICAL EXPEDITION TO CHILI, . . . . . 203

\section{SECTION III.}

ASTRONOMICAL RESULTS OF PUBLIC SURVEIS, . • • 207

\section{SECTION IV.}

DETERMINATION OF LOYGITUDE BY THE ELECTRIC TELEGRAPH, 212

Experiments between New York and Washington, • , 213

Experiments between New York and Cambridge, . . 218

Dr. Locke's Electro-magnetic Clock, . • • • . 223

Application to Astronomical Observations, . . . 225

Notice of similar Inventions, . . . . . . 230

Different Modes of Registering, . . . . . . 234

Velocity of the Electric Wave, . . . . . . 235

\section{SECTION $\mathrm{V}$.}

ASTRONOMICAL PUBLICATIONS, . . . . . . 237

\section{SECTION VI.}

THE MANUFACTURE OF TELESCOPES IN THE UNITED STATES, . 242

Reflecting Telescopes, . . . . . . . . 242

Refracting Telescopes, . . . . . . . 245

Manufacture of Glass for Optical Purposes, . . . . 246

Clark's Telescopes, . . . . . . . . . 252

Fitz's Telescopes, . . . . . . . . . 253 


\section{CHAPTER I.}

\section{RECENT ADDITIONS TO OUR KNOWLEDGE OF THE PLANETARY SYSTEM.}

\section{SECTION I.}

THE DISCOVERY OF THE PLANET NEPTUNE.

The discovery of the planet Neptune, took place under circumstances most extraordinary. The existence of the planet was predicted, its path in the heavens was assigned, its mass was calculated from considerations purely theoretical. The astronomer was told where to direct his telescope, and he would see a planet hitherto unobserved. The telescope was pointed, and there the planet was found. In the whole history of astronomy we can find few things equally wonderful. This discovery resulted from the study of the motions of the planet Uranus.

Uranus was first discovered to be a planet in 1781, but it had been repeatedly observed before by different astronomers, and mistaken for a fixed star. Nineteen observations of this description are 
on record, one of them dating as far back as 1690 . In 1821, M. Bouvard, of Paris, published a set of tables for computing the place of this planet. The materials for the construction of these tables consisted of forty years' regular observations at Greenwich and Paris since 1781, and the nineteen accidental observations, reaching back almost a century further. Upon comparing these observations, Bouvard found unexpected difficulties. He was unable to combine all the observations in one elliptic orbit. When he attempted to unite the ancient with the modern observations, the former might be tolerably well represented, but the latter exhibited discordances too great to be ascribed to errors of observation. Not being able to explain this discrepancy in any satisfactory manner, he rejected the ancient observations, and founded his tables upon the observations since 1781. "It being necessary," says he, "to decide between the ancient and the modern observations, I have held to the modern ones as being the most likely to be accurate, and I leave it to time to show whether the difficulty of reconciling the two sets of observations depends upon the inaccuracy of the ancient ones, or on some foreign and unknown influence to which the planet is subjected." 
These tables represent very well the observations of the forty years from which they were derived; but soon after 1821, new discrepancies began to appear, which have lately increased with great rapidity. In 1832, the discordance between the observed and computed place of the planet, amounted to near half a minute of space, and now the error exceeds two minutes. In order to exhibit more palpably the nature of these discrepancies, I have represented them upon the figure on the next page. If the straight line, $\mathrm{AB}$, be taken to represent the path of Uranus, as computed from the elements of Bouvard, the broken line will represent the observed orbit. The deviation of these two lines indicates the discrepancy between theory and observation for the dates at the top of the page, the amount of the discrepancy being given on the left margin. If it was doubtful whether this difference in the case of the ancient observations was not due to the carelessness of the observers, no such supposition is admissible in the case of the observations since 1821. The discrepancy between Bouvard's orbit and the observations is now enormous, and is increasing with alarming rapidity.

What can be the cause of these discrepancies? Do they indicate errors in the computations of $\mathbf{M}$. 


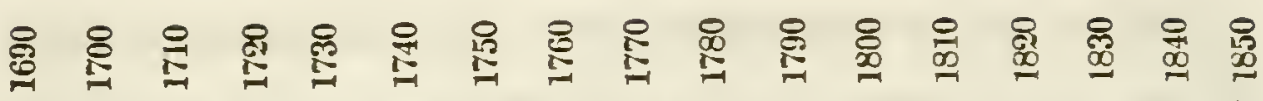
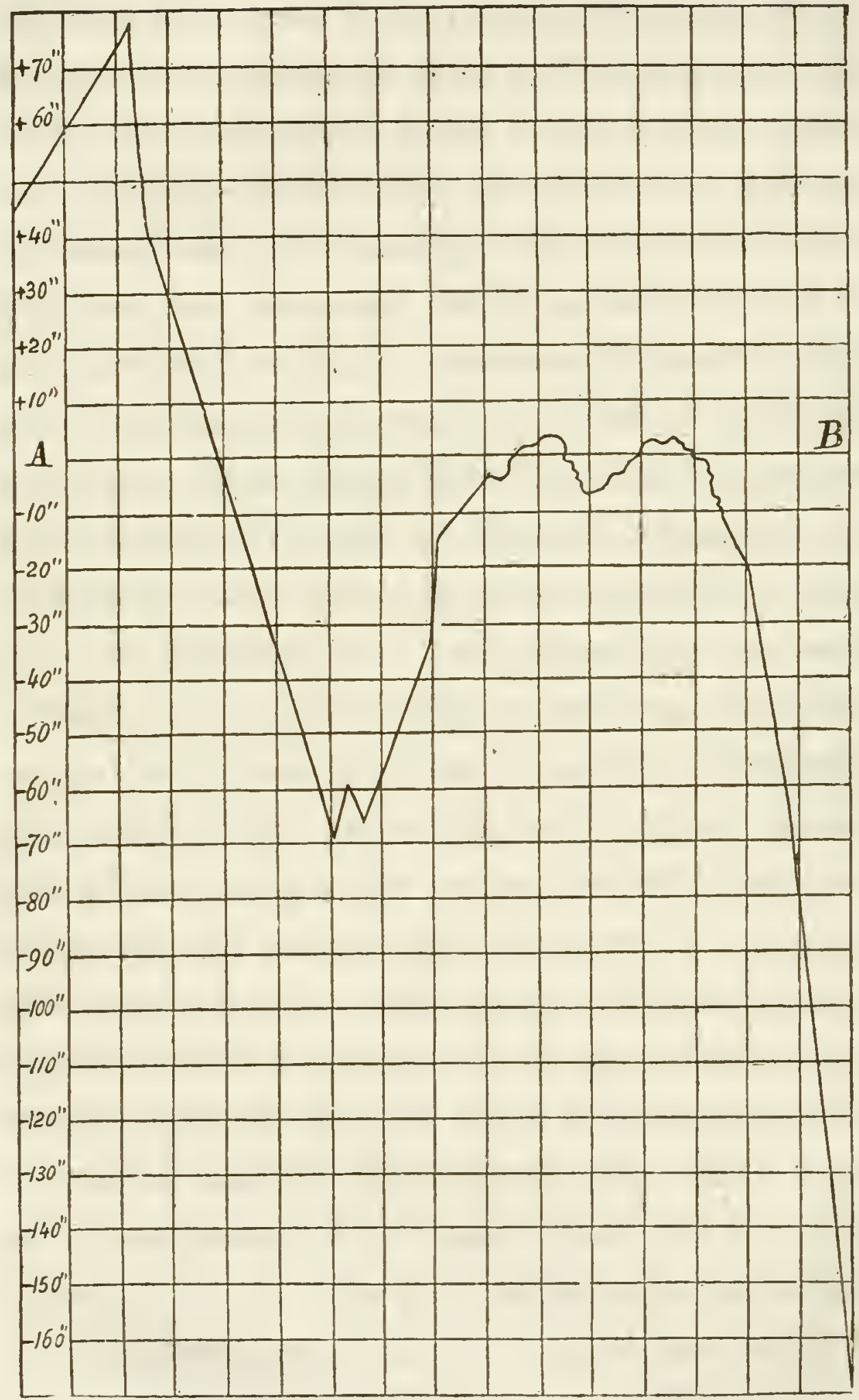
Bouvard? In order to decide this question, the illustrious Bessel, about the year 1840, subjected all the observations to a new calculation; and although he detected one or two errors of Bouvard, they did not materially influence the results. He satisfied himself that the ancient and modern observations could not be reconciled by any modification of the elements, and that the differences could not be attributed to inaccuracy of instruments, or to methods of observation. Are these anomalies due to the attraction of some unknown disturbing body? This idea was seriously entertained more than twelve years ago by Bouvard, Hansen, Hussey, Bessel, and some others. In a public lecture delivered in the year 1840, Bessel stated, "I have arrived at the full conviction that we have in Uranus a case to which Laplace's assertion, that the law of gravitation explains all the motions observed in our solar system, is inapplicable. We have here to do with discordances whose explanation can only be found in a new physical discovery. Farther attempts to explain them must be based upon the endeavor to discover an orbit and a mass for some unknown planet, of such a nature, that the resulting perturbations of Uranus may reconcile the present want of harmony in the observations." 
$\mathrm{Mr}$. Hussey, in 1834, proposed to compute an approximate place of the supposed disturbing body, and then commence searching for it with his large reflector. Mr. Airy, now Astronomer Royal of Great Britain, at that time professor in Cambridge, pronounced the problem hopeless. His words were: "If it were certain that there was any extraneous action upon Uranus, I doubt much the possibility of determining the place of the planet which produced it. I am sure it could not be done till the nature of the irregularity was well determined from several successive revolutions;" that is, till after the lapse of several centuries.

This deliberate opinion from one who, by common consent, stood at the head of British mathematicians and astronomers, would have deterred any but the most daring mathematician from attacking the problem. Again in 1837, Mr. Airy repeats the same idea: "If these errors are the effect of any unseen body, it will be nearly impossible ever to find out its place."

In the year 1842, the Royal Society of Sciences of Göttingen, proposed as a prize question, the full discussion of the theory of the motions of Uranus, with special reference to the cause of the large and increasing error of Bouvard's tables. During the 
same year, 1842, Bessel was engaged in researches relative to this problem; but his labors were soon interrupted by sickness and subsequent death; and from this time we find but two mathematicians, $\mathrm{Mr}$. Adams of Cambridge University, in England, and M. Le Verrier, of Paris, who busied themselves with the problem.

It should be remembered, that in accordance with the Newtonian law of gravitation, every body in the solar system attracts every other; that the attraction of each body is proportioned to its quantity of matter; and that in the same body the power of attraction varies inversely as the square of the distance. In order, therefore, to compute the exact place of a planet in its orbit about the sun, it is necessary not merely to regard the attraction of the central body, but also to allow for the influence of all the other bodies of the solar system. For instance, if the sun alone had acted, Jupiter would revolve around the central luminary in a perfect ellipse, which we may represent by the annexed black curve;

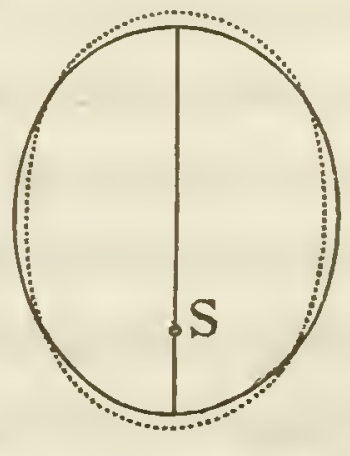
but the real orbit vibrates around this curve as in the dotted line, a curve which is not reproduced at every revolution, but will pass through an infinite 
number of variations. To compute the exact orbit which a planet will describe, subject to the attractions of all the members of the solar system, is one of the grandest problems in astronomy.

Hitherto, mathematicians had only aspired to compute the disturbing influence of one body upon another, when the magnitude and position of both bodies were known. But in the case of Uranus it was necessary to solve the inverse problem which Professor Airy had pronounced hopeless, viz., from the observed disturbances of one body, to compute the place of the disturbing body.

After taking his degree of Bachelor of Arts in January, 1843, with the honor of Senior Wrangler, $\mathrm{Mr}$. Adams ventured to attack this problem, and obtained an approximate solution by supposing the disturbing body to move in a circle at twice the distance of Uranus from the sun. His results were so far satisfactory, as to encourage him to attempt a more complete solution. Accordingly, in February, 1844, having obtained through Professor Airy a complete copy of the Greenwich observations of Uranus, he renewed his computations, which he continued during that and the subsequent years. In September, 1845, he had obtained the approximate orbit of the disturbing planet, which 
he showed to Professor Challis, the director of the observatory at Cambridge; and near the close of the next month, he communicated his results to the Astronomer Royal, together with a comparison of his theory with the observations. The discrepancies were quite small, except for the single observation of 1690. Professor Airy, in acknowledging the receipt of this letter, pronounced the results extremely satisfactory, and inquired of $\mathrm{Mr}$. Adams whether his theory would explain the error of the tables in regard to the distance of Uranus from the sun, which error he had shown to be very great. To this inquiry Mr. Adams returned no answer for nearly a year; probably because he was not able to answer the question entirely to his own satisfaction.

Meanwhile, this grand problem was undertaken by another mathematician who was entirely ignorant of the progress which $\mathrm{Mr}$. Adams had made; for none of his results had yet been published. In the summer of 1845, M. Arago, of Paris, requested M. Le Verrier, a young mathematician who had already distinguished himself by his improved tables of Mercury, to attempt the solution of this problem. This he accordingly did, and his success astonished all Europe. He commenced his investigations by 
inquiring whether the observations of Uranus could be reconciled with the supposition, that this body is subject to no other attraction than that of the sun and the known planets, acting according to the Newtonian law of gravitation. He carefully computed the effects due to the action of Jupiter and Saturn, neglecting no quantities until he had proved that their influence was insensible. He thus discovered some important terms which had been neglected by Laplace. He then compared his theory with observation, and proved conclusively that the observations of Uranus could not be reconciled with the law of gravitation, except by admitting some extraneous action. These results were communicated to the Academy of Sciences, Nov. 10, 1845; and such was the reputation secured by this and his preceding memoirs, that in January, 1846, he was elected to fill the vacancy which had occurred in the Institute in the section of Astronomy, by the death of Cassini. This memoir was but preliminary to his grand investigation; and it should be remarked, that Mr. Adams had already deposited with the Astronomer Royal at Greenwich, a paper containing the elements of the supposed disturbing planet, and agreeing closely 
with the results which Le Verrier subsequently obtained.

Le Verrier next proceeds to inquire after the cause of the discovered irregularities. Is it possible that at the immense distance of Uranus from the sun, the force of attraction does not vary inversely as the square of the distance? The law of gravitation is too firmly established to permit such a supposition, until every other resource has failed. Are these irregularities due to the resistance of a rare ether diffused everywhere through space? No other planet has afforded any indication of such a resistance. Can they be ascribed to a great satellite accompanying the planet? Such a cause would produce inequalities having a very short period; while the observed anomalies of Uranus are precisely the reverse. Moreover, it would be necessary to assign it such dimensions that it could not fail to have been visible in our telescopes. Has a comet impinged upon Uranus, and changed the form of its orbit? Such a cause might render it impossible to represent the entire series of observations by a single elliptic orbit; but the observations before the supposed collision, would all be consistent with each other; and the observations after collision would also be consistent with each other. Yet the 
observations of Uranus from 1781 to 1821 , as may be seen from the diagram, page 12 , accord neither with the earlier observations nor with the more recent ones.

There seems to remain no other probable supposition than that of an undiscovered planet. But if these disturbances are due to such a body, we can not suppose it situated within the orbit of Saturn. This would disturb the orbit of Saturn more than that of Uranus, while we know that its influence on Saturn is inappreciable, for Saturn's motion is well represented by the tables. Can this body be situated between Saturn and Uranus? We must then place it much nearer Uranus than Saturn, for the reason already assigned, in which case its mass must be supposed to be small, or it would produce too great an effect upon Uranus. Under these circumstances, its action would only be appreciable when in the immediate neighborhood of Uranus, which supposition does not accord well with the observations. The disturbing body must then be situated beyond Uranus, and at a considerable distance from it, for reasons already given. Now the distance of each of the more remote planets from the sun, is about double that of the preceding one. It is natural then to conjecture that the disturbing 
planet may be at a distance from the sun double that of Uranus, and it must move nearly in the ecliptic, because the observed inequalities of Uranus are chiefly in the direction of the ecliptic. Le Verrier then propounds the following specific problem :-

"Are the irregularities in the motion of Uranus due to the action of a planet situated in the ecliptic, at a distance from the sun double that of Uranus? If so, what is its present place, its mass, and the elements of its orbit." This problem he proceeds to resolve.

If we could determine for each day the precise effect produced by the unknown body, we could deduce from it the direction in which Uranus is drawn; that is, we should know the direction of the disturbing body. But the problem is far from being thus simple. The amount of the disturbance can not be deduced directly from the observations, unless we know the exact orbit which Uranus would describe, provided it were free from this disturbing action; and this orbit in turn can not be computed unless we know the amount of the disturbance. Le Verrier therefore computes for every nine degrees of the entire circumference, the effect which would be produced by supposing a planet situ- 
ated in different parts of the ecliptic. He finds that when he locates the supposed disturbing planet in one part of the ecliptic, the discrepancies between the observed and computed effects are enormous. By varying the place of the planet, the discrepancies become smaller, until at a certain point they nearly disappear. Hence he concludes that there is but one point of the ecliptic where the planet can be placed, so as to satisfy the observations of Uranus. Having thus determined its approximate place, he proceeds to compute more rigorously its effects; and on the first of June, 1846, he announces as the result of his investigations, that the longitude of the disturbing planet for the beginning of 1847 , must be about $325^{\circ}$.

The result thus obtained by Le Verrier, differed but one degree from that communicated by $\mathrm{Mr}$. Adams to Professor Airy, more than seven months previous. Upon receiving this intelligence, Professor Airy expressed himself satisfied with regard to the general accuracy of both computations, and immediately wrote to Le Verrier, inquiring as he had done before of $\mathrm{Mr}$. Adams, whether his theory explained the error of the tables in respect to the distance of Uranus from the sun. Le Verrier answered that it did this perfectly. Professor Airy 
was now so well convinced of the existence of a planet yet undiscovered, that he was anxious to liave a systematic search for it forthwith undertaken. The Observatory of Cambridge is provided with one of the finest telescopes of Europe, presented by the late Duke of Northumberland. Professor Airy urged upon the director, Professor Challis, to undertake the desired search, and recommended the examination of a belt of the heavens ten degrees in breadth, and extending thirty degrees in the direction of the ecliptic. This belt was to be swept over at least three times. If any star in the second sweep had a different position from that observed in the first, it might be presumed that it was the planet. If two sweeps failed of detecting the planet, it might be caught in the third.

Professor Challis commenced his search July 29th, and continued it each favorable evening, recording the exact position of every star down to the eleventh magnitude. Meanwhile Le Verrier was proceeding with his computations, and on the 31st of August, he announced to the Academy the elements he had obtained for the supposed planet. $\mathrm{He}$ assigned its exact place in the heavens, and estimated that it should appear as a star of the eighth magnitude, with an apparent diameter of 
about three seconds; and consequently that the planet ought to be visible in good telescopes, and with a perceptible disc. The fixed stars are situated at such immense distances from us, that to the most powerful telescopes they appear only as points, although with a brilliancy augmented in proportion to the size of the telescope; while all the planets exhibit a measurable disc. Le Verrier was of opinion that the new planet might be found by its possession of a visible disc, and therefore without any very great labor.

Soon after this communication was made to the Academy, Le Verrier wrote to Dr. Galle, of the Berlin Observatory, (where is found one of the largest telescopes of Europe,) requesting him to undertake a search for his computed planet, and assigning its supposed place in the heavens. The Berlin Academy had just published a chart of this part of the heavens, indicating the exact place of every star down to the tenth magnitude. On the evening of the very day upon which this letter was received, (September 23,) Galle found near the place computed by Le Verrier, a star of the eighth magnitude, not contained on the Berlin chart. Its place was carefully measured; and the observations being repeated on the succeeding evening, showed 
a motion of more than a minute of space. The new star was found in longitude $325^{\circ} 52^{\prime}$; the place of the planet computed by Le Verrier was $324^{\circ} 58^{\prime}$; so that this body was within one degree of the computed point. Its diameter measured nearly three seconds. A coincidence so exact, left no doubt that this was really the body whose effects had been detected in the motions of Uranus. Mr. Galle accordingly writes to Le Verrier, "The planet whose position you marked out actually exists." The news of the discovery spread rapidly over Europe. The planet was observed at Göttingen on the 27th of September, at Altona and Hamburgh on the 28th, and at London on the 30th.

We must now return to Professor Challis, whom we left exploring a large zone of the heavens, and recording the exact position of every star down to the eleventh magnitude. These observations were continued from the 29th of July to the 29th of September, during which time he had made more than three thousand observations of stars. On the 29th of September, Professor Challis saw for the first time Le 'Verrier's memoir communicated to the Academy August 31st. Struck with the confidence which Le Verrier manifested in his own conclusions, Professor Challis immediately changed his 
mode of observation, and endeavored to distinguish the planet from the fixed stars by means of its disc. On the same evening he swept over the zone marked out by Le Verrier, paying particular attention to the physical appearance of the brighter stars. Out of three hundred stars whose positions were recorded that night, he selected one which appeared to have a disc, and which proved to be the planet. On the first of October, he heard of the discovery at Berlin; and now on comparing his numerous observations, he finds that he has twice observed the planet before, viz., on August fourth and twelfth; but he lost the opportunity of being first to announce the discovery by deferring too long the discussion of his observations.

The news of this capital discovery was brought to this country by the steamer of Oct. 4th, and every telescope was immediately turned upon the planet. It was observed at Cambridge by $\mathrm{Mr}$. Bond, Oct. 21st; it was seen at Washington Oct. $23 \mathrm{~d}$, and was regularly observed there till Jan. 27th, when it approached too near the sun to be longel followed.

Le Verrier, although quite a young man, thus established at once an enviable reputation. He was literally overwhelmed with honors received from 
the sovereigns and academies of Europe. He was created an officer of the Legion of Honor, by the King of France, and a special chair of Celestial Mechanics was established for him at the Faculty of Sciences. From the King of Denmark, he received the title of Commander of the Royal Order of Dannebroga; and the Royal Society of London conferred on him the Copley medal. The Academy of St. Petersburg resolved to offer him the first vacancy in their body; and the Royal Society of Göttingen elected him to the rank of Foreign Associate.

Thus were the predictions of Adams and Le Verrier, with regard to the direction of the planet at the present time, wonderfully fulfilled; but is this body pursuing the orbit which these mathematicians had prescribed for it? Since its first discovery, the planet has advanced but six or seven degrees in its orbit. We have less than four years' observations to determine an orbit which it requires more than a century to complete. The computation has been made; but a result derived from so short a period must be received with some distrust, on account of the unavoidable imperfection of all observations. The best observations are liable to small errors; and a slight error in the meas- 
urement of a minute portion of the orbit, would lead to a much larger error in the computed length of the remainder of the path. We must have observations for a long series of years, to furnish the orbit with all desirable precision. Under these circumstances it becomes a question of the highest interest, whether this body may not have been observed by astronomers of former years, and mistaken for a fixed star. If we could obtain one good observation, made some time in the last century, it would enable us at once to determine the orbit with nearly the same precision as that of Jupiter itself. It will then be presumed that astronomers have not neglected to explore the records of the past, to discover if possible some chance observation of the new planet.

Mr. Hind, of London, adopting the predicted elements of Le Verrier, examined Lalande's and other observations for this purpose, and satisfied himself that the new planet was not there to be found. An American astronomer, Mr. Sears C. Walker, was more fortunate. Mr. Walker proceeded in the following manner. He first computed the orbit which best represented all the observations which had been made at the Washington Observatory, as well as those which had been re- 
ceived from Europe. He then computed the planet's probable place for a long series of preceding years, and sought among the records of astronomers for observations of stars in the neighborhood of the computed path. Bradley, Mayer, and Lacaille have left us an immense collection of observations, yet they seldom recorded stars so small as the body in question. Among the observations of Piazzi, no one was found which could be identified with the planet. The Madras observations were generally confined to the stars of Piazzi's catalogue. The Paramatta Catalogue seldom extends north of the thirty-third parallel of south declination; and Bessel, in preparing his zones of 75,000 stars, did not sweep far enough south to comprehend the planet. The only remaining chance of finding an observation of the planet was among the observations of Lalande. The Histoire Celeste Française embraces 50,000 stars, and Mr. Walker soon found that Lalande had swept over the supposed path of the planet, on the 8th and 10th of May, 1795. He accordingly computed more carefully the place of the planet for this period, making small variations in the elements of the orbit, so as to include the entire region within which the planet could possibly have been comprised. He then selected from the 
Histoire Celeste, all the stars within a quarter of a degree of the computed path. These stars were nine in number; of which six had, however, been subsequently observed by Bessel, and of course were to be set down as fixed stars. But three stars remained which required special examination; and of these, one was too small to be mistaken for the planet, and a second was thought to be too far from the computed place. The remaining star was distant only two minutes from the computed place of the planet; it was of the same magnitude, and was not to be found in Bessel's observations, although this part of the heavens must have been included in the field of his telescope. This discovery was made on the 2d of February, 1847; and on the first clear subsequent evening, February 4th, the great equatorial of the Washington Observatory was pointed to the heavens, and this star was missing. Where Lalande, in 1795, saw a star of the ninth magnitude, there remained only a blank. The conclusion seemed almost certain, that $\mathrm{Mr}$. Walker had here obtained the object of his search. $\mathrm{He}$ accordingly computed the path upon this supposition, and found that a single elliptic orbit would represent, with almost mathematical precision, the 
observation of 1795, and all the observations of 1846.

The case seemed completely made out. But there was a weak point in the argument. Lalande had marked his observation of the altitude of this star as doubtful. Could we rest the decision of a question so important upon a bad observation? How unfortunate that among the 50,000 stars contained in this precious collection, there was only one which could be presumed to have been the planet, and this observation the author had marked as doubtful! Thus the question stood-astronomers were afraid to admit, and still could not reject the conclusions of Mr. Walker. The steamer which left Boston on the first of March, carried a copy of the Boston Courier, containing the account of Mr. Walker's researches. This paper was destined for M. Le Verrier; and on the very day of its arrival, he also received a letter from Altona, dated March 21st, announcing that M. Petersen had discovered that this very star, observed by Lalande in 1795, was now missing from the heavens. M. Peter'sen's discovery was made on the 17th of March; Mr. Walker made the same discovery theoretically, February 2d; and it was confirmed by an actual inspection of the heavens, February 
4th. Mr. Walker then has the priority of six weeks in the discovery. Fortunately, the original manuscripts of Lalande had been preserved, and were deposited in the Observatory of Paris. On consulting them, it was found that the doubtful mark appended to the published observations, did not exist in the manuscript. Moreover, the star had been twice observed, viz., on the 8th and 10th of May, 1795; but as the two observations did not agree, Lalande suppressed the former, and in his printed book, marked the latter doubtful. The discrepancy between the two observations, is almost exactly that which is due to two days' motion of the planet, according to the orbit of Mr. Walker.

Thus, then, we have most unexpectedly secured two good observations in place of one doubtful one. We can no longer withhold our full belief. A single elliptic orbit represents with great precision the two observations of Lalande, and all the observations of the past three years.

Quite recently it has been announced that Dr. Lamont, of Munich, has twice observed the planet Neptune as a fixed star in his zones; the first time, Oct. 25th, 1845, when he estimated it as of the ninth magnitude; the second time was Sept. 7th, 1846, when it was entered as of the eighth magni- 
tude. The following, then, are the dates of the seven earliest observations of this planet, so far as at present known.

$\begin{array}{lrrr}1795 & \text { May } \text { 8th, } & \text { by Lalande. } \\ 1795 & \text { " 10th, } & \text { by Lalande. } \\ 1845 & \text { Oct. 25th, } & \text { by Lamont. } \\ 1846 & \text { Aug. 4th, } & \text { by Challis. } \\ 1846 & \text { Aug. 12th, } & \text { by Challis. } \\ 1846 & \text { Sept. 7th, } & \text { by Lamont. } \\ 1846 & \text { Sept. 23d, } & \text { by Galle. }\end{array}$

Let us now compare the predicted orbits of Adams and Le Verrier with the true orbit according to Mr. Walker, and the mass of the planet as deduced from Bond's observations of the satellite. 'The comparison stands as follows :-

\begin{tabular}{|c|c|c|c|}
\hline & ADAMS. & LE VERRIER. & WALKER. \\
\hline Long. of the perihelion, & $299^{\circ} 11^{\prime}$ & $284^{\circ} 45^{\prime}$ & $47^{\circ} 12^{\prime} 57^{\prime \prime}$ \\
\hline Long. of ascending node, & unknowon. & $156 \quad 0$ & $\begin{array}{lll}130 & 5 & 11\end{array}$ \\
\hline Inclination of the orbit, & anknowon. & 60 & $146 \quad 59$ \\
\hline Mean long. Jan. 1, 1847, & $323 \quad 24$ & $318 \quad 47$ & $32 \quad 44$ \\
\hline True long. Jan. 1, 1847, & $329 \quad 57$ & $326 \quad 32$ & $\begin{array}{lll}327 & 33 & 47\end{array}$ \\
\hline Eccentricity, & $0 \cdot 120615$ & 0.10761 & 0.00871946 \\
\hline Mean distance from sun, & $37 \cdot 25$ & $36 \cdot 154$ & $30 \cdot 03666$ \\
\hline Time of revolution in yrs. & $227 \cdot 323$ & $217 \cdot 387$ & $164 \cdot 6181$ \\
\hline $\begin{array}{l}\text { Mean daily motion, } \\
\text { Mass, }\end{array}$ & $\begin{array}{l}15^{. / 1609} \\
\frac{1}{6666}\end{array}$ & $\begin{array}{c}16 \cdot " 1318 \\
\frac{1}{9300}\end{array}$ & $\begin{array}{c}21^{\prime \prime} 55448 \\
\frac{1}{9} \frac{1}{400}\end{array}$ \\
\hline
\end{tabular}

In order to render the comparison more striking, I have represented on the annexed figure the orbits $\mathrm{B} *$ 


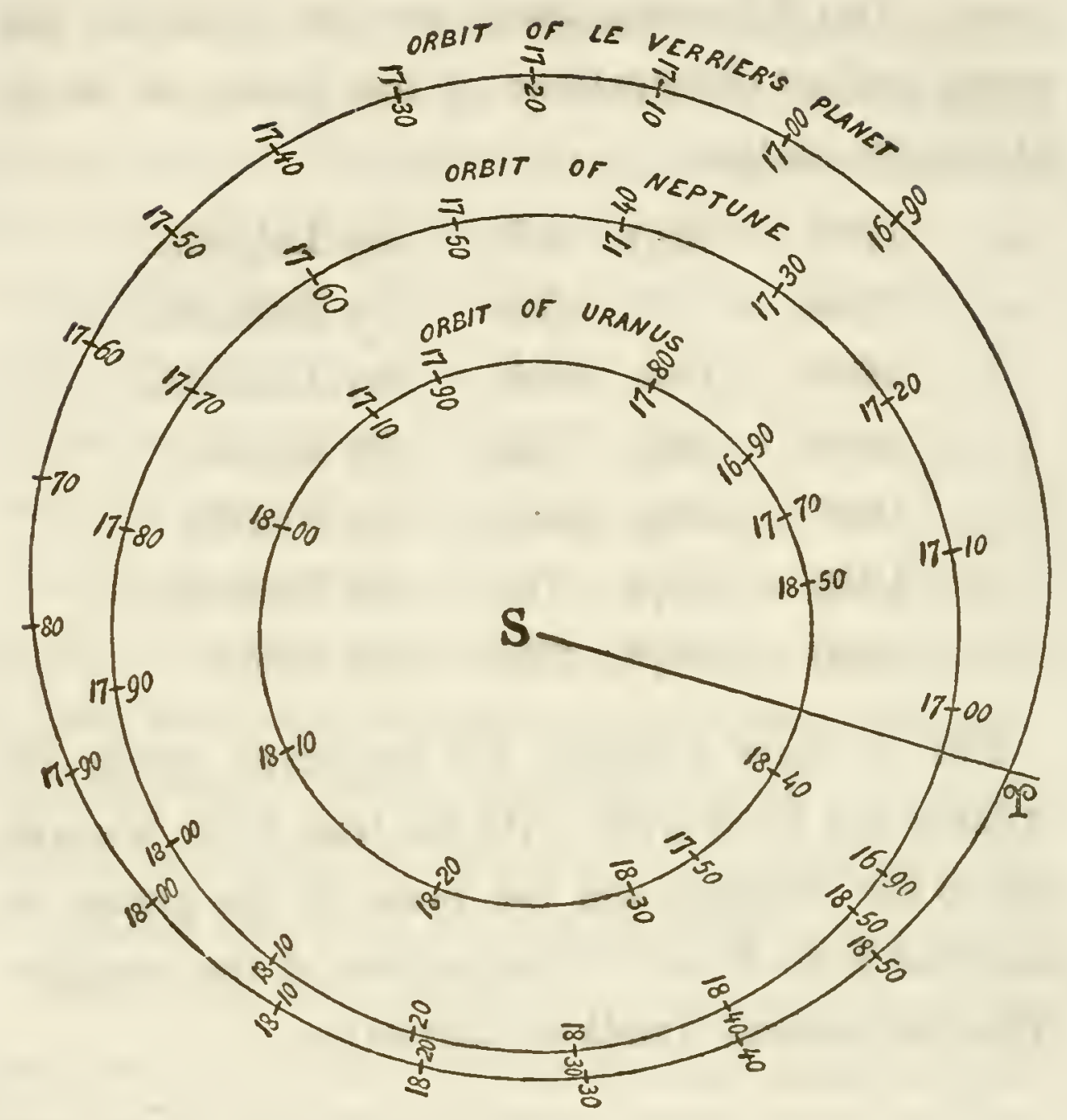

of Le Verrier and Walker. The orbits of Adams and Le Verrier are almost identical, but both differ materially from Mr. Walker; that is, we are compelled to admit that they differ considerably from the truth. They represent remarkably well the direction in which the planet is now seen from the earth, but they give its distance too great by three hundred millions of miles; and in 1690, the planet Neptune was more than four thousand millions of 
miles distant from the place assigned by Le Verrier to his planet. This discrepancy is so great as to have given occasion for the remark, that the planet actually discovered is not the planet predicted by Le Verrier. What reason there may be for this remark, I shall consider hereafter.

Some difficulty at first occurred in deciding upon a name for the new planet. The Bureau des Longitudes of Paris, were in favor of calling it Neptune, and this name was given out by Le Verrier in private letters to different astronomers in England and Germany. Subsequently, Le Verrier commissioned his friend Arago to give the planet a name; and Arago declared he would never call it by any other name than Le Verrier. When Sir William Herschel discovered a planet, he named it Georgium Sidus; and the name of "the Georgian" was retained until recently in the English Nautical Almanac. But this name being offensive to the national pride of the French, they at first called the planet Herschel, and afterward Uranus. The latter name has now come into exclusive use; but Arago, in order to secure an honor to his friend Le Verrier, proposed to restore the name of Herschel, and also that each of the smaller planets should receive the name of its discoverer. 
The astronomers of Europe refused to concur in the decision of Arago. There are objections to this principle of nomenclature, some of which have considerable weight. The name of the discoverer of a planet may happen to be immoderately long, or ludicrously short, difficult to pronounce, or comically significant. Then, also, if the same astronomer should be fortunate enough to discover more than one planet, we should be obliged to repeat the surname with a prefix. Already we have two planets discovered by Olbers; two discovered by Hencke, and two by Hind.

Moreover, it often happens that several persons contribute an important part in the discovery of the same body. Thus the planet Ceres was first discovered by Piazzi, in the course of a series of observations having a different object in view. After a few weeks, the planet became invisible from its proximity to the sun. Astronomers computed the orbit from Piazzi's observations, and searched for it some months afterward, when it ought again to have come into view. But the planet could not be found. Ceres was entirely lost, and would not have been seen again, had not Gauss, by methods of his own invention, computed a much more accurate orbit, which disclosed the exact place of the 
fugitive, and enabled De Zach to find it immediately upon pointing his telescope to the heavens. To Gauss, therefore, belongs the honor of being the second discoverer of Ceres; and the second discovery was far more glorious than the first.

The discovery of the new planet has been justly characterized by Professor Airy, as "the effect of a movement of the age." The honor of the discovery is not to be exclusively engrossed by either Adams or Le Verrier. The labors of numerous astronomers had prepared the way, and contributed more or less directly to the discovery. An eminent critic has ridiculed this idea. But $\mathrm{Mr}$. Adams himself informs us that his attention was first directed to the subject of the motions of Uranus, by reading Airy's report on the recent progress of astronomy; and Le Verrier states that in the summer of 1845 , he suspended the researches on comets, upon which he was then employed, to devote his time to Uranus, at the urgent solicitation of $\boldsymbol{M}$. Arago. Omitting several who have indirectly contributed to this result, we find four whose names will ever be honorably associated with the discovery of the planet Neptune; viz., Adams, Challis, Le Verrier, and Galle. Adams first determined the approximate place of the new planet from the perturbations of 
Uranus. Professor Challis was the first to institute a systematic search for the planet, and had actually secured two observations of it, before it was seen at Berlin. True, he did not at the time know that he had found the planet, for he had not interrogated his observations. But the prize was secured, and he would infallibly have recognized it, as soon as he had instituted a comparison of his observations. In his eager zeal to make sure of the diamond, he shoveled up with it a great mass of rubbish, and stored it all away to examine at his leisure.

To Le Verrier belongs the credit of having been the first to publish to the world the process by which he arrived at the conclusion of the existence of a new planet; and it is conceded that his researches were more complete and elaborate than those of his rival ; while to Galle belongs the undisputed honor of having been the first practically to recognize this body as a planet.

To give to the new planet the name of Le Verrier, would be indeed to confer honor where honor was due; but it would be dishonor to others whose pretensions are but little inferior to his own. The astronomers of Europe have preferred to take a name from the divinities of the Roman mythology, in conformity with a well-established usage; and 
as the name of Neptune harmonizes with this system, and withal was first suggested by the Bureau des Longitudes, they decided to adhere to it. This was the unanimous voice of Europe with the exception of France, and the astronomers of France have at length acquiesced in this decision.

The discovery of Neptune has given an unequivocal refutation to Bode's law of the planetary distances. This famous law may be thus stated. If we set down the number 4 several times in a row, and to the second 4 add 3 , to the third 4 add twice 3 or 6 , to the next 4 add twice 6 or 12 , and so on, as in the following table, the resulting numbers will represent nearly the relative distances of the planets from the sun.

\begin{tabular}{rrrrrr}
4 & 4 & 4 & 4 & 4 & 4 etc. \\
& 3 & 6 & 12 & 24 & 48 etc. \\
\hline 4 & $\frac{7}{7}$ & $\frac{1}{10}$ & $\frac{1}{16}$ & $\overline{28}$ & $\overline{52}$ etc.
\end{tabular}

If the distance of the earth from the sun be called 10, then 4 will represent nearly the distance of Mercury; 7 that of Venus; and so of the rest. This law was never accurately verified in the case of any of the planets, and Neptune forms a decided exception to it. This fact is exhibited more clearly in the following table, which shows first the true 
relative distance of each of the planets; secondly, the distance according to Bode's law, and thirdly, the error of this law.

\begin{tabular}{|c|c|c|c|c|c|c|c|}
\hline & $\begin{array}{c}\text { True } \\
\text { distance. }\end{array}$ & $\begin{array}{l}\text { Bode's } \\
\text { law. }\end{array}$ & Error. & & $\begin{array}{c}\text { True } \\
\text { distance. }\end{array}$ & $\begin{array}{l}\text { Bode's } \\
\text { law. }\end{array}$ & Error. \\
\hline Mercu & & 4 & $0 \cdot 13$ & Jupite & $52 \cdot 03$ & 52 & 0.03 \\
\hline Venus, & $7 \cdot 23$ & 7 & 0.23 & Satur & $95 \cdot 39$ & 100 & $4 \cdot 61$ \\
\hline Earth, & $10 \cdot 00$ & 10 & & Uranus, & $191 \cdot 82$ & 196 & $4 \cdot 18$ \\
\hline Mars, & $15 \cdot 24$ & 16 & $0 \cdot 76$ & Neptune, & $300 \cdot 37$ & 388 & 87.63 \\
\hline 10 Asteroids, & $25 \cdot 68$ & 28 & $2 \cdot 32$ & & & & \\
\hline
\end{tabular}

It will be seen from this table, that although this law represents pretty well the distances of the nearer planets, the error is quite large for Saturn and Uranus; and for Neptune the error is altogether overwhelming, amounting to more than eight hundred millions of miles; a quantity almost equal to the distance of Saturn from the sun. It is mere mockery to dignify such coincidences with the name of a law. A law of nature is precise-it is capable of exact numerical application. Let then the preceding rule be called the law of Bode; it is not a law of nature.

It has been the opinion of some observers, that Neptune is surrounded by a ring like Saturn. Mr. Lassell, of Liverpool, has an excellent Newtonian reflector of twenty feet focal length, and two feet aperture, with which he has made numerous obser- 
vations of the planet. On the $3 \mathrm{~d}$ of October, 1846, he was struck with the shape of the planet, as being not that of a round ball; and again, on the 10th of October, he received a distinct impression that the planet was surrounded by an obliquely situated ring. On the 10th of November, the planet appeared very much like Saturn, as seen with a small telescope, and low power, though much fainter. Several other persons also saw the supposed ring, and all in the same direction. During the season of 1847 , Mr. Lassell frequently saw the same appearance again, and found its angle of position to be 70 degrees S. W. He also satisfied himself that this appearance did not arise from any defect in his telescope.

Professor Challis states that on the 12th of January, 1847 , he received for the first time a distinct impression that the planet was surrounded by a ring. Two independent drawings made by himself and his assistant, gave the annexed representation of its appearance. On the 14th, he saw the ring again, and was surprised

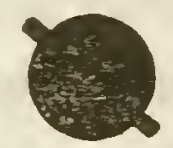
that he had not noticed it in his earlier observations. The ratio of the diameter of the ring to that of the planet, was about that of three to two.

On the other hand, the great telescope at Cam- 
bridge, Mass., shows no ring. The following is the testimony of the director, Mr. W. C. Bond. "We are satisfied that there is not at present visible any ring surrounding Neptune within the reach of the Cambridge telescope. Both my son George and myself have repeatedly had opportunities of examining the planet under high powers with the full aperture of fifteen inches, and have seen only a round disc, while our micrometrical measures of his diameter agreed well together."

When we consider that Professor Challis saw the supposed ring while the planet was very near the horizon, we may easily persuade ourselves that the elongation observed was an atmospheric phenomenon. It seems more difficult to explain away $\mathrm{Mr}$. Lassell's observations, as they were made with an excellent instrument, and have been many times repeated. Nevertheless, when we remember that the altitude of Neptune above the horizon of Liverpool is only twenty-four degrees even upon the meridian, while at Cambridge it attains the elevation of thirty-five degrees, we feel that Mr. Bond's negative testimony, founded upon repeated examinations under the most favorable circumstances, is as good as Mr. Lassell's positive testimony; and if we do not entirely deny the possible existence of a 
ring, we must at least hold our minds in suspense, and wait patiently for further evidence. It is possible that this question may never be fully cleared up, until some more powerful telescope is turned upon the planet, or it can be observed in a different part of its orbit.

Neptune is attended by at least one satellite. $\mathrm{Mr}$. Lassell states that on the 10th of October, 1846, he observed a faint star, distant from the planet about three diameters. On the 11th and 30th of November, and also December 3d, he saw a small star having about the same appearance; and he considered it probable that the star was a satellite. On the 7th of July, 1847, he again saw the supposed satellite, and on the following evening, the planet and satellite had both changed their position with reference to the neighboring stars. On the $22 \mathrm{~d}, 25 \mathrm{th}$, and $26 \mathrm{th}$ of the same month, the planet appeared attended by a satellite; and on the 1st of August he obtained the fullest evidence of the verity of the satellite, in being able clearly to ascertain that during the two hours he watched the planet, it had carried the satellite along with it in its orbital motion. On the 20th of September, $1847, \mathrm{Mr}$. Lassell announced that during the current year he had obtained twenty observations of 
the satellite, and from them all he concluded that its time of revolution was five days, twenty hours, and fifty minutes. Mr. Bond at Cambridge, during the years 1847 and 1848, obtained repeated measures of the distance and angle of position of this satellite by means of a micrometer with illuminated wires. By a combination of all the Cambridge observations, $\mathrm{Mr}$. Bond has deduced the time of revolution five days and twenty-one hours. The radius of its orbit is sixteen and a half seconds, which gives about 230,000 miles for the distance of the satellite from the planet. The light of the satellite is nearly equivalent to that of a star of the fourteenth magnitude. It is always more brilliant in the S. W. than in the N. E. part of its orbit, presenting, in this respect, a striking analogy with the outer satellite of Saturn. In the former position, Mr. Lassell found it easy to observe, in the latter, extremely difficult.

The preceding results enable us to compute the mass of Neptune, which is found to be $\frac{1}{18780}$ part of the sun. By employing Bond's observations alone, we find the mass to be $\frac{1}{19400}$ part of the sun.

Mr. Bond states that he has at times been quite confident of seeing a second satellite, but has never 
yet been able to obtain successive measures of its distance from the primary.

The grand question still remains untouchedWill the new planet explain the observed irregularities in the motion of Uranus?

The planet having been actually discovered in the heavens, by means of certain predicted elements, and within one degree of the predicted place, the natural conclusion was, that those elements were extremely near the truth, and that the planet would perfectly explain those effects by whose study its own existence had been detected. When, however, observation had rendered it certain that the planet moved in a smaller and less eccentric orbit than had been predicted, it became doubtful whether it would account for the anomalies in the motion of Uranus. When Le Verrier, in March, 1847 , received notice of the computations of $\mathrm{Mr}$. Walker, who obtained an orbit differing but little from a circle, he at once pronounced the small eccentricity incompatible with the observed perturbations. Mr. Adams, in a letter of June 11th, 1847, says, "I am hard at work on the perturbations of Uranus, in order to obtain a new theoretical determination of the place. The general values of the perturbations are enormous, far exceeding any 
thing else of the same kind in the system of the primary planets. A comparison of the numerical expressions for the perturbations, which I have now obtained, with those which I used before, would justify some skepticism as to former conclusions. But we shall soon see how this great apparent difference affects the result."

By referring to the table on page 33 , it will be seen that Adams and Le Verrier explain the anomalies of Uranus by assuming a very large body (having twice the mass of Uranus) moving in a very eccentric orbit. It is now discovered that the orbit hardly differs at all from a circle, and that the mass is less than one half of that which had been assumed. Now the more eccentric the orbit, the greater must be the inequality of a planet's action upon other bodies whose orbits are nearly circular. A considerable part of the observed irregularity in the motion of Uranus, was explained by Adams and Le Verrier, by means of the great eccentricity ascribed to their hypothetical planet. This portion is now gone with the failure of the eccentricity. But, on the other hand, Neptune is found to be much nearer Uranus than the hypothetical planet, and in consequence of this proximity, its disturbing action is increased, so that 
these two variations of the elements partly compensate each other. The mass of Neptune is also less than the hypothetical planet of Le Verrier, and on this account its disturbing action is diminished. To what extent the planet Neptune will account for the perturbations of Uranus, has only been recently determined. Professor Pierce has shown that the motions of Uranus are perfectly explained, provided we adopt Mr. Walker's orbit, and the mass of Neptune which is derived from Mr. Bond's observations of Lassell's satellite. By his computations, the great anomalies which had been observed, and which are represented on page 12, almost entirely disappear. All the modern observations are represented quite as well as by the theories of Adams and Le Verrier, and the observation of 1690 much better. The error of Flamsteed's observation of 1690 , according to Adams's computation, was 50", and according to Le Verrier's computation, 20" ; but according to Pierce's theory, this observation is represented within a single second.

So then the anomalies of Uranus, which had so long perplexed astronomers, are perfectly accounted for. But it is obvious, from a glance at the diagram on page 34 , that the planet actually discovered is 
moving in an orbit considerably different from what had been computed, so that it has been claimed that Neptune is not the planet whose existence had been predicted by Le Verrier. Is this discrepancy between the observed and predicted orbits of a serious nature; and if so, how is it to be accounted for? This question has been fully discussed by Le Verrier himself. Le Verrier attempted to deduce the position of a new planet, by studying the irregularities in the motion of Uranus. The data which he was obliged to employ, were liable to some uncertainty. This uncertainty of the data did not result merely from the uncertainty of the observations, but from two other causes, viz., a possible error in the mass of Saturn sufficient to add $3^{\prime \prime}$ to the uncertainty of the observations, and from the possible influence of a planet situated beyond Neptune, whose action upon Uranus might easily amount to $5^{\prime \prime}$ or $7^{\prime \prime}$. The uncertainty of the data results from the combination of these three effects, and might amount to $10^{\prime \prime}$ or $12^{\prime \prime}$, while the uncertainty of the modern observations does not exceed $2^{\prime \prime}$ or $3^{\prime \prime}$. Now the irregularities in the motion of Uranus, which serve as the basis of the discussion, do not exceed at the utmost two minutes of space, and for the most part they are less than one minute; 
so that the data were uncertain to one tenth of their whole amount. Le Verrier, therefore, claims that it is unreasonable to demand of him a greater degree of accuracy in the positions assigned to his computed planet, than one tenth of their value, and he has attempted to show that these positions are not in error by so large a quantity. Moreover, as he computes the position of his planet only by means of the disturbance which it causes in the motion of Uranus, he can only compute this position when this disturbance is appreciable. Now this disturbance, on account of the distance of the planets from each other, is inappreciable from 1690 to 1812 . It was only from 1812 to 1842 , that he was furnished with observations in which the disturbing action of Neptune was sensible, and the place of the planet for any other time must be deduced from its motion during these 30 years. He then proceeds to show that the positions he had assigned to Neptune during this period, and also for a much longer time, were not in error by one tenth of their whole amount. Let us consider,

I. The error in the computed longitudes of Neptune.

The following is the comparison between Le Verrier's predicted places and those resulting 
from Mr. Walker's orbit during a period of 120 years.

$\begin{array}{cccc}\text { Year. } & \begin{array}{c}\text { Predicted } \\ \text { longitude. }\end{array} & \begin{array}{c}\text { Longitude according } \\ \text { to Mr. Walker. }\end{array} & \begin{array}{c}\text { Error. } \\ 155.05\end{array} \\ 1767 & 174.03 & 18.08 \\ 1777 & 190 \cdot 4 & 176.7 & +13.7 \\ 1787 & 207.6 & 198.0 & +9.6 \\ 1797 & 225.9 & 219.3 & +6.6 \\ 1807 & 245.2 & 240.7 & +4.5 \\ 1817 & 265.3 & 262.2 & +3.1 \\ 1827 & 285.9 & 283.9 & +2.0 \\ 1837 & 306.4 & 305.7 & +0.7 \\ 1847 & 326.5 & 327.5 & -1.0 \\ 1857 & 345.7 & 349.7 & -4.0 \\ 1867 & 3.9 & 11.6 & -7.7 \\ 1877 & 20.9 & 33.6 & -12.7 \\ 1887 & 36.9 & 55.5 & -18.6\end{array}$

Thus it appears that during a period of 120 years, the longitude of Neptune, according to Le Verrier's computation, did not differ from that determined by Mr. Walker from the observations, more than $18^{\circ} 8$, or about one twentieth part of an entire circumference; and during the period in which the action of Neptune has been clearly marked, that is, since 1812, the error of Le Verrier's theory has not exceeded $3^{\circ} \%$. For 1690 , the theory is indeed very much at fault, but that is the result of a compara- 
tively small error in the positions assigned during the present century.

II. The error in the computed distance from the sun.

The following table shows the distance of the planet from the sun, as predicted by Le Verrier, and that deduced from the computations of $\mathrm{Mr}$. Walker, the distance being expressed in radii of the earth's orbit.

$\begin{array}{rccc}\text { In } 1812 & \begin{array}{c}\text { Predicted } \\ \text { distance. }\end{array} & \begin{array}{c}\text { Observed } \\ \text { distance. }\end{array} & \text { Error. } \\ 1822 & 32 \cdot 7 & 30 \cdot 4 & +2 \cdot 3 \\ 1832 & 32 \cdot 6 & 30 \cdot 3 & +2 \cdot 0 \\ 1842 & 32 \cdot 8 & 30 \cdot 2 & +2 \cdot 4 \\ & & 30 \cdot 1 & +2 \cdot 7\end{array}$

Thus it appears that during the 30 years in which the action of Neptune upon Uranus has been sensible, the error of the predicted distance from the sun has never amounted to one tenth of the whole quantity.

There appears, however, a discrepancy between the limits of distance which Le Verrier assigned to his planet before its discovery, and those which he has since published. In 1846, he attempted to de. termine the limits within which the distance might be supposed to vary without involving an error greater than $5^{\prime \prime}$ in any of the observations since 
1781. He decided that the mean distance could not be less than $35 \cdot 04$, nor more than $37 \cdot 90$. Now the mean distance of Neptune from the sun is known to be only $30 \cdot 04$. From these two propositions the legitimate conclusion would seem to be that Neptune is not the planet predicted by Le Verrier. But Le Verrier has lately changed his ground, and he has discovered that without supposing the uncertainty of the modern data to exceed $5^{\prime \prime}$, the theory of Uranus may be satisfied by a planet situated in 1846 at any distance from the sun between $29^{\circ} 6$ and $35 \cdot 2$. It is not obvious how this last statement can be reconciled with the limits published in 1846 . Doubtless Le Verrier has discovered that the limits which he first assigned were erroneous. If we compare the predicted mean distance with that deduced from the observations, we shall find the error of the former to amount to one fifth of the whole quantity.

III. The error in the eccentricity of Neptune.

Le Verrier assigned to the orbit of his planet an eccentricity of 0.1076 ; the computations of $\mathrm{Mr}$. Walker make the eccentricity of Neptune 0.0087 .

The discrepancy is considerable; but Le Verrier states that if we admit an uncertainty of $5^{\prime \prime}$ only in the modern data, the eccentricity of the body pro. 
ducing the irregularities of Uranus may be chosen arbitrarily between 0.2031 and 0.0592 ; and if we admit an uncertainty of $7^{\prime \prime}$ or $8^{\prime \prime}$ in the modern data, the eccentricity may have any value between 0.25 and zero. Professor Pierce has shown that the planet Neptune, with an eccentricity almost zero, reconciles all the modern observations of Uranus within $3^{\prime \prime}$.

IV. Error of the computed mass of Neptune.

The mass assigned by Le Verrier to his predicted planet was $\frac{1}{930} \overline{0}$ of the sun's mass; but he adds, that if we admit an uncertainty of $5^{\prime \prime}$ in the data, this mass may have any value between $\frac{1}{4700}$ and $\frac{1}{14500}$. The mass of Neptune deduced by Struve, from his own observations of the satellite, is $\frac{1}{14 \frac{1}{44}}$; but the mass deduced by $\mathrm{Mr}$. Bond, from the Cambridge observations, is $\frac{1}{19400}$. The former value comes fairly within the limits assigned by Le Verrier, the latter somewhat exceeds them.

On the whole, we must conclude that the orbit of Neptune agrees with the orbit predicted by Le Verrier, very nearly within the limits which Le Verrier now assigns, upon the supposition of an uncertainty of $5^{\prime \prime}$ in the data since 1781. But these limits, with respect to distance and time of revolution, are very different from those assigned before 
the discovery of the planet. The orbit of Neptune is not included within the limits which Le Verrier then assigned; and it is a legitimate inference, from his own premises, that Neptune is not the planet whose existence he had announced. But now that Le Verrier has discovered an error in his computations, we must admit that Neptune accords with the planet of theory quite as well as could have been reasonably anticipated.

But it will naturally be asked, how has it happened that two astronomers, Adams and Le Verrier, have arrived, by independent computations, at almost identically the same result, and have made such mistakes with respect to the mean distance, eccentricity, and mass of the planet? The answer is plain: they were misled by placing too great confidence in Bode's law of the planetary distances. Since it was necessary, in the first instance, to make some hypothesis with regard to the distance of the disturbing body from the sun, both computers started with that supposition which was generally thought most probable. The distance of Saturn from the sun is nearly double that of Jupiter; the distance of Uranus is almost exactly double that of Saturn; hence it seemed probable that the planet they were in search of, would be found at a distance about 
double that of Uranus. Accordingly this assumption was made the basis of their first computations; but neither of the computers accepted this as his final result, without attempting to verify it. They both varied the assumed distance, and found that by bringing the planet a little nearer the sun, the observed irregularities of Uranus were still better explained. The distance of $36 \cdot 154$, (or about 3435 millions of miles) finally adopted by Le Verrier, was that which appeared to reconcile all the observations most satisfactorily. This distance corresponds to a period of two hundred and seventeen years. Le Verrier found (or thought he found) that whether he increased or diminished this distance, the observations of Uranus were not so well represented. He hence inferred that the mean distance from the sun could not be less than $35^{\circ} 04$, nor greater than $37 \cdot 90$. (Le demi-grand axe de l'orbite ne peut varier qu'entre les limites 35.04 et $37 \cdot 90$.) The periods of revolution corresponding to these distances are about 207 and 233 years. This conclusion was unauthorized, and is now admitted by Le Verrier to have been erroneous. The mean distance of Neptune from the sun is only thirty times that of the earth, and still it explains the mo- 
tions of Uranus even better than the hypothetical planet of Le Verrier:

To some it has appeared a matter of surprise that the new planet was not sooner discovered. Le Verrier's second memoir, which assigned the probable place of the disturbing body, was presented to the Academy on the first of June, 1846; and his third memoir (containing every thing which Dr. Galle had in his possession at the time of his discovery) was presented August 31st; yet Galle's discovery was not made till September 23d. What were the astronomers of Paris doing meanwhile? Why did they not immediately point their telescopes to the heavens? Why did they neglect the opportunity of securing to France the glory of both the theoretical and practical discovery, and leave to a German astronomer the verification of the sublimest theory of modern science? The answer is plain. The astronomers of Paris did not expect to find a planet within one degree of the place computed by Le Verrier. Le Verrier himself did not expect it. He assigned the most probable place of his planet in longitude $325^{\circ}$. He expressed the opinion that its longitude would not be less than $321^{\circ}$, nor more than $335^{\circ}$. But he adds, "If the planet should not be discovered within these limits, then we must 
extend our search beyond them." If he was sure of being able to find his planet without a long-continued and laborious search, why did he not borrow a telescope, and at once verify his own predictions?

Nor had the astronomers of the rest of Europe much higher faith than those of Paris. Professor Encke, in announcing the discovery, characterizes it as "far exceeding any expectations which could have been previously entertained." That Professors Airy and Challis, although they were pretty well satisfied of the existence of a planet yet undiscovered, regarded its exact place in the heavens as extremely uncertain, is plain from their comprehensive plan of observation, viz., to sweep three times orer a belt of the heavens, thirty degrees in length, and ten degrees in breadth; a plan which Professor Challis states it would have been impossible for him to complete within the year 1846 .

Do we then charge Encke and Airy with a want of sagacity? By no means. On the contrary, we maintain that they had no reason to expect to find the planet within one degree of the computed place. Le Verrier's own statement of the limits within which the planet should be sought for, is sufficient proof of this. "L'incertitude des données pourrait produire une incertitude de plus de 18 dégrés dans 
le lieu de l'astre, a l'une des epoques ou l'on pourait le mieux repondre de sa position. The uncertainty of the data caused an uncertainty of more than eighteen degrees in the position of the planet, even at the time when its situation was best determined." Professor Challis, therefore, proceeded like a sagacious as well as brave general. He contemplated a long siege-yet his plan rendered ultimate success almost certain. Dr. Galle took the citadel by storm -yet he had no reason to expect so easy a conquest. His success must have astonished himself as much as it did the world.

Let us then be candid, and claim for astronomy no more than is reasonably due. When in 1846 Le Verrier announced the existence of a planet hitherto unseen, when he assigned its exact position in the heavens, and declared that it shone like a star of the eighth magnitude, and with a perceptible disc, not an astronomer of France, and scarce an astronomer in Europe, had sufficient faith in the prediction to prompt him to point his telescope to the heavens. But when it was announced that the planet had been seen at Berlin; that it was found within one degree of the computed place; that it was indeed a star of the eighth magnitude, and had a sensible disc, then the enthusiasm not merely of 
the public generally, but of astronomers also, was even more wonderful than their former apathy. The sagacity of Le Verrier was felt to be almost superhuman. Language could hardly be found strong enough to express the general admiration. The praise then lavished upon Le Verrier was somewhat extravagant. The singularly close agreement between the observed and computed places of the planet was accidental. So exact a coincidence could not have been reasonably anticipated. If the planet had been found even ten degrees from what Le Verrier assigned as its most probable place, this discrepancy would have surprised no astronomer. The discovery would still have been one of the most remarkable events in the history of astronomy, and Le Verrier would have merited the title of First Astronomer of the age. 


\section{SECTION II.}

THE DISCOVERY OF SEVERAL ASTEROIDS.

The planet Ceres was discovered at Palermo, in Sicily, on the 1st of January, 1801, by Piazzi. He continued to observe it until the 12th of February, when he was compelled by illness to discontinue his observations. It was rediscovered on the 7 th of December by De Zach, almost exactly in the place computed by Gauss.

The planet Pallas was discovered at Bremen on the 28th of March, 1802, by Dr. Olbers, and its mean distance from the sun was found to be almost exactly the same as that of Ceres. It is nearly of the same magnitude with Ceres, and the orbits of these two planets mutually intersect.

The planet Juno was discovered by Harding at the observatory of Lilienthal, near Bremen, on the evening of the 1st of September, 1804. While this astronomer was forming a chart of all the stars, down to the eighth magnitude, which are near the orbits of Ceres and Pallas, he observed a small star 
of the eighth magnitude, which was not mentioned in the Histoire Celeste of Lalande. Two days afterward the star disappeared; but he perceived another which he had not noticed before, resembling the first in size and color, and situated a little to the south-west of it. He observed it again on the 5th of September, and finding that it had moved a little farther to the south-west, he concluded that this star belonged to the planetary system. Its diameter and distance from the sun are a little less than those of the other new planets.

On account of the regularity observed in the distances of the old planets from the sun, some astronomers had conjectured that a planet existed between the orbits of Jupiter and Mars. This conjecture was verified in the discovery of Ceres; but the opinion which it seemed to establish respecting the harmony of the solar system, appeared to be completely overturned by the discovery of Pallas and Juno. Dr. Olbers, however, imagined that these smiall bodies were merely the fragments of a larger planet, which had exploded from some internal convulsion, and that several more might yet be discovered between the orbits of Mars and Jupiter. $\mathrm{He}$ concluded that though the orbits of all these fragments might be differently inclined to the ecliptic, 
yet as they must all have diverged from the same point, they ought to have two common points of reunion, or two nodes in opposite regions of the heavens, through which all the planetary fragments must sooner or later pass. One of these nodes Dr. Olbers found to be in Virgo, and the other in the Whale, and it was actually in the latter of these positions that Harding discovered the planet Juno. With the intention, therefore, of detecting other fragments of the supposed planet, Dr. Olbers examined thrice every year all the little stars in the opposite constellations of the Virgin and the Whale, till his labors were crowned with success on the 29th of March, 1807, by the discovery of a new planet in the constellation Virgo, to which he gave the name of Vesta. The orbit of Vesta cuts the orbit of Pallas, but not in the same place where it is cut by that of Ceres.

Dr. Olbers continued his systematic examination of the same parts of the heavens, with untiring perseverance, till 1816, up to which time he felt confident that no new planet had passed. The search for new planets seemed now to have been generally abandoned as hopeless; but at length on the 8th of December, 1845, another was discovered by $M$. Hencke of Driesen. M. Hencke being employed 
in observations of the planet Vesta, examined attentively the stars in its vicinity, and found one of the ninth magnitude which was not upon his chart, nor upon that of the Berlin Academy. As he had bestowed great care upon his chart of this part of the heavens, he felt confident that he had found a planet, and immediately announced the discovery. On the 14th, the planet was observed at Berlin, and its true character was speedily recognized. It received the name of Astraea. Its distance from the sun was found to be greater than that of Vesta, but less than that of either of the remaining asteroids.

The discovery of Astraea stimulated astronomers to renew their systematic search for other fragments, and their labors have been singularly successful. On the 1st of July, 1847, Mr. Hencke (the discoverer of the planet Astraea) found a star of about the ninth magnitude, not marked on the Berlin charts. On the $3 \mathrm{~d}$, he observed it again, and perceived that its place had changed. The new star was then, without doubt, a planet, and it received the name of Hebe. Its distance from the sun was a little less than that of Astraea.

On the 13th of August, 1847, a new planet was discorered by $\mathrm{Mr}$. Hind of London. Mr. Hind had previously prepared charts of stars down to the 
tenth magnitude for some of the hours of Right Ascension, and on the 13th of August was comparing the map of Hour XIX with the heavens, when he found a star of the ninth magnitude, in a position where none had been seen the preceding month. By employing a micrometer, he was enabled, in less than half an hour, to establish its motion, and thus convinced himself that he had discovered a new planet, to which he immediately gave the name of Iris. Its distance from the sun was found to be nearly the same as that of Vesta.

On the 18th of October, 1847, Mr. Hind (the discoverer of the planet Iris) detected another planet belonging to the same group. It appeared like a star of the ninth magnitude, and received the name of Flora. Its distance from the sun is less than that of either of the other asteroids.

On the 25th of April, 1848, a new planet was discovered by Mr. Graham, at Markree, in Ireland. It appeared like a star of the tenth magnitude, and its distance from the sun is about the same as that of Vesta. It has received the name of Metis.

On the 12th of April, 1849, as M. De Gasparis of Naples was comparing Steinheil's chart of the stars of the twelfth hour of Right Ascension with the heavens, he discovered a new planet. It resembled 
a star of between the ninth and tenth magnitudes. The weather prevented complete observations on the 12th; but on the 14th, and each succeeding evening to the 20 th, he compared its place with a neighboring star, and found that during this interval its motion amounted to about ten minutes daily. This planet has received the name of Hygeia. Its distance from the sun is considerably greater than that of either of the other asteroids, and its orbit is less inclined to the ecliptic.

The rapid discovery of six new asteroids, after a barren interval of almost forty years from the discovery of Vesta, is calculated to excite surprise; but it is explained by the diminutive size of the new planets, and the great increase in the number of observers, and the use of more powerful instruments. Vesta appears like a star of the sixth magnitude, while Ceres, Pallas, and Juno, are of the eighth. The six asteroids lately discovered are all of about the ninth magnitude, except Metis, which is of the tenth or eleventh. The reason that Olbers was not more successful in his search was, that he did not extend his examination beyond stars of the eighth magnitude.

The following table exhibits a summary of the principal elements of the ten asteroids, the distance 
from the sun being given in radii of the earth's orbit.

\begin{tabular}{|c|c|c|c|c|c|c|}
\hline & & $\begin{array}{l}\text { Distance } \\
\text { from sun. }\end{array}$ & $\begin{array}{l}\text { Time of } \\
\text { revolution } \\
\text { in days. }\end{array}$ & $\begin{array}{l}\text { Eccentri- } \\
\text { city. }\end{array}$ & $\begin{array}{l}\text { Inclination } \\
\text { of orbit. }\end{array}$ & $\begin{array}{l}\text { Long. of } \\
\text { ascending } \\
\text { node. }\end{array}$ \\
\hline Flora, . & . & $2 \cdot 202$ & 1193 & 0.157 & $6^{\circ}$ & $110^{\circ}$ \\
\hline Vesta, . & . & $2 \cdot 361$ & 1325 & $\cdot 090$ & 7 & 103 \\
\hline Iris, & - & $2 \cdot 385$ & 1345 & $\cdot 232$ & 5 & 260 \\
\hline Metis, . & . & $2 \cdot 386$ & 1346 & $\cdot 120$ & 6 & 69 \\
\hline Hebe, . & . & $2 \cdot 426$ & 1380 & .200 & 15 & 138 \\
\hline Astraea, & - & 2.577 & 1511 & $\cdot 188$ & 5 & 141 \\
\hline Juno, . & . & $2 \cdot 671$ & 1594 & $\cdot 255$ & 13 & 171 \\
\hline Ceres, . & . & $2 \cdot 768$ & 1682 & .077 & 11 & 81 \\
\hline Pallas, . & . & $2 \cdot 773$ & 1686 & $\cdot 240$ & 35 & 173 \\
\hline Hygeia, & - & $3 \cdot 131$ & 2024 & .095 & 4 & 288 \\
\hline
\end{tabular}

The existence of ten planets revolving round the sun at nearly the same distances, and differing from all the other planets in their diminutive size, is one of the most singular phenomena in our solar system. It appears wholly at variance with the general harmony of the system, and with the regularity observed elsewhere with regard to the planetary distances, and naturally suggests the idea that these ten bodies once belonged to a large planet which revolved between Mars and Jupiter. If we admit that these planets are the remains of a larger body, since they must have diverged from the same point, they must, as has been already intimated, have two common points of reunion in opposite regions of the heavens, through which all the fragments must 
pass. The following diagram will show how nearly this conclusion conforms to observation.

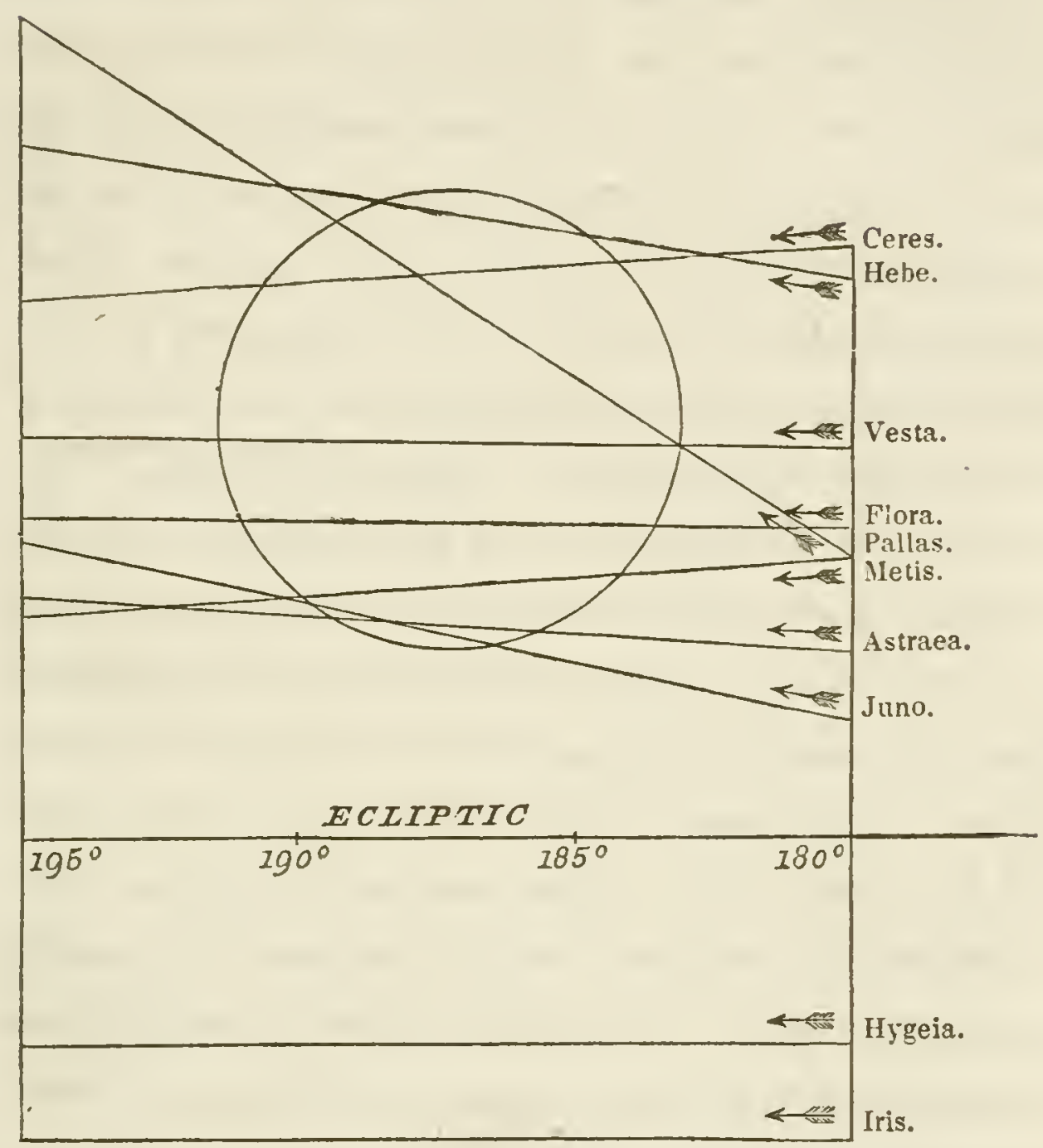

This diagram represents a portion of the orbits of the asteroids as seen from the sun, corresponding to a heliocentric longitude of $180^{\circ}$ to $195^{\circ}$, and the circle which is added, has a radius of four degrees. We perceive, then, that a circle of four degrees radius embraces a portion of the orbit of each of the 
asteroids, except Iris and Hygeia. In the position of their ascending node, Iris and Hygeia are almost diametrically opposed to the other asteroids. It may be thought that the theory of Olbers requires that the orbits should all pass exactly through the same point; and inasmuch as the orbits of the eight can only be brought within a circle of four degrees radius, while the ninth and tenth wander almost nine degrees from this circle, the theory of a common origin has but slight foundation. The answer to this objection is, that the orbits are disturbed by the attractions of the other planets; and that the theory only requires that the orbits should have had a common point of intersection about the time of separation. Since that period, the position of the nodes, that is, the point in which the orbits intersect the ecliptic, must have been continually changing, so that at present there remains but an obscure trace of their former coincidence. Some attempts have been made to determine whether the nodes of the orbits of the asteroids indicate any such motion as is consistent with the theory; but now that the number of the asteroids has so much increased, the computation has become exceedingly laborious. The nodes of all the planetary orbits are in constant motion, but the motion for a single 
year is extremely small. The annual motion of the node of Mercury is eight seconds; that of Venus eighteen seconds, Mars twenty-three seconds, Jupiter sixteen seconds, Saturn nineteen seconds, and of Uranus thirty-six seconds. The nodes of the asteroids, so far as the computation has been made, move at somewhat similar rates. By referring to the table on page 66 , it will be seen that the longitude of the nodes (employing the descending node of Iris and Hygeia, and the ascending node of each of the other planets, ) varies from 69 to $173^{\circ}$, being a range of $104^{\circ}$ If we suppose these two nodes to approach each other at a uniform rate of forty seconds a year, it would require a lapse of 9360 years to bring them to coincidence. We may safely assume that the nodes of all the asteroids have not coincided within a period of many thousand years; and therefore, that if these bodies are the fragments of a larger planet which has exploded, this explosion must have taken place at a very remote epoch.

It should also be observed, that not only must the nodes of all the asteroids coincide, but the distance of the planets from the sun must be the same at that instant. Now the distance of these planets from the sun when at their nodes, varies by nearly 
the radius of the earth's orbit; so that to bring them all together, we must suppose a corresponding change in the place of their perihelions. This also would require the lapse of many centuries; and when we consider the necessity of a coincidence at the same instant, both in distance and direction, we can easily suppose that such a result could not have taken place within a million of years.

The difficulties in the way of our regarding these small planets as fragments of a single body, were well nigh insuperable before the discovery of $\mathrm{Hy}$ geia. This last discovery has probably given the final blow to the theory of Olbers. The orbit of Hygeia completely incloses the orbits of several of the asteroids; its perihelion distance, that is, its least distance from the sun, exceeding the aphelion distance of Flora and Vesta by tuenty-five millions of miles. No change of position of the orbits could therefore bring these orbits to coincidence. It is necessary to admit, at the same time, a great variation of the eccentricity. But the change of eccentricity of the planetary orbits is exceedingly slow, and the present rate of increase of the eccentricity of Vesta must be continued twenty-seven thousand years to render the aphelion distance of that planet equal to the perihelion distance of Hygeia. 
On the whole, then, although the great similarity of the orbits of these ten bodies indicates some peculiar connection distinguishing them from all the other planets, still if we are disposed to regard them as fragments of a single body, we must suppose the separation to have taken place at a period immeasurably remote. The same theory would lead us to anticipate the discovery of numerous other fragments; but those yet undiscovered are doubtless extremely minute. Already we have one asteroid of the sixth magnitude, three of the eighth, five of the ninth, and one of the tenth or eleventh. When we consider the shortness of the period during which stars below the eighth magnitude have been systematically observed, we see room for the discovery of several more planets of the ninth magnitude, and an indefinite number of inferior dimensions.

P. S. Since the preceding was in type it has been announced that a new asteroid was discovered May 11 th, at Naples Observatory, by M. de Gasparis, the discoverer of Hygeia. It appears as a star of the ninth magnitude, and at the time of its discovery was in opposition with the sun. 


\section{SECTION III.}

THE DISCOVERY OF AN EIGHTH SATELLITE OF SATURN.

Saturn has long been known to be attended by seven satellites. If we number these satellites in the order of their distances from the primary, the sixth was discovered by Huygens in 1655, the seventh by Cassini in 1671, the fifth by the same in 1672 , the third and fourth also by Cassini in 1684 . The first and second were discovered by Dr. Herschel in 1789. The five satellites first discovered may be seen by a ten feet achromatic; but the two interior satellites can only be seen by a very powerful telescope. Sir John Herschel, at the Cape of Good Hope, in 1836 and 1837, repeatedly observed the second satellite with his reflector of 18 inches aperture; and in one instance only, he caught a glimpse of a point of light, which he suspected to be the first satellite. Mr. Lassell, with his large reflector, obtained three observations of the first satellite, in 1846. Sir John Herschel has proposed 
to distinguish these satellites by proper names, as follows :-

1. Mimas, which makes its revolution in 0 d. $22 \mathrm{~h} .37 \mathrm{~m}$.

$\begin{array}{lllrrr}\text { 2. Enceladus, } & \text { “ } & \text { " } & 1 & 8 & 53 \\ \text { 3. Tethys, } & \text { " } & \text { " } & 1 & 21 & 18 \\ \text { 4. Dione, } & \text { " } & \text { " } & 2 & 17 & 41 \\ \text { 5. Rhea, } & \text { " } & \text { " } & 4 & 12 & 25 \\ \text { 6. Titan } & \text { " } & \text { " } & 15 & 22 & 41 \\ \text { 7. Tapetus, } & \text { " } & \text { " } & 79 & 7 & 54\end{array}$

During the year 1848, this planet was subjected to the most rigid scrutiny, in consequence of the disappearance of its ring, it being presented edgewise toward the sun; and on the 16th of September, an eighth satellite was discovered by the Messrs. Bond of Cambridge, Mass. The following is $\mathrm{Mr}$. Bond's account of the discovery. "On the evening of Sept. 16th, we noticed a small star situated nearly in the plane of Saturn's ring, and between the satellites Titan and Iapetus. This circumstance was at that time regarded as accidental; nevertheless, the position of the star, with respect to Saturn, was recorded. The next night favorable for observations was the 18th. While comparing the relative brightness of the satellites, we again noticed the same object, similarly situated with respect to the planet, and we carefully observed its position. 
But up to this moment, its real nature was scarcely suspected. Measures, carefully made during the evening of the 19th, having proved that the star partook of the retrograde motion of Saturn, we studied that part of the heavens. toward which the planet was moving. Each of the stars which it was expected to approach during the two following nights was marked upon a chart, and micrometric measurements fixed its position and distance with respect to neighboring objects.

"The evening of the 20th was cloudy.

"On the 21st the new satellite had approached the planet, and it sensibly changed its position with respect to the stars during the time of observation. Similar observations were repeated on the nights of the $22 \mathrm{~d}$ and $23 \mathrm{~d}$."

On the 18th of September, the same object was observed by Mr. Lassell, of Liverpool. The following is Mr. Lassell's account of the discovery. "On the 18th, while I was attentively examining the planet Saturn, I was struck with the appearance of two stars situated on the line of the satellite. I supposed that one of them, which I shall designate by $c$, was the most distant satellite, and the other, which I shall designate by $x$, a fixed star. In order to prepare myself for the subsequent observations, I 
made a careful map of its position with respect to some fixed stars in its vicinity, one of which I shall designate by $a$.

"On the 19th I was surprised to find that the two stars, $c$ and $x$, already mentioned, had receded from the fixed star $a, x$ remaining exactly on the line of the satellites, but appearing to have approached the planet; while $c$, although it followed Saturn, had passed to the north of the plane of the orbits of the interior satellites.

"This appearance suggested the idea that $x$ must be a new satellite, and $c$ Iapetus. In order to verify this conjecture, I took the differences of Right Ascension between $x$ and $a$, and between $c$ and $a$. The results showed that in $2.6, x$ had moved to the west of $a$ by 2.46 : and that in $1^{\mathrm{h}} 4, c$ had moved ${ }^{1.27}$ to the west of $a$; which clearly proves that the two stars $x$ and $c$ were in motion. I measured twice at an interval of four hours, the distance of $x$ from the line passing through the interior satellites, and satisfied myself that during this interval, the distance experienced no sensible change. As the motion of Saturn toward the south was $18^{\prime \prime}$ in 4 hours, it would plainly have left the point $x$ behind, if it had been a fixed star. The conclusion is inevitable; $x$ is a satellite hitherto undiscovered. 
This is explained by its being a very faint object, even in my telescope of 24 inches aperture; and it may experience variations of light, which render it invisible in some parts of its orbit.

"I obtained two other observations of the satellite on the 21st and 22d. In the former case, the elongation to the east of the planet was $3^{\prime} 54^{\prime \prime}$; and in the latter $3^{\prime} 27^{\prime \prime}$; the star followed sensibly the line of the interior satellites."

Thus it appears that a most important discovery has been made independently and almost simultaneously on opposite sides of the Atlantic-but $\mathrm{Mr}$. Bond has an unequivocal priority of two days. This then is the first addition to our planetary system made by an American astronomer. The orbit of the new satellite lies between Titan and Iapetus, and serves to fill up a large chasm before existing. It is fainter than either of the two interior satellites discovered by Sir William Herschel. Its time of revolution is about 21.18 days, its semi-axis at the mean distance of Saturn 214", and Messrs. Bond and Lassell have concurred in giving it the name of Hyperion.

It will be observed that there is still a large gap between Hyperion and Iapetus, rendering it not improb: ble that other satellites yet remain to be discovered. 


\section{SECTION IV.}

NEW OBSERVATIONS OF THE SATELLITES OF URANUS.

The planet Uranus was discovered by Sir William Herschel in 1781, and in 1787 he discovered two satellites. In 1790 and 1794, he announced four others, but their distances and periodic times were not so well ascertained as the other two. In 1833, Sir John Herschel announced that his own observations confirmed his father's results with regard to the two satellites first mentioned, (the second and fourth,) but he had not been able to obtain a view of the other four, and their existence rested entirely upon the testimony of Sir William Herschel. In 1838, M. Lamont, at Munich, announced that he had seen a third satellite of Uranus. In the autumn of 1847 , M. Struve, at the Observatory of Pulkova, observed besides the two brighter satellites of Uranus, a fainter satellite on five different evenings, from which he deduced the period of three days and twenty hours. Herschel had de- 
duced the period of the nearest satellite five days and twenty-one hours, but this discrepancy $M$. Struve thinks may be ascribed to the looseness of Herschel's estimates.

In the autumn of $1847, \mathrm{Mr}$. Lassell, of Liverpool also made numerous observations of the two brightest satellites, (the second and fourth of Herschel,) and on five evenings he observed a faint satellite, which he pronounced to have been the first of Herschel, and on one evening, Nov. 6th, he saw a point of light which he conjectured to be the third satellite of Herschel. He could obtain no observation of any satellite exterior to the fourth. Mr. Dawes has discussed the observations of Lassell and Struve upon the nearest satellite, and considers them incompatible with each other. While Struve's observations indicate a period of three days and twentytwo hours, Lassell's observations indicate a period of only two days and two hours. He therefore infers that there must be at least two satellites interior to that which Herschel denominates the second; and he also considers it probable that the point of light seen by Mr. Lassell, Nov. 6, 1847, was a third satellite interior to Herschel's second.

On the whole, then, we may consider the periods of two satellites of Uranus as well determined, viz. 
about eight and thirteen days; while the existence of one, and perhaps three others, is indicated by the recent observations, but their periods can not yet be considered as well established. 


\section{CHAPTER II.}

REOENT ADDITIONS TO OUR KNOWLEDGE OF COMETS.

\section{SECTION I. \\ THE GREAT COMET OF 1843.}

Modern astronomers were generally agreed that the ancient accounts of comets were greatly exaggerated; for, said they, since we have had careful and scientific observers, the appalling comets of antiquity have disappeared. What then shall we say of a comet in the nineteenth century, rivaling the noonday splendor of the sun?

On Tuesday, the 28th of February, 1843, a brilliant body resembling a comet, situated near the sun, was seen in broad daylight, by numerous observers in various parts of the world. It was seen in each of the New England states, (except, perhaps, Rhode Island,) in Delaware, at Halifax, N. S., in Mexico, in Italy, and it is said also in the East and West Indies. It was seen in New England as early 
as half-past seven in the morning, and continued till after 3 P. м., when the sky became considerably obscured by clouds and haziness. The appearance was that of a luminous globular body with a short train-the whole taken together being found by measurement about one degree in length. The head of the comet, as observed by the naked eye, appeared circular; its light equal to that of the moon at midnight in a clear sky; and its apparent size about one eighth the area of the full moon. Some of the observers compared it to a small cloud strongly illuminated by the sun. The train was of a paler light, gradually diverging from the nucleus, and melting away into the brilliant sky. An observer at Woodstock, Vt., viewed it through a common three feet telescope. It presented a distinct and most beautiful appearance,-exhibiting a very white and bright nucleus, and a tail dividing near the nucleus into two separate branches. At Portland, Me., Captain Clark measured the distance of the nucleus from the sun, the only measurement (with one exception) known to have been made in any part of the globe before the $3 \mathrm{~d}$ of March. At $3^{\mathrm{h}} 2^{\mathrm{m}} 15^{\mathrm{s}}$, mean time, the distance of the sun's farthest limb from the nearest limb of the nucleus was $4^{\circ} 6^{\prime} 15^{\prime \prime}$. 
In Mexico, Lat. $26^{\circ} 8^{\prime} \mathrm{N}$., Long. $106^{\circ} 48^{\prime} \mathrm{W}$. of Greenwich, the comet was observed from nine in the morning until sunset, by Mr. Bowring, and the altitude of the comet repeatedly measured with a sextant. Professor Bianchi, of Modena, in Italy, writes that on the 28th of February, the comet was seen by numbers at Boulogne, Parma, and Genoa.

It is said also that Captain Ray, being at Conception, in South America, saw the comet on the 27th of February, east of the sun, distant about one sixth of his diameter.

The comet was seen at Pernambuco, Brazil, and in Van Dieman's Land, on the 1st of March. On the second, it was seen in great brilliancy at St. Thomas, and by various navigators in the equatorial regions. On the evening of the $3 \mathrm{~d}$, it was noticed at Key West, and excited much attention. On the 4 th, it was seen by a few in the latitude of New York, and on Sunday evening the 5th, it was noticed very generally. From this date, until about the close of the month, it presented a most magnificent spectacle every clear evening in the absence of the moon. As seen near the equator, the tail had a darkish line from its head through the center to the end. It was occasionally brilliant enough to throw a strong light upon the sea. The greatest 
length of tail was about the 5th of March, $69^{\circ}$ as measured with a sextant, and it was observed to have considerable curvature. One observer describes it as an elongated birch rod slightly curved, and having a breadth of one degree. At the Cape of Good Hope, on the 3d, it is described as a double tail, about $25^{\circ}$ in length, the two streamers making with each other an angle of about a quarter of a degree, and proceeding from the head in perfectly straight lines. The greatest length of tail observed in the United States, was about $50^{\circ}$. The curvature of the tail upward, though very noticeable, scarcely exceeded two degrees. The first observation of the nucleus (with the exception of the noonday observations) is believed to have been made at the Cape of Good Hope, on the 3d, after which it was observed regularly until its disappearance. At Trevandrun, in India; it was observed from the 6 th ; at Cambridge. Mass., it was observed on the 9th, and at numerous places on the 11th. The first European observation of the nucleus was made on the 17 th at Rome and Naples, after which it was seen at most of the continental observatories till the end of March.

The comet nowhere continued visible many days. It was seldom seen in Europe after the 1st 
of April. The last observation at Naples was on the 7th. Only one later observation has been announced from Europe. This was at Berlin, on the 15th, when Professor Encke thought he caught a faint glimpse of the comet, but it could not be found again on the subsequent evening. The most complete series of observations in this country was made by Messrs. Walker and Kendall of Philadelphia, where the comet was followed until April 10th. At Hudson, Ohio, the comet was seen for the last time April 6th.

A great many astronomers have computed the orbit of this comet, and have obtained very extraordinary results. The comet receded from the sun almost in a straight line, so that it required careful observations to determine in which direction the comet passed round the sun, and some at first obtained a direct orbit, when it should have been retrograde. The perihelion distance was extremely small, very little exceeding the sun's radius. Some have obtained a smaller quantity than this, but such a supposition seems to involve an impossibility. It is certain, however, that the comet almost grazed the sun; perhaps some portion of its nebulosity may have come into direct collision with it. The best orbits give a perihelion distance of $\cdot 0056$, or a dis- 
tance of 90,000 miles from the sun's surface, which is equal to about one fifth of the sun's radius.

'The velocity with which the comet whirled round the sun at the instant of perihelion was prodigious. This was such as, if continued, would have carried it round the sun in two hours and a half; in fact, it did go more than half round the sun in this time. In one day, (that is from twelve hours before, to twelve hours after perihelion passage,) it made 291 degrees of anomaly; in other words, it made more than three quarters of its circuit round the sun. In 40 days, the period of its visibility, it had described 173 degrees from perihelion; while to describe the next seven degrees, requires a period of many years, and perhaps centuries.

The head of this comet was exceedingly small in comparison with its tail. When first discovered, many were unwilling to believe it a comet, because it had no head. The head was probably nowhere seen by the naked eye after the first days of March. At the close of March, the head was so faint as to render observations somewhat difficult even with a good telescope, while the tail might still be followed by the naked eye about thirty degrees. Bessel remarked that "this comet seemed to have exhausted its head in the manufacture of its tail." It is not, 
however, to be hence inferred, that the tail was really brighter than the head, only more conspicuous from its greater size. A large object, though faint, is much more noticeable than a small one of intenser light. Thus the milky-way is little more than an assemblage of faint stars, no one of which singly would make any distinct impression upon the naked eye.

The nearest approach of the comet's head to the earth was about 80 millions of miles, being very soon after the perihelion passage. The absolute diameter of the nebulosity surrounding the head was about 36,000 miles. The apparent length of the tail has already been stated; but the absolute dimensions were still more extraordinary. The following table was computed from the best observations, and shows the progress of the formation of the tail after perihelion. The comet passed its perihelion on the afternoon of Feb. 27th, Greenwich time.

\begin{tabular}{rr|r|r}
$\begin{array}{r}\text { Length of tail. } \\
\text { Miles. }\end{array}$ & $\begin{array}{r}\text { Length of tail. } \\
\text { Miles. }\end{array}$ & $\begin{array}{r}\text { Length of tail. } \\
\text { Miles. }\end{array}$ \\
Feb. 28, $35,000,000$ & Mar. $8,101,000,000$ & Mar. 20, 107,000,000 \\
Mar. 1, 55,000,000 & $9,102,000,000$ & $21,108,000,000$ \\
$2,70,000,000$ & $11,103,000,000$ & $24,108,000,000$ \\
3, 82,000,000 & $13,104,000,000$ & $26,106,000,000$ \\
4, 91,000,000 & $15,105,000,000$ & $27,105,000,000$ \\
5, 96,000,000 & $17,106,000,000$ & $30,101,000,000$ \\
6, 99,000,000 & $18,106,000,000$ & $31,98,000,000$ \\
7, $100,000,000$ & $19,107,000,000$ & April 1, $95,000,000$
\end{tabular}


The visible portion of the tail attained its greatest length early in March, remained nearly stationary for some time, and during the first week of April suddenly disappeared, from increased distance, without any great diminution of length. The comet doubtless had a tail before perihelion, but it seems physically impossible that this should have formed any part of that which was seen after perihelion. The tail was turned nearly toward the earth, on the night of Feb. 27th, in such a direction, that had it reached the earth's orbit, it would have passed fifteen millions of miles south of us. Its length was, however, at that time, insufficient to reach any considerable part of the distance to the earth.

What gave the comet its extraordinary brilliancy on the 28th of February? Evidently its proximity to the sun. The day before, it had almost grazed the sun's disc. The heat it received, according to the computations of Sir John Herschel, must have been 47,000 times that received by the earth from a vertical sun. The rays of the sun united in the focus of a lens thirty-two inches in diameter and six feet eight inches focal length have melted carnelian, agate, and rock crystal. The heat to which the comet was subjected must have exceeded by twenty-five times that in the focus of such a lens. 
Such a temperature would convert into vapor almost every substance on the earth's surface; and if any thing retained the solid form, it would be in a state of intense ignition. The comet, on the 28th of February, was red hot-and for some days after its perihelion, it retained a peculiar fiery appearance. In the equatorial regions, the tail is described as resembling "a stream of fire from a furnace." The reason why the tail was seen on the 28 th, was that it was turned almost directly toward the earth, and we therefore saw it in the direction of its length.

Has this comet ever been seen before? In the year 1668, a comet appeared very similar to the present one. Cassini saw the tail at Boulogne, March 10, and subsequently an hour after sunset; but the head was plunged in the rays of the sun. The tail was $45^{\circ}$ in length, and extended almost horizontally from west to south. It was so brilliant that its image was distinctly seen reflected from the sea; but this brightness lasted only three days. The head was small and faint, and difficult to be seen. Professor Henderson of Edinburgh computed the orbit of this comet, and obtained a result very similar to the early results with the comet of 1843 . He then assumed the elements of the latter comet, and from them computed the places in 1668. The 
results accorded pretty well with the observations. Mr. Peterson has made the comparison with corrected elements, and found the accordance still better. On the whole, it appears that the comets of 1668 , and 1843 pursued nearly the same path, and exhibited nearly the same appearances.

A similar comet was seen in 1689 . It was not seen in Europe, but was observed at Pekin, and was most brilliant in the southern hemisphere, where the tail attained a length of about $68^{\circ}$. The head was bright, but the tail was paler, and had the shape of a huge sabre curved at the extremity. The orbit of this comet was computed by Pingré, and its elements agree pretty well with those of the present comet, except the inclination, which was too great. Professor Peirce, of Cambridge, has recomputed the orbit and obtained a much better coincidence. In short, it appears that the three comets of 1668,1689 , and 1843, all pursued nearly the same path, and presented somewhat similar appearances. What are we to infer? Mr. Walker inferred that these were different appearances of the same comet, with a period of $21 \frac{7}{8}$ years, the comet having made seven revolutions from 1689 to 1843. But why was it not seen at either of the intermediate returns? Because (it is said) the 
position of the comet was unfavorable for observation. From the position of its orbit, the comet will always have considerable southern declination, which is unfavorable to its being seen in the northern hemisphere. This answer is not entirely satisfactory, as it is improbable that so prodigious a tail should pass unnoticed during six successive returns.

Professor Schumacher is inclined to regard this comet as identical only with that of 1668 , giving it a period of 175 years. Prof. Peirce has made a comparison of all the best observations, and his result is that any ellipse of short period is inadmissible. The observations may all be represented by a parabola within the usual limits of the errors of cometary observations. An ellipse of about 180 years represents them a little better. Prof. Hubbard, of the Washington Observatory, has recently undertaken a thorough discussion of all the observations of this comet, and has computed the effect due to the perturbations of the planets. He finds the most probable orbit to be an ellipse of 170 years. We seem obliged then, entirely to reject any short period, as 20 or 30 years, and there is an increased probability that this comet is identical with that of 16:8. It is doubtful whether the period of this 
comet can be certainly determined until it has been again observed on its return to the sun.

The following circumstances invest the comet of 1843 with peculiar interest.

1. Its small perihelion distance; being as small as that of any comet whose orbit has been computed, and nearly as small as is physically possible.

2. Its prodigious length of tail; being equal to that of any comet hitherto observed.

And 3. Its probable periodicity. 


\section{SECTION II.}

FAYE'S COMET OF 1843.

ON the 22d of November, 1843, a telescopic comet was discovered by M. Faye, of the Paris Observatory. It had a brilliant nucleus, and a short tail like a fan about four minutes in length. It was rediscovered in this country on the 27 th of December, by Mr. J. S. Hubbard, at New Haven. The comet was closely watched at the European observatories during December and January, and at the Pulkova Observatory it was followed until the 10th of April. The orbit was first computed as usual on the supposition of its being a parabola, but the parabolic elements being found unsatisfactory, an elliptic orbit was computed, and the period found to be about seven years. Its eccentricity was found to be 0.55 , thus forming a connecting link between the asteroids and comets. Hitherto there was a well-marked distinction between planets and comets. The most eccentric of the plane- 
tary orbits is that of Juno, $(0 \cdot 26$, $)$ or about one quarter. The least eccentric cometary orbit hitherto well established, was that of Biela's comet, $(0 \cdot 75$,$) or almost exactly three quarters. Faye's$ comet, with an eccentricity of one half $(0.55)$ occupies an intermediate rank, and nearly removes what had hitherto been regarded as one of the most distinctive features of comets.

The position of its orbit in the heavens is very unstable. At aphelion its distance from the sun is five hundred and sixty millions of miles, bringing it into close proximity to the planet Jupiter. Such a conjunction happened in 1840 , at which time the attraction of Jupiter for the comet was about one tenth part of the sun's, and must have produced a considerable alteration of its orbit. In 1815, the comet probably came still nearer to Jupiter, by which its former orbit must have been greatly changed. The former path of this comet may, therefore, have been very different from that which it pursued in 1843, and M. Valz expressed the opinion that this comet was identical with the famous comet of $17 \% 0$. The latter comet, at its appearance in 1770 , was found to be moving in an ellipse, whose period was only five and a half years, and astronomers were surprised that it had never 
been seen before. By tracing back its motion, it was found that at the beginning of $\mathbf{1 7 6 7}$, it was very near to Jupiter, and the two bodies remained in the neighborhood of each other for several months. Computation, moreover, disclosed the fact that previous to $\mathbf{1 7 6 7}$, the elliptic orbit which it described corresponded not to five, but to fifty years of revolution round the sun. Again, in 1779, according to Lexell's elements, it was 500 times nearer to Jupiter than to the sun; so that then, notwithstanding the immense size of the sun, its attractive power on the comet was not the 200th part that of Jupiter. It was found that on the departure of this comet out of the attraction of Jupiter in 1779, its circuit could not be performed in less than twenty years. Thus the action of Jupiter brought the comet of 1770 to us in 1767 , and removed it from us in 1779. Moreover, at every revolution, the comet of 1770 ought to come into close proximity to Jupiter: and suffer enormous perturbations, and M. Valz conjectured that the orbit of this comet had been at last transformed into that of the comet observed in 1843. M. Le Verrier has recently undertaken a thorough investigation of this question, and he thinks he has dem- 


$$
\text { FAYE'S COMET OF } 1843 .
$$

onstrated that the comet of 1770 has nothing in common either with Faye's comet of 1843, or with that discovered by De Vico in 1844, or any other comet whose orbit has been computed. 


\section{SECTION III.}

DE VICO'S CONET OF 1844.

On the 22d of August, 1844, M. De Vico, Director of the Observatory at Rome, discovered a comet in the constellation of the Whale. He immediately announced the discovery to Professor Schumacher, of Altona, but his letter did not arrive till the 26th of September. Meanwhile, the comet had been discovered independently by several different observers. It was seen by Prof. Encke at Berlin, on the 5 th of September, and on the 6 th it was seen at Hamburg by M. Melhop, an amateur astronomer. The nucleus was very bright; it had a tail about one degree in length, and was visible to the naked eye. On the 10th of September, the same body was discovered by Mr. H. L. Smith, of Cleveland, Ohio, who observed it every day for nearly a fortnight. At the Pulkova Observatory, the comet was followed till the 31st of December.

The path of this comet deviated remarkably from 
a parabolic orbit. Dr. Brunnow, of Berlin, has undertaken a thorough investigation of all the observations, embracing a period of more than four months, and has taken account of the effect of the perturbations of all the planets within the orbit of Uranus. He has thus obtained an orbit which satisfies all the observations with extreme precision. The following are the resulting elements.

Perihelion passage, 1844, Sept. 2511 mean Berlin time.

Longitude of perihelion,

Longitude of ascending node, Inclination of orbit,

Semi-axis major,

Eccentricity, $342^{\circ} 30^{\prime} 50^{\prime \prime}$

$\begin{array}{lll}63 & 49 \quad 0\end{array}$

$254 \quad 50$

$3 \cdot 10295$

$0 \cdot 61765$

Periodic time, 1996.5 days, or $5 \cdot 4659$ years.

This period (supposing its orbit undisturbed) would bring the comet back to perihelion, about the 20th of February, 1850.

Messrs. Laugier and Mauvais, of Paris, have computed the orbit of the comet of $\mathbf{1 5 8 5}$ from Tycho's and Rothmann's observations, and have obtained elements very similar to the preceding. They therefore concluded that the comet of De Vico was 
identical with the comet of 1585 , and possibly also with those of 1743,1766 , and 1819 .

M. Le Verrier has undertaken, by a computation of the perturbations, to decide whether this comet has been observed at any former return to the sun. $\mathrm{He}$ concludes that this comet can not be identical with the famous comet of 1770 , nor with that of 1585 , nor any other on record, except that of 1678 . He pronounces the comets of 1678 and 1844 to be probably identical. Dr. Brunnow has lately undertaken similar computations, and has arrived at the same results as Le Verrier. 


\section{SECTION IV.}

THE RETURN OF BIELA'S COMET IN 1846.

$\mathrm{O}_{N}$ the 27th of February, 1826, M. Biela, an Austrian officer, discovered a comet; and on computing its elements, it was found that the same body had been observed in 1805 and in 1772. It was soon discovered that the comet made its revolution round the sun in a period of about six years and two thirds. It was of course predicted that the comet would return in 1832. Computation also disclosed another fact, which excited no little alarm. It was predicted that on the 29th of October, 1832, the comet would cross the plane of the ecliptic at a distance of less than 20,000 miles from the earth's path. Now the comet's radius, from observations in 1805, had been determined to be greater than 20,000 miles; from which it followed, that a portion of the earth's orbit would be included within the nebulosity of the comet. It was found, however, that the earth would not arrive at this point of its orbit 
until a full month afterward. There was therefore no great danger of collision; nevertheless, no little alarm was experienced by those not much conversant with astronomy. The comet returned at the time predicted, and was observed by Sir John Herschel; but it was extremely faint, and could only be seen in good telescopes.

In 1839 , this comet must have returned again to the sun; but its position was most unfavorable for observation, and it is not known to have been observed at all.

In 1846 , this comet returned to its perihelion under circumstances more favorable for observation. It was first seen at Rome on the 26th of November, 1845 ; at Berlin on the 28th ; at Cambridge, Eng., on the 1st of December, and afterward at most of the observatories of Europe. It continued to be observed at Naples until the 19th of April, 1846.

This return of Biela's comet will always be remarkable in its history for an appearance quite new in the annals of modern astronomy. When first observed through the five inch refractor at Y Yale College, Dec. 29th, it was seen attended by a faint nebulous spot, estimated to be rather more than a minute of space distant from its brightest point. This surprising phenomenon was first publicly an- 
nounced by Lieut. Maury of the Washington Observatory. On the 13th of January, Lieut. Maury discovered that instead of being, as usual, a single comet, it apparently consisted of two comets moving through space side by side. Each body had all the characteristics of a telescopic comet, being gradually condensed toward the center, without any well-defined disc; each being elongated on the side opposite the sun. For convenience of description, we will designate one of these bodies by the name of Biela, and the other as his companion. There are three distinct circumstances worthy of attention -their relative magnitude, intensity of light, and distance from each other.

On the 13th of January, the companion was estimated to have one eighth the magnitude of Biela; from this time it steadily increased until the middle of February, when it was judged to be equal to Biela; after which it rapidly declined, until it disappeared during the fore part of March.

Again, on the 13th of January, the light of the companion was estimated to have one fourth the intensity of Biela; from which time its light increased till the middle of February, when it was judged to be somewhat brighter than Biela; after which it rapidly declined, and on the 1st of March 
could with difficulty be seen, although Biela remained quite conspicuous. On the 24th, the comet appeared single, and so continued until the $22 \mathrm{~d}$ of April, when it entirely disappeared.

Also on the 13th of January, the distance of the companion from Biela was estimated at about two minutes of space; near the middle of February it was five minutes; on the first of March the distance was ten minutes; and at the close of March it was fifteen minutes.

The preceding facts afford abundant materials for speculation. What was the relation of these two bodies? The appearances, when first noticed, suggested the idea that the companion was a satellite to Biela. Such an idea is now inadmissible. It is found that all the observations are very well represented by supposing that each nucleus described an independent ellipse about the sun. M. Plantamour, Director of the Observatory at Geneva, has computed the orbits, and taken account of the disturbing influence of Jupiter, Mars, the Earth, and Venus. He finds that all the observations of each nucleus may be represented by an elliptic orbit within the probable limits of the errors of such observations; and he concludes that the disturbing influence of one nucleus upon the 
other must have been extremely small, and it is doubtful whether the observations were sufficiently precise to render this influence in any degree sensible. The following table shows the distance of one nucleus from the other, in a straight line, expressed in English miles, according to the elements of M. Plantamour.

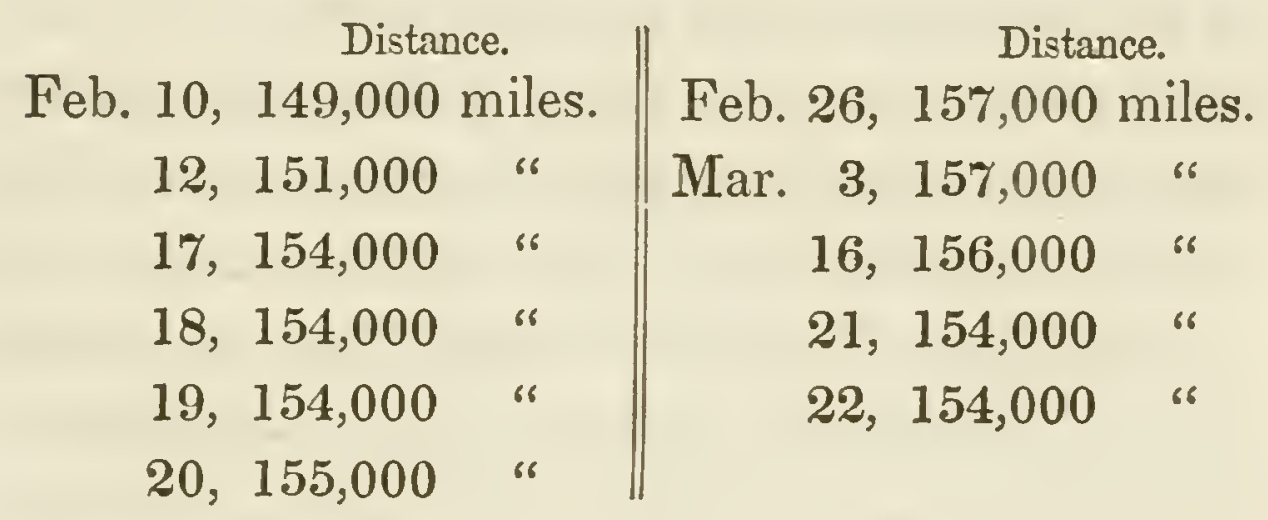

Thus it appears that these two bodies, during the entire period of their visibility, remained at a distance from each other less than two thirds the distance of the moon from the earth; nevertheless, the perturbations arising from their mutual attraction, did not change their positions beyond a very small number of seconds at the furthest, from which we must infer that their masses were excessively small.

What then is the history of these two bodies? Are they both new comets-is one a new comet, and the other Biela-or are both of them parts of Biela? Each body is within a few hours' motion 
of the place where Biela's comet should be at the present time, from predictions based on its path when last seen in 1832. No doubt then Biela has been separated into two parts. When and how were they separated?

The observations of their angular distance from each other might lead us to infer that the separation of the parts took place about the close of the year 1845, but the computations of M. Plantamour show that these changes were merely apparent, due to a change of position with respect to the earth. The absolute distance of the two bodies from each other remained nearly the same during the entire period of the observations. We must then abandon the idea that the two parts became detached from each other about the time of their perihelion passage in 1846. Moreover, according to the computations of $\mathrm{M}$. Plantamour, the orbit of the companion is smaller than that of Biela, and is entirely included within it, so that there is no point of intersection, from which it might be inferred that the two bodies never formed parts of the same comet. However, the two ellipses nowhere separate very widely from each other, and a small variation in either orbit would produce a coincidence. As the comet was not seen double in 1832, it seems an obvious infer- 
ence that the separation took place between 1832 and 1845. But M. Plantamour thinks that even this conclusion may be questioned. The extraordinary changes of brightness which the companion exhibited within the period of a few days, and which have often been noticed in other comets, seem to indicate that the brightness of these objects does not depend merely upon their distance from the earth and sun, but upon other unknown causes. These causes might have developed sufficient brightness in the companion, at its late return to the sun, to render it visible to us ; while at its former returns, on account of its unfavorable position, the companion was too faint to be noticed.

What has caused this separation of the comet into two portions? Was it caused by collision with some foreign body? Such a collision would have materially changed the figure of the orbit, and therefore we can not suppose it to have taken place since the observation of the comet in 1772, when it was found to be pursuing nearly the same path as at present. It is probable, that in case of an encounter with some other body, both bodies would have moved on together in some new orbit.

Was it caused by an explosion arising from some internal force? Forces of this kind we see in oper- 
ation in our own globe, ejecting liquid mountains from the bowels of the earth. The surface of our moon bears marks of similar agency-the sun appears agitated by powerful forces, perhaps the expansion of gaseous substances-and it has been conjectured that a planet was once split into numerous fragments. If we knew that Biela's comet was a solid body, we might easily suppose it to have been divided by some force similar to volcanic agency. But most of the matter of this body is of the rarest kind, and it may be doubted whether any part of it is in the solid state.

Was this separation caused by a repulsive force emanating from the sun? The phenomena exhibited by Halley's comet at its return to the sun in 1835, require us to admit the existence of repulsive as well as attractive forces. The effect of the sun's repulsion upon the atmosphere of the comet, would be to distort it from the spherical form which it would assume under the attraction of the nucleus alone-to crowd the particles on the side next the sun nearer to the nucleus, and to drive those on the opposite side farther from it-causing an oval form, whose length, as compared with its breadth, would be the greater, the stronger the repulsive force is supposed; and the repulsive force may be conceived 
to become so great as to drive the remoter particles beyond the influence of the nucleus, and carry them off into space. It is necessary, in the opinion of Sir John Herschel, to suppose that the tail is attracted by the nucleus, otherwise they would at once part company. The compound mass of the comet is therefore urged toward the sun by the difference of the total attractive and repulsive forces; and so long as the repulsive power is insufficient to separate them, they will revolve together as one body, continually elongating itself as it approaches the sun, and on the position of whose larger axis the sun exercises a directive power, as it would on a magnet, if itself magnetic; or rather as a positively electrified body would on a non-conducting body of elongated form, having one end positively, the other negatively excited.

As a comet approaches the sun, a portion of its matter appears to be converted into vapor. In this vaporization, the two electricities might be separated, the nucleus and tail being in opposite electrical states. If now we suppose the sun to be in a permanently excited electrical state, we have an explanation of the repulsive force which has been ascribed to the sun.

Suppose the repulsive force of the sun upon the 
particles of the tail to overcome the attraction of the nucleus, they must be driven off irrecoverably. Such a separation could hardly be accomplished without carrying off some portion of the gravitating matter; and thus a new comet would be formed, as in the case of Biela.

Sir J. Herschel mentions another mode in which the separation of a comet might be effected. The oscillations of a fluid covering a central body may, under certain conditions as to the coercive power of that central mass, cease to continue of small extent, and may increase in magnitude beyond any limit which analysis is capable of assigning, even to the extent of destroying the continuity of the fluid, and separating it into distinct masses. If such an extreme case could ever occur, it must be in a comet like Biela's, consisting of a mass of vapor with very little cohesion, and in which the attractive power of the nucleus is exceedingly small. 


\section{SECTION V.}

MISS MITCHELL'S COMET.

This comet was discovered on the 1st of October, 1847, by Miss Maria Mitchell, of Nantucket. As a relaxation from the severer toil of a systematic course of observations, she had employed the intervals through the preceding year in sweeping for comets; but her labors had hitherto been only rewarded by a familiarity with comet-resembling nebulæ, which she had constantly and carefully recorded. The instrument employed on these occasions, was a forty-six inch refractor, with an aperture of three inches, mounted on a tripod, and furnished with a terrestrial eye-piece of moderate power. On the evening of Oct. 1st, a circular nebulous body appeared in the field of the telescope, a few degrees above Polaris. There was scarcely a doubt of the cometary character of this object, inasmuch as the region which it occupied had frequently been examined. Still as the object was 
faint, and the weather uncommonly clear, a possibility existed that this too was a nebula not before observed. On the evening of the $2 d$, its change of place was manifest. No appearance of condensation of light toward its center, nor any indication of a train, could be detected. It is evident that its apparition even to the telescope was sudden. Its first apparent motion was inconsiderable, and the region of its discovery had been constantly swept over by the assistant observer at Cambridge, with his excellent comet-seeker, even as late as the previous evening. This idea is strengthened by the subsequent rapid increase of the brilliancy of the comet, and the acceleration of its apparent motion. On the 3 d, its motion and brightness had much in. creased, and there was noticed a slight increase of light toward its center. On the 4th, all observations were prevented by the weather. On the 5th, the evening was delightful. At an early period it was evident that the comet must pass over a fixed star of the fifth magnitude, and preparations were made to note the beginning and end of the transit; but the border of the comet proved too uncertain to rely upon. At $10^{\mathrm{h}} 54^{\mathrm{m}}$, the star appeared to be exactly in the center of the comet; and during several seconds it was impossible to determine, with a 
power of 100 , in which direction was the greatest extent of nebulosity. It appeared in fact like the nucleus of the comet shining through it with undiminished brilliancy.

On the 6 th, the comet was visible to the naked eye, and continued to increase in brightness till obscured by the light of the moon. On the 9 th, as seen at Cambridge, it exhibited a faint train, a degree and a half in length, and opposite to the sun.

This comet was discovered by M. De Vico, at Rome, on the $3 \mathrm{~d}$ of October ; it was discovered by Mr. Dawes, of England, on the 7th; and on the 11 th it was discovered by Madame Rümker, of Hamburg.

As there was no doubt of Miss Mitchell's having been the first discoverer of this body, she seemed fairly entitled to the gold medal offered by the King of Denmark for the first discovery of a comet. In consequence, however, of her not having complied strictly with the conditions of giving immediate notice of the discovery by letter to Prof. Airy, it was for a time doubtful whether the medal would not be awarded to M. De Vico. A full statement of the circumstances of the discovery having been made to the King of Denmark, his majesty ordered a reference of the case to Professor Schumacher, who 
reported in favor of granting the medal to Miss Mitchell. This report was accepted by the king, and the medal has been transmitted accordingly. This is the first instance in which the gold medal, founded by the King of Denmark, in 1831, for the first discovery of a comet, has been awarded to an American; and the first instance in which it has been awarded to a lady in any part of the world. 


\section{SECTION VI.}

THE EXPECTED RETURN OF THE COMET OF 1264.

A splendid comet appeared in the year 1264, during the months of July, August, and September, and, according to some authorities, in October also. It was observed throughout Europe, and also in China. On the 17th of July, it was seen after sunset; a few days later it was seen in the morning. Its tail was visible long before the head rose above the horizon. On the 1st of August, it rose two hours before the sun; on the $22 \mathrm{~d}$ of September, it came to the meridian before dawn. Its tail daily diminished in breadth, but increased in length, extending even to a hundred degrees. It is said to have disappeared Oct. $3 \mathrm{~d}$, on the very day of the death of Pope Urban IV., and it was inferred that the comet appeared only to announce his death. Pingré and Dunthorne both computed the orbit of this comet; and their results are given on the next page.

In the year 1556, another splendid comet made 
its appearance. It wàs seen in some places near the end of February, and was equal in size to half the moon. Its beard was short, and was unsteady. It exhibited a movement like that of a flame, or a torch disturbed by the wind. The length of its tail was about four degrees; its color resembled that of Mars, but somewhat paler. On the 12th of March, it had reached a north declination of $42^{\circ}$, and it moved over $15^{\circ}$ of a great circle in a day. It was then distant from the earth only about seven millions of miles; and showed considerable train. It continued visible until the $23 \mathrm{~d}$ of April, when it disappeared in consequence of its proximity to the sun. Halley computed the orbit of this comet, and Mr. Hind has recently repeated the computation. The following table gives a comparison of the two orbits of the comet of 1556, and those of the comet of 1264 .

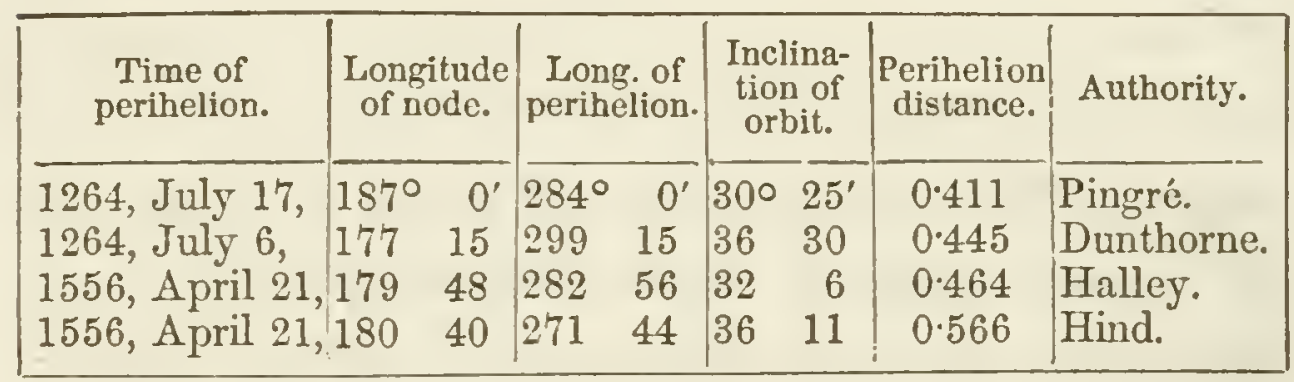

According to this table, the orbit of the comet of 1264 agrees quite as well with that of 1556 as the computations of Halley and Hind agree with each 
other. Pingré concluded that these two comets were probably the same, that its period was about 292 years, and that its return might be expected in 1848. Mr. Hind, from a more complete investigation of both orbits, came to the same conclusion. He also remarked that the comet of 975 bears indications of identity with that of 1556 . Admitting the identity of these comets, and that the period of the last revolution was the same as the preceding, the comet should have come to its perihelion by the middle of February, 1848. Although a watch has been constantly maintained since that period, the comet has not been detected. But its return is not to be entirely despaired of. Mr. Hind states that Mr. Barber has computed the effect of the perturbations due chiefly to Jupiter's attraction during the last revolution. $\mathrm{He}$ finds that between the years 1556 and 1592, the united attraction of Jupiter and Saturn would diminish the period 263 days; but that between 1592 and 1806 it would be increased by the action of Jupiter alone no less than 751 days, so that a retardation of 488 days must take place. How much longer Saturn, Uranus and Neptune may detain it beyond this time, we do not at present know. Mr. Hind considers it important that search for the comet should be continued until the close of the year 1851 . 


\section{CHAPTER III.}

ADDITIONS TO OUR KNOWLEDGE OF THE FIXED STARS AND NEBULE.

\section{SECTION I.}

DETERMINATION OF THE PARALLAX OF FIXED STARS.

UNTIL recently, astronomers had been unable to measure the distance of a single fixed star. The parallax arising from the motion of the earth in its orbit, even for the nearest fixed star which had been examined, remained concealed among the errors incidental to all astronomical observations. Nevertheless, it was generally agreed among astronomers that no star visible in northern latitudes, to which attention had been directed, manifested an amount of parallax exceeding a single second of arc. A parallax of one second implies a distance of about twenty millions of millions of miles, a distance which light, traveling at the rate of 192,000 miles per second, requires $3 \frac{1}{4}$ years to traverse. This being the inferior limit which the nearest 
stars exceed, it is not unreasonable to suppose that among the innumerable stars which the telescope discloses, there may be those whose light requires hundreds, and perhaps thousands of years to travel down to us.

The difficulty of measuring, by direct meridional observations, a quantity so minute as the parallax of the stars, has led astronomers to try a system of differential observations, susceptible of far greater accuracy. Suppose two stars at unequal distances from us, so situated as to appear nearly along the same line of vision. Aberration, precession, nutation, refraction, and instrumental errors, must affect their places alike; so that although it is difficult to determine the true Right Ascension and Declination of either star within one second of arc, we may measure the difference of position of one star from the other with extreme precision, without the necessity of taking account of the preceding corrections. Now this difference of position of the two stars, if measured for every season of the year, gives us their difference of parallax; and if we select one of the nearest stars to be compared with one of the more remote, this difference of parallax will be sensibly the entire parallax of the former star. This method was applied, in the year 1837 , by the late Professor 
Bessel, to determine the parallax of the double star 61 Cygni. This is a small star, hardly exceeding the sixth magnitude, which had been pointed out for special observation by the circumstance of its having a very great proper motion, viz., more than 5 " per year, being a more rapid motion than has been detected in the case of any other star (with but a single exception), on which account it had been suspected to be comparatively near to our system. Bessel repeatedly measured, with his grand heliometer, the distance of this star from two other stars in its neighborhood, both of them very minute, and therefore presumed to be very distant; and he continued his observations every month when practicable, for three years. It appeared that in January of each year, the distance of 61 Cygni from one of the stars of comparison was one third of a second less than the mean distance; in June it was one third of a second greater than the mean.

This effect is precisely such as should be produced by the motion of the earth about the sun, causing an apparent displacement of the nearer stars as compared with those which are more remote, and as no other explanation of the phenomenon seems admissible, these observations are considered as settling the long vexed question of paral- 
lax. In 1841, M. Bessel received the gold medal of the Royal Astronomical Society of London, for this important discovery. The parallax of $61 \mathrm{Cyg}$ $\mathrm{ni}$, according to these observations, is $0^{\prime \prime} \cdot 348$, making the distance of this star from the sun 592,000 times the radius of the earth's orbit,-a distance which light would require more than nine years to traverse.

Prof. Henderson, of Edinburgh, about the same time, attempted to determine the parallax of Alpha Centauri, a star of the first magnitude in the southern hemisphere. This is a double star, having a proper motion of $3^{\prime \prime} \cdot 6$ annually. The result of a long series of observations gives a parallax of almost exactly one second. Subsequent observations by Mr. Maclear, with a much better instrument, lead to almost exactly the same result.

Dr. Peters, of the observatory at Pulkova, has attempted to determine the parallax of the Pole star from the Dorpat observations. The result thus obtained is one sixth of a second, indicating a distance which light would require 20 years to traverse. According to this result, it must have been 20 years after the pole star was placed in the firmament before its light shone upon the earth; and if it were now annihilated, it would still serve for 20 years more to guide the mariner across the ocean. 
Quite recently M. Peters has determined the parallax of a considerable number of stars, from observations made at Pulkova with the Ertel circle. This circle is 43 inches in diameter, graduated to two minutes, and reading with four microscopes to one tenth of a second. The result of these observations is as follows:-

\begin{tabular}{|c|c|c|}
\hline Parallax & 61 Cygni, & $0^{\prime \prime} \cdot 349$ \\
\hline “ & 1830 Groombridge, & $0 \cdot 226$ \\
\hline “ & Iota Ursæ Majoris, & $0 \cdot 133$ \\
\hline “ & Arcturus, & $0 \cdot 127$ \\
\hline “ & Alpha Lyræ, & $0 \cdot 103$ \\
\hline “ & Polaris, & 0.067 \\
\hline
\end{tabular}

The parallax of 61 Cygni here given, is almost identical with that obtained by Bessel with his heliometer, and affords the strongest confirmation of its accuracy. The parallax of Alpha Lyræ must be considered extremely doubtful. The parallax of the pole star is confirmed by the observations of Struve and Lindenau, and is thought to be a near approximation to the truth. M. Faye, of Paris, obtained a parallax of more than a second for the star 1830 Groombridge, but so great a parallax seems incompatible with the Pulkova observations.

M. Peters has also attempted to determine the 
average parallax of stars of the different magnitudes. For this purpose he availed himself of the long series of observations made at Dorpat, and concludes that the average parallax of stars of the second magnitude is 011116 . Combining this result with the estimated relative distances of stars of the different orders, we obtain an estimate of their parallaxes, and hence their absolute distances. The following is Dr. Peters' result for stars of the first six magnitudes:-

$\begin{array}{clrcc}\begin{array}{c}\text { App Mag- } \\ \text { nitude. }\end{array} & \begin{array}{l}\text { Parallax. } \\ 1\end{array} & \begin{array}{c}\text { Distance in radii of of } \\ \text { the earth's orbit. }\end{array} & \begin{array}{c}\text { Time required for light } \\ \text { to traverse this distance. }\end{array} \\ 2 & 0.116 & 1509 & 986,000 & 15 \text { years. } \\ 3 & 0.076 & 2,778,000 & 28 & \text { " } \\ 4 & 0.054 & 3,850,000 & 43 & \text { " } \\ 5 & 0.037 & 5,378,000 & 61 & 85 \\ 6 & 0.027 & 7,616,000 & 120 \text { " }\end{array}$

Thus light, which travels at the rate of 190,000 miles every second, requires 15 years to come to us from stars of the first magnitude, and 120 years to come from one of those small stars which are just visible to the naked eye. These results, as is stated on page 136, Prof. Encke considers entitled to very little confidence. It is not, however, too much to expect that ere long a similar table for at least the brighter stars may be constructed, founded on unquestionable data. 


\section{SECTION II.}

OBSERVATIONS OF NEW AND VARIABLE STARS.

IT has long been known that among the fixed stars are several which experience a periodical increase and diminution of brightness. The star Omicron, in the constellation Cetus, sometimes appears as a star of the second magnitude, but continues of this brightness only about a fortnight, when it decreases for about three months, till it becomes completely invisible to the naked eye, in which state it remains about five months, and then increases again to the second magnitude, the interval between its periods of greatest brightness being about eleven months. The star Algol varies from the second to the fourth magnitude, going through its changes in less than three days. Between thirty and forty such cases have been noticed, although in many of them the change of brightness is not very remarkable.

In the case of a few stars, remarkable changes of 
brightness have been observed, which have not been reduced to any law of periodicity. The star $\eta$ (eta) Argus is of this kind. This is a star of the southern hemisphere in Right Ascension $10^{\mathrm{h}} 39^{\mathrm{m}}$; south declination $58^{\circ} 54^{\prime}$. In Halley's catalogue, constructed in $167 \%$, it is marked as of the fourth magnitude; yet in Lacaille's in 1751, and in subsequent catalogues, it is recorded as of the second magnitude. In the interval from 1811 to 1815 , it was again of the fourth; and again from 1822 to 1826 of the second magnitude. In 1827, it increased to the first magnitude; it thence receded to the second, and so continued until the end of $183 \%$ In the beginning of 1838, it suddenly increased in luster so as to surpass all the stars of the first magnitude except Sirius, Canopus, and Alpha Centauri, which last star it nearly equaled. Thence it again diminished, and in 1842, it was pronounced by Maclear as inferior to Alpha Crucis, but the next year it again revived, and became nearly equal to Sirius.

These facts afford abundant materials for speculation. The changes of brightness of $\eta$ Argus are spread over centuries, and apparently without any regular period. What can be the cause of these changes? To this question we are unable to assign 
any satisfactory answer, and must wait patiently until a greater accumulation of facts shall afford us a more certain basis for a theory.

Several instances are on record of temporary stars, which have suddenly become visible, and after remaining a while, apparently immovable, have died away and left no trace behind. Such a star is said to have appeared about the year $125 \mathrm{~B}$. C. Such stars are also recorded in the years, A. D. $389,945,1264,1572,1604$, and 1670. A similar phenomenon has recently taken place. On the 27 th of April, 1848, Mr. Hind of London observed a star of the sixth magnitude in the constellation Ophinchus, where he was certain that, up to the 5 th of that month, no star as bright as the ninth magnitude previously existed. Neither has any record been discovered of a star being there observed at any previous time. Its place was in Right Ascension, $16^{\mathrm{h}} 51^{\mathrm{m}} 1^{\mathrm{s}}$, South Declination, $12^{\circ} 39^{\prime} 14^{\prime \prime}$. On the $2 \mathrm{~d}$ of May he estimated it to be of the fifth magnitude, or a little brighter, and therefore distinctly visible to the naked eye. Its light was reddish in the telescope; and Dr. Petersen observed that the reddish color at times increased suddenly in intensity, and again as suddenly disappeared. Other observers noticed these peculiar red flashes. On the 
19th of May, Mr. Hind pronounced it fainter than when he first noticed it; and on the 24 th, it was ranked as a star of the sixth magnitude. The Messrs. Bond at Cambridge made a series of comparisons between this star and one of the fifteenth magnitude in its vicinity, and found that during three months of observation its position remained unchanged. They remarked, "This star resembles Antares, but its red is deeper. It is one of the most strikingly colored stars we remember to have seen. With a power of 1500 it showed no sign of a planetary disc." On the 15th of August they state, "This star appears to have decreased in brilliancy, and is now of the seventh magnitude; its ruby red color still remains. It is at once recognized from its neighbors by its color alone." On the 23d of March, 1849, Professor Kendall of Philadelphia, pronounced this star to be of the eighth magnitude. On the evening of June 4th, 1850, I made a careful survey of all the stars in this vicinity, and found only one which could be estimated as high as the tenth magnitude, and this had no very decided red color. Hind's star may therefore now be pronounced extinct.

Hind's star was not many degrees distant from the place where a new star was seen in 1604. This 
star was first announced on the 10th of October, and it was seen by Kepler on the 17th. The star was perfectly round, without nebulosity or tail ; its light was brighter and more unsteady than that of the other stars. After it had risen above the vapors of the horizon, its light was white. It not only surpassed stars of the first magnitude, but also Mars and Jupiter. Some even compared it to Venus, but Kepler was not of this opinion. Observations proved that it had no motion or sensible parallax. On the 9th of November it was seen in a twilight, which rendered Jupiter invisible. On the 16th, Kepler saw it for the last time, before its conjunction with the sun. On the 24 th of December it reappeared in the east with diminished brightness. It was still brighter than Antares, but inferior to Arcturus. On the 20th of March it appeared smaller than Saturn; but it was much larger than the stars of the third magnitude in Ophiuchus. On the 13th of September it was smaller than the third magnitude, and on the 8th of October it could be seen with difficulty. A few days later it disappeared in the sun's rays. In January and February some observers thought they saw this star again, but without being confident of it. In the month of March it could not possibly be seen, so that it must 
have disappeared between October, 1605, and February, 1606. Mr. Hind's star is about $12^{\circ}$ north of the place of that discovered in 1604, and about 17 minutes of time less in Right Ascension.

Mr. Hind has recently announced another scarlet star, between Orion and Eridanus. Its place is in Right Ascension $4^{\mathrm{h}} 52^{\mathrm{m}} 45^{\mathrm{s}}$, Declination $15^{\circ} 2^{\prime}$ south. He says, "I found this star in October, 1845, and have kept a close watch upon it since. It is of about the seventh magnitude, and the most curious colored object I have seen." 


\section{SECTION III.}

DISTRIBUTION OF THE STARS IN SPACE.

Before the invention of the telescope, it was impossible to acquire any very precise knowledge of the distance of the stars and their distribution in space; and even after the invention of the telescope, no one attempted to use it in any adequate manner to determine the constitution of the heavens, until the time of Sir William Herschel. This astronomer, having the command of instruments far superior to any who had preceded him, undertook a series of exact observations, upon which to found a knowledge of the starry heavens. In 1784, he first advanced an hypothesis respecting the Milky Way, which was substantially as follows:-The stars of our firmament, instead of being scattered in all directions indifferently through space, constitute a cluster with definite limits, in the form of a stratum, of which the thickness is small in comparison with its length and breadth; and in which the earth oc- 
cupies a place somewhere about the middle of its thickness, and near the point where it subdivides into two principal laminæ, inclined at a small angle to each other. For, to an eye so situated, the apparent density of the stars, supposing them pretty equally scattered through the space they occupy, would be least in the direction of a visual ray perpendicular to the lamina, and greatest in that of its breadth; increasing rapidly in passing from one to the other direction, just as we see a slight haze in the atmosphere thickening into a decided fog-bank near the horizon, by the rapid increase of the mere length of the visual ray.

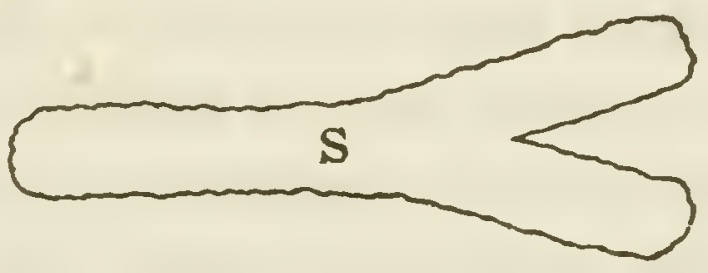

Herschel was conducted to this view of the Milky Way by the following considerations. Supposing the stars to be situated, in general, at equal distances from each other, the number of stars observed in the field of a telescope, ought to be about the same in all possible directions, provided the stars extend in all directions to the same distance. But if we have a stratum of stars at equal distances from each other, of a form whose thickness is small in com- 
parison with its diameter, then the number of stars visible in the different directions, will lead us to a knowledge both of the exterior form of the starry stratum, and of the place occupied by the observer. For example, if within a certain circle of the heavens we count ten stars, and in a circle of the same diameter, taken in a different direction, we count eighty stars with the same telescope, the lengths of the two visual rays will be in the ratio of 1 to 2 , or the cube roots of 1 and 8 . This is substantially Herschel's method of star-gages, in which he employed a telescope of 18 inches aperture, with a field of view of about a quarter of a degree. Herschel made 3400 gages of this kind. These gages indicate the number of stars visible in the field of his telescope, and from this number he deduced the corresponding lengths of the visual rays. Assuming the distance of the nearest of the fixed stars, in accordance with the estimates of Struve, we find that, according to Herschel, the stars upon the border of our stratum, in the constellation of the Eagle, are at such a distance as light requires 7000 years to traverse-and from the remoter stars, light would require 13,000 years to come to us.

The great nebulæ of the heavens, such as those of Orion and Andromeda, Herschel conjectured to 
be Milky Ways like our orwn, only of much superior dimensions. The nebula of Andromeda, which he concluded to be the nearest, he placed at a distance 2000 times greater than that of stars of the first magnitude.

This hypothesis respecting the phenomena of the Milky Way, would be tenable, provided it were true, 1st, that the stars are uniformly distributed through space; and $2 \mathrm{~d}$, that Herschel was able, with his telescope of 20 feet, to penetrate to the limits of our stratum.

With regard to the first of these hypotheses, we find that Herschel himself subsequently abandoned it as untenable. In 1796 he says, "The hypothesis of a uniform distribution of the stars is too far from the exact truth, to serve as a basis in this research." Again, in 1811, he adds, "The uniform distribution of the stars may be admitted in certain calculations ; but when we examine the Milky Way, this equal distribution must be abandoned." And in 1817 he says, "Although an increased number of stars in the field of the telescope is generally an indication of their greater distance, my gages refer more directly to the degree of condensation of the stars."

As to the second of the above conditions, viz., that in his gages he was able to penetrate to the 
extreme limits of the Milky Way, Herschel's views underwent an entire change in the progress of his researches. In 1817 , speaking of some of his gages, he says, "It is plain that the extreme penetrating power of the 20 feet telescope was insufficient to sound the depth of the Milky Way." Again, in 1818 , he says, "In these ten observations the gages were arrested in their progress by the extreme faintness of the stars. There is, however, no doubt respecting the further extent of the starry region. For if in one of the observations a feeble nebulosity had been suspected, the application of a higher magnifying power showed that the doubtful appearance was caused by the blending of numerous stars, too small to be seen by the aid of a lower magnifying power. We hence infer that if our gages cease to resolve the Milky Way into stars, it is not because its nature is doubtful, but because it is fathomless."

Thus we see that the hypothesis which Herschel announced in 1785, with regard to the constitution of the Milky Way, and which is still connected with Herschel's name in almost all the popular treatises on astronomy, was afterward entirely abandoned by its author.

Quite recently, M. Struve of Pulkova has under- 
taken a discussion of the same subject, employing, as the basis of his researches, the most extensive catalogues of stars. He has determined, partly by enumeration, and partly by estimation, the number of stars of each class as far as the ninth magnitude, and their distribution throughout the heavens. He finds that these stars are not uniformly distributed; but that near the equator they are most abundant, in the neighborhood of two points almost diametrically opposed, viz., in Right Ascension $6^{\mathrm{b}} 40^{\mathrm{m}}$, and $18^{\mathrm{h}} 40^{\mathrm{m}}$. The stars are least abundant near the diameter passing through $1^{\mathrm{h}} 30^{\mathrm{m}}$, and $13^{\mathrm{h}} 30^{\mathrm{m}}$. This diameter makes an angle of $78^{\circ}$ with the preceding. The diameter of greatest condensation coincides almost exactly with the position of the Milky Way; thus proving that the phenomena of the Milky Way are intimately connected. with the distribution of the stars from the first to the ninth magnitudes, or rather that the two phenomena are identical. Herschel proved, in 1817, that the Milky Way was fathomless, even with his telescope of 40 feet. The same uncertainty respecting the limits of the visible stars exists in every part of the heavens, even toward the poles of the Milky Way. Hence, if we regard all the fixed stars which surround the sun as forming one grand system, that of the Milky 
Way, we are entirely ignorant of its extent, and have not the least idea of the external form of this immense system.

M. Struve has attempted to determine the average number of stars visible in the field of Herschel's telescope, (15 minutes in diameter,) according to his numerous gages, for every fifteen degrees of angular distance from the Milky Way, and has obtained the following results :-

FOR THE NORTHERN HEMISPHERE.

\begin{tabular}{|c|c|c|c|c|c|c|c|c|}
\hline $\begin{array}{l}\text { Distance from } \\
\text { Milky WVa }\end{array}$ & & & & & & & & $\begin{array}{c}\text { Number of sta } \\
\text { visible. }\end{array}$ \\
\hline $0^{\circ}$ & - & - & - & - & - & - & - & - $122 \cdot 00$ \\
\hline 15 . & - & - & - & - & - & - & - & $30 \cdot 30$ \\
\hline 30 & - & - & - & - & - & - & - & $17 \cdot 68$ \\
\hline 45 . & - & - & - & - & - & - & - & $10 \cdot 36$ \\
\hline 60 . & - & - & - & - & - & - & - & $6 \cdot 52$ \\
\hline 75 . & - & - & - & - & - & - & - & $4^{\cdot} 68$ \\
\hline 90 . & • & . & • & • & . & . & . & $4 \cdot 15$ \\
\hline
\end{tabular}

Whence it appears that Herschel's telescope disclosed about 30 times as many stars in the middle of the Milky Way as near its pole.

Struve next proceeded to estimate the relative distances of stars of the several magnitudes as deduced from their number, supposing the stars to be distributed at uniform distances from each other along 
the middle of the Milky Way, and obtained the following results :-

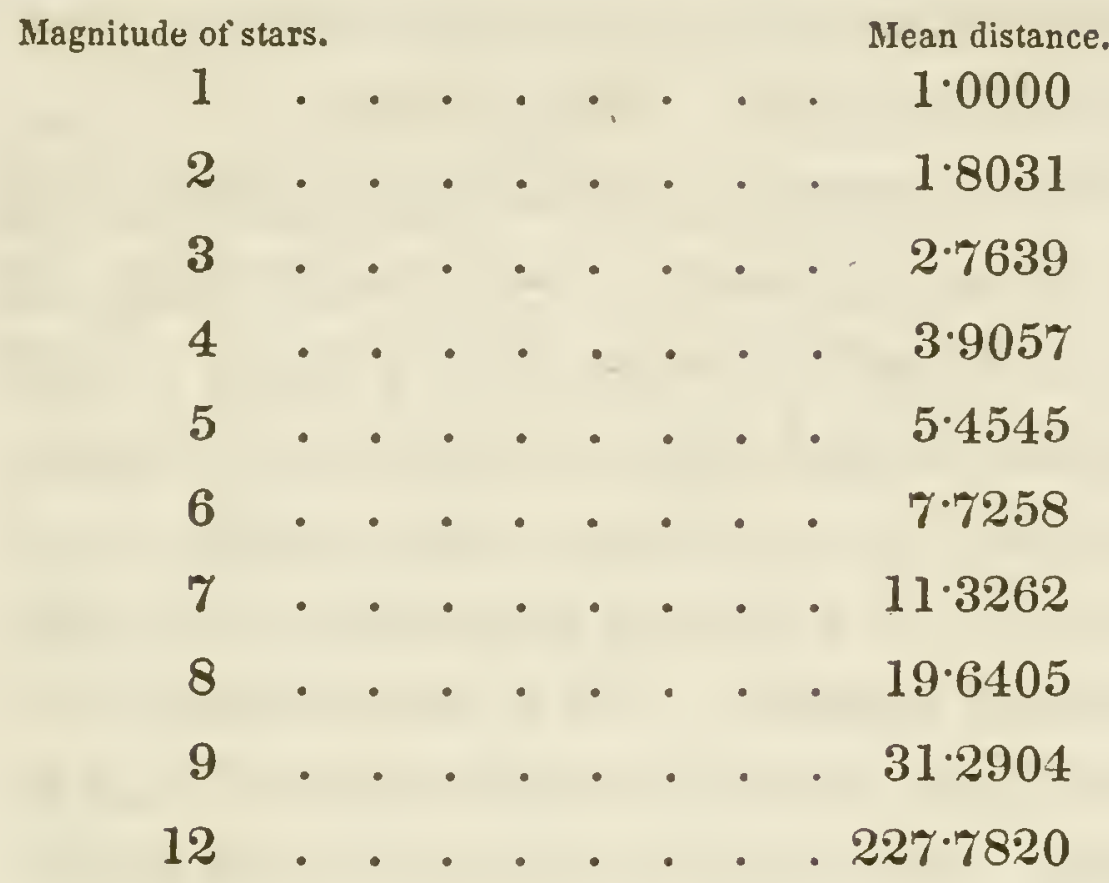

According to this table, the distance of stars of sixth magnitude, which are just visible to the naked eye, is about eight times as great as that of stars of the first magnitude. The distance of stars of the 12th magnitude, by which is meant those stars which were barely visible in Herschel's 20 feet telescope, is 228 times as great as that of stars of the first magnitude.

Assuming the preceding relative distances, and also that the average parallax of a star of the second magnitude is $0 " .116$, we obtain the absolute distance of stars of each magnitude as given on page 121 . 
Prof. Encke, of Berlin, has criticized these speculations of Struve with some severity. He thinks that they involve several hypotheses which are altogether unwarrantable. They assume,

I. That the apparent brightness of the stars is the simple effect of distance, so that we can assign the radius of the sphere within which the stars of each class are comprised. Encke objects to this assumption, 1. That it is contrary to the analogy of our solar system, in which the magnitudes of the planets are very unequal. 2. It is contradicted by the parallax of the stars so far as the same has been determined. The parallax of several stars of the fifth and sixth magnitudes is greater than that of most stars of the first magnitude. The star 61 Cygni, of the fifth magnitude, has a parallax certainly greater than what Struve has given for the average parallax of stars of the first magnitude. 3. It is contradicted by the phenomena of the binary stars. There is a large number of double stars, which are proved to be physically connected, and therefore both are situated at nearly the same distance from the earth, while in most of them there is a perceptible disparity of brightness, and in some cases this disparity amounts to four magnitudes.

II. The distribution of the stars over the entire 
heavens is admitted not to be uniform, nevertheless such a uniform distribution is assumed for the plane of the Milky Way, and the irregularities which we observe in it are regarded as in part unimportant, and in part ascribed to the eccentric position of the sun, and its distance from the plane of the Milky Way. Hence it is inferred that from the number of the stars of a given brightness, we may determine the ratio of the radius of their sphere to that of stars of any other brightness.

These and several other hypotheses which are involved in Struve's reasoning, Prof. Encke regards as altogether inadmissible, and he concludes that the mean parallax which Struve ascribes to stars of the first magnitude (viz. $0^{\prime \prime} \cdot 209$ ) is entirely unworthy of cofidence.

During his residence at the Cape of Good Hope, in the years 1834-8, Sir John Herschel undertook a series of star-gages similar to those executed by his father for the northern hemisphere. About 2300 gages were obtained, distributed with tolerable impartiality over the southern heavens. The following table shows the average number of stars to a field of fifteen minutes in diameter, visible in his 20 feet reflector with the usual sweeping power 
180, for every fifteen degrees of angular distance from the Milky Way.

FOR THE SOUTHERN HEMISPHERE.

\begin{tabular}{|c|c|c|c|c|c|c|c|}
\hline $\begin{array}{l}\text { Distance from the } \\
\text { Milky Way. }\end{array}$ & & & & & & & $\begin{array}{l}\text { Number of sta } \\
\text { visible. }\end{array}$ \\
\hline $1 \frac{110}{2}$ & . & - & ${ }^{\circ}$ & - & - & - & . $\quad 74.50$ \\
\hline $0^{\circ}-15^{\circ}$ & - & - & - & 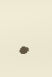 & . & - & $59 \cdot 06$ \\
\hline $15-30$ & - & . & - & - & . & . & $26 \cdot 29$ \\
\hline $30-45$ & - & - & $\cdot$ & - & . & - & . $\quad 13.49$ \\
\hline $45-60$ & . & & . & - & . & . & $9 \cdot 08$ \\
\hline $60-75$ & - & & $\bullet$ & & - & - & $6 \cdot 62$ \\
\hline $75-90$ & • & • & . & & . & . & $6 \cdot 05$ \\
\hline
\end{tabular}

On the northern side of the Milky Way, Sir J. Herschel's observations give the following result:-

\begin{tabular}{|c|c|c|c|c|c|c|c|}
\hline $\begin{array}{l}\text { istance from the } \\
\text { Nilky Way. } \\
0^{\circ}-15^{\circ}\end{array}$ & - & - & - & & & & $\begin{array}{c}\begin{array}{c}\text { Number of st } \\
\text { visible. }\end{array} \\
51 \cdot 28\end{array}$ \\
\hline $15-30$ & 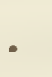 & - & - & & & & $23 \cdot 47$ \\
\hline $30--45$ & 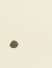 & . & ${ }^{\circ}$ & & & & $14 \cdot 4$ \\
\hline $45-60$ & & . & . & & & & \\
\hline
\end{tabular}

These numbers accord tolerably well with the deductions of Struve, on page 134, except for the middle zone of the Milky Way itself. But Sir J. Herschel has referred his observations to a great circle of the sphere which approaches nearest to coincidence with the Milky Way. If a zone fol- 
lowing the irregular line of maximum intensity of the Milky Way had been chosen, the average number of stars visible in the field of the telescope would be about ninety, exclusive of the more densely clustering masses.

These observations clearly show the rapid increase in the number of stars as we approach the Milky Way on either side, and that nearly the same law of gradation holds for the southern as for the northern side. From these gages Sir J. Herschel has computed that the number of stars visible enough to be distinctly counted in the 20 feet reflector, in both hemispheres, is about five and a half millions. That the actual number is much greater than this, he infers from the fact that there are large tracts of the Milky Way so crowded as to defy counting the gages, not by reason of the smallness of the stars, but on account of their number.

Sir J. Herschel, in counting the gages, not only set down the total number of stars, but the number for each magnitude down to the eleventh, and even for the estimated half-magnitudes. Upon classifying the stars according to their magnitudes, it appears that the increase of density in approaching the Milky Way is quite imperceptible among stars of a higher magnitude than the eighth, and except 
on the very verge of the Milky Way itself, stars of the eighth magnitude can hardly be said to participate in the general law of increase. For the ninth and tenth magnitudes the increase, though unequivocally indicated over a zone extending at least $30^{\circ}$ on either side of the Milky Way is by no means striking. It is with the eleventh magnitude that it first becomes conspicuous, though still of small amount when compared with that which prevails among the mass of stars inferior to the eleventh, which constitute sixteen seventeenths of the totality of stars within 30 degrees on either side of the Milky Way.

From these observations Sir J. Herschel draws the two following conclusions; viz.- " 1 st. That the larger stars are really nearer to us (taken en masse, and without denying individual exceptions) than the smaller ones. Were this not the case, were there really among the infinite multitude of stars constituting the remoter portion of the galaxy, numerous.individuals of extravagant size and brightness, as compared with the generality of those around them, so as to overcome the effect of distance, and apppear to us as larger stars, the probability of their occurrence in any given region would increase with the total apparent density of stars in that region, 
and would result in a preponderance of considerable stars in the Milky Way, beyond what the heavens really present over its whole circumference. 2d. That the depth at which our system is plunged in the sidereal stratum constituting the galaxy; reckoning from the southern surface or limit of that stratum, is about equal to that distance which, on a general average, corresponds to the light of a star of the ninth or tenth magnitude, and certainly does not exceed that corresponding to the eleventh."

This last conclusion seems clearly to assume, not only that our Milky Way consists of a stratum of stars which has determinate limits, but that these limits (at least in certain directions) have been indicated by observation. It does not, however, appear that such a conclusion is authorized by the gages. The number of stars of the smallest magnitude visible, increases rapidly even up to the poles of the Milky Way, although this increase is most rapid in the middle zone of the galaxy. The gages therefore indicate a condensation of stars in the neighborhood of the Milky Way, but not that our telescopes have penetrated to the boundaries of our stratum. Every increase in the power of our telescopes has hitherto disclosed new stars in every part of the heavens; it is therefore unphilosophical 
to infer that such would not continue to be the case if we could command a further increase of telescopic power. It is, however, remarkable that those portions of the heavens which are most remote from the Milky Way are richest in nebulæ and clusters of stars. In the neighborhood of the north pole of the Milky Way, within a region occupying about one eighth of the whole surface of the sphere, one third of the entire nebulous contents of the heavens are congregated. A large portion of these nebulæ have been resolved into clusters of stars, and these stars, upon the principle that faintness is merely the effect of distance, must be inferred to be as near to us as the faintest stars of the Milky Way.

On the whole, we must conclude that the stars, in every part of the heavens, extend to a distance beyond the reach of the most powerful telescope hitherto constructed; that therefore the shape of that portion of space which the stars occupy is entirely unknown to us; that within this space the stars are not uniformly distributed, but are most crowded in the neighborhood of a plane which we call the Milky Way; that out of this plane the stars exhibit a great many centers of attraction, about which an immense number of them are clustered; but that the entire space, so far as we can perceive, is stud- 
ded, though more sparsely, with stars. The material universe therefore appears to us boundless; and astronomers, certainly of the present age, need not be apprehensive that they will ever witness the time when there will be no more worlds to conquer. 


\section{SECTION IV.}

MOTION OF THE SUN AND FIXED STARS.

To common observation, the fixed stars retain sensibly the same relative position from age to age; but the exact observations of modern astronomy have detected a relative motion in a large number of them. A small star in the leg of the Great Bear (called 1830 Groombridge) has an annual motion of seven seconds of arc as compared with neighboring stars; and there are more than thirty stars known, whose annual proper motion exceeds one second. It might have been expected, a priori, that motion of some kind must exist among such a multitude of objects all subject to mutual attraction; and it appears highly probable, not to say certain, that the sun must participate in this movement. The effect of a motion of the sun, with reference to the stars, would be an apparent divergence or separation of those stars toward which we were moving, and an apparent convergence or clos- 
ng up of the stars in the region which we were leaving. We might therefore expect to detect such a motion, if it really exists, by comparing the proper motions of all the stars of the firmament. In accordance with this idea, Sir William Herschel, in 1783 , by a comparison of the proper motions of such star's as were then best ascertained, arrived at the conclusion that the sun had a relative motion among the fixed stars, in the direction of a point in the constellation Hercules, whose Right Ascension is $260^{\circ} 34^{\prime}$, and Declination $26^{\circ} 17^{\prime}$ north.

More recently, M. Argelander, by comparing the proper motions of 390 stars, has located this point in R. A. $257^{\circ} 35^{\prime}$, and Declination $36^{\circ} 3^{\prime} \mathrm{N}$. M. Luhndahl, by a comparison of the proper motions of 147 stars, has obtained for this point, R. A. $252^{\circ}$ $53^{\prime}$, Dec. $14^{\circ} 26^{\prime}$ N.; and M. Struve, by comparing the proper motions of 392 stars, has located this point in R. A. $261^{\circ} 22^{\prime}$, Dec. $27^{\circ} 36^{\prime} \mathrm{N}$. 'The most probable mean of the results of these three astronomers is R. A. $259^{\circ} 9^{\prime}$, Dec. $34^{\circ} 37^{\prime} \mathrm{N}$.

Quite recently Mr. Galloway has made a similar comparison of stars visible in the southern hemisphere; and from the proper motion of 81 southern stars not employed in the preceding investigations, he has located the point toward which the sun is 
moving in R. A. $260^{\circ} 1^{\prime}$ : Dec. $34^{\circ} 23^{\prime} \mathrm{N}$., a result almost identical with that obtained in the northern hemisphere.

It seems then nearly certain that the apparent motion of these stars is due, at least in part, to a relative motion of our sun, and the same observations afford us the means of estimating its velocity. According to Struve's calculations, this velocity is such as would carry it annually over an angle of one third of a second, if seen at right angles from the average distance of a star of the first magnitude. If we assume the parallax of such a star as equal to one fifth of a second, we shall find that the sun advances through space, carrying with it the whole system of planets and comets, with a velocity about one fourth of the earth's annual motion in its orbit.

A grcat many questions here naturally suggest themselves. Is the sun's motion uniform and rectilinear, or is it moving slowly in an orbit about some center? Are the star's moving in straight lines, or in grand orbits? Have all the stars, including our sun, a common movement of rotation about some general center? This question has been examined by Prof. Mädler; of the Dorpat Observatory, and he has attempted to assign the center round which the 
sun and stars revolve, which center he places in the group of the Pleiades.

If we assume that the orbit described by our sun about the central point is a circle, this central point must be found on the circumference of a great circle, whose pole is that point toward which the sun is moving in R. A. $259 \frac{10}{2}$, Dec. $34 \frac{1}{2}^{\circ} \mathrm{N}$. This circle cuts the Milky Way in the constellation Perseus, and Argelander conjectured the central point to be here in Perseus. The most remarkable cluster of stars in this neighborhood is the Pleiades, and Mädler conjectured that here might be the central point. Accordingly he determined the proper motion of the eleven principal stars in this cluster by comparing the observations of Bessel with those of Bradley and other astronomers. These motions exhibit considerable uniformity, and their direction is invariably toward the south.

Mädler next examined the 12 principal stars within five degrees of this group, and finds that aight exhibit a decided southern motion, while in the other four the motion is too small to be decisive, but in no case is the motion toward the north. Among 30 stars between 5 and 10 degrees distant from the Plejades, Mädler finds that 20 are moring toward the south; while the motion of the re- 
maining 10 is scarcely perceptible. Among 57 stars between 10 and 15 degrees from the Pleiades, 16 are moving toward the south, while the motion of the remaining 41 is scarcely perceptible. Not one moves toward the north. Out of 66 stars, between 15 and 20 degrees of the Pleiades, 30 have a decided southern motion, and 36 are undecided. Thus out of 176 stars within 20 degrees of the Pleiades we find 85 moving toward the south, and 91 whose motion is scarcely perceptible, but not a single case in which there is a considerable motion toward the north.

Mädler next examined all of Bradley's stars between 20 and 30 degrees of the Pleiades, of which the number is 175 : of these, 78 exhibit a motion toward the south, 92 are uncertain, and 5 have a slow motion toward the north, amounting in the most rapid case to only seven seconds in a century. Such a result Prof. Mädler considers a necessary consequence of his hypothesis. Since only small real motions are to be expected in the neighborhood of the central point, the motions which are only apparent, and therefore contrary to the solar motion, must preponderate for all stars between the sun and the Pleiades.

The most rapid proper motions, according to this 
hypothesis, must be sought for near the great circle described about the Pleiades as a pole; and accordingly we find near this circle two of the most decided of all the proper motions hitherto discovered.

Prof. Mädler accordingly infers that the central point of the starry heavens must be placed in the neighborhood of the Pleiades. This group is the nearest, the brightest, and the richest cluster in the whole heavens. Moreover, Alcyone is the optical center of this group, and he infers that this is the star which combines the strongest probability of being the true central sun.

Alcyone, known also as $\eta$ Tauri, or 25 Tauri, is a double star of the third or fourth magnitude, in Right Ascension $3^{\mathrm{h}} 38^{\mathrm{m}}$; Declination $23^{\circ} 39^{\prime} \mathrm{N}$.

Assuming the parallax of $61 \mathrm{Cygni}$, as determined by Bessel, and that the sun and this star are moving with the same velocity about Alcyone, Mädler has computed that the distance of Alcyone is 34 millions of times that of the sun, requiring 537 years for its light to come to us, although moving at the rate of twelve millions of miles per minute. The periodic time of the sun about Alcyone is estimated at 18 millions of years; and the sum of the masses of all the stars within the sphere described about Alcyone as a center, with a radius equal to the 
sun's distance, is 117 million times the mass of the sun.

The preceding conclusions are certainly wonderful; but, unfortunately, they rest upon a very unsatisfactory basis. Professor Mädler has subjected the stars in the neighborhood of Alcyone to a very careful examination, and finds decisive indications of the sun's relative motion, as it had been previously established by the labors of Argelander and others. But beyond the neighborhood of the Pleiades, the number of stars examined is altogether too small to form the basis of so important conclusions. Sir John Herschel pronounces it almost inconceivable, that any general circulation of the stars can take place out of the plane of the Milky Way, while the Pleiades are situated 20 degrees out of this plane. It is not, however, presumptuous to expect that the problem which Mädler has propounded will one day be resolved. A careful determination of the proper motion of a considerable number of stars suitably situated in different parts of the heavens, could not fail to settle the question. 


\section{SECTION V.}

RESOLUTION OF REMARKABLF NEBUI,E.

The last few years have been remarkable for the production of the largest telescope ever manufactured. Sir William Herschel constructed, with his own hands, telescopes of 20 and 40 feet focus, with which he made some of the most brilliant discoveries recorded in the history of astronomy. But quite recently, the Earl of Rosse has completed a. telescope still more gigantic than the largest of Sir William Herschel. He had previously constructed a telescope of three feet aperture, which received the highest commendation from Dr. Robinson and Sir James South. In 1842, he commenced another of far superior dimensions, whose speculum was six feet in diameter, and weighed three tons. The materials of which it is composed are copper and tin, united in the proportion of fifteen parts of copper to seren of tin. The process of grinding was conducted under water, and the moving power em- 
ployed was a steam-engine of three horse power. The substance made use of to wear down the surface was emery and water, and it required six weeks to grind it to a fair surface.

The tube of the telescope is 56 feet long, and is made of wood one inch thick, and hooped with iron. The diameter of this tube is 7 feet. At 12 feet distance on each side of the telescope, a wall is built, 72 feet long, 48 high on the outer side, and 56 on the inner, the walls being 24 feet distant from each other, and lying exactly in the meridian. When directed to the south, the tube may be lowered till it becomes almost horizontal; but when pointed to the north, it only falls till it is parallel with the earth's axis. Its lateral movements take place only from wall to wall, and this commands a view for half an hour on each side of the meridian; that is, the whole of its motion from east to west is limited to 15 degrees. The expense of this instrument was not less than twelve thousand pounds. It has a reflecting surface of 4071 square inches, while that of Herschel's 40 feet telescope had only 1811 square inches.

In March, 1845, Sir James South made trial of this telescope, and gives the following account of his observations:- "Never before in my life did I 
see such glorious sidereal pictures as this instrument afforded us. The most popularly known nebulæ observed were the ring nebula in the Canes Venatici, which was resolved into stars with a magnifying power of 548, and the 94th of Messier, which is in the same constellation, and which was resolved into a large globular cluster of stars, not much unlike the well-known cluster in Hercules. On subsequent nights, observations of other nebulæ, amounting to some thirty or more, removed most of these from the list of nebulæ, where they had long figured, to that of clusters; while some of these latter exhibited a sidereal picture in the telescope such as man before had never seen, and which, for its magnificence, baffles all description."

In the Philosophical Transactions for 1844, Lord Rosse has given some observations of nebulæ made with his three feet speculum, accompanied with drawings of the most remarkable objects. Among these is one which Sir John Herschel had figured as an oval resolvable nebula. Lord Rosse's telescope exhibits it with resolvable filaments singularly disposed, springing principally from its southern extremity, and not, as is usual in clusters, irregularly in all directions. It is studded with stars, mixed, however, with a nebulosity, probably consisting of 
stars too minute to be recognized. This has been called the crab nebula.

The Dumb Bell nebula, known everywhere by the drawing of Sir John Herschel, is seen to consist of innumerable stars mixed with nebulosity; and Lord Rosse remarks, that when we turn the eye from the telescope to the Milky Way, the similarity is so striking that it is impossible not to feel a conviction that the nebulosity in both proceeds from the same cause.

The annular nebula in Lyra shows filaments proceeding from the edge of the ring, and also several filaments partly filling up the interior of the ring. By the three feet speculum it was not resolved, but the filaments became conspicuous under increasing magnifying power, which circumstance is strikingly characteristic of a cluster.

The nebula in the Dog's Ear was formerly regarded as a representation of our own Milky Way, and although unresolved, it was by common consent considered a mighty cluster. At the meeting of the British Association in 1845, Lord Rosse showed a sketch of its appearance as seen by aid of his six feet mirror. The former simple shape of this nebula is transformed into a scroll, apparently unwinding with numerous filaments, and a mottled 
appearance, which looks like the breaking up of a cluster.

The great nebula in Orion has been examined with every great telescope since the invention of that instrument, but until recently without the remotest aspect of a stellar constitution. During Sir John Herschel's residence at the Cape of Good Hope, he examined this nebula under the most favorable circumstances, when it was near the zenith-but still there was no trace of a star, only branches added without number, so as almost to obliterate the nebula's previous form. During the winter of 1844-5, Lord Rosse examined it with his three feet mirror with the utmost care, but without detecting the vestige of a star. In the winter of 1845-6, the six feet telescope was directed, for the first time, to this wonderful object, and in March, 1846, Lord Rosse made the following announcement: "I think I may safely say that there can be little if any doubt as to the resolvability of this nebula. We can plainly see that all about the trapezium is a mass of stars; the rest of the nebula also abounding with stars, and exhibiting the characteristics of resolvability strongly marked."

Mr. Bond, with the great telescope at Cambridge, has also seen this nebula partially resolved. To 
him the head of the nebula appears composed of several clusters of stars, the components being separately seen for a moment under favorable circumstances.

The Great Nebula in Andromeda, has also been carefully observed with the Cambridge telescope. The most conspicuous features were the sudden condensation of light at the center into an almost star-like nucleus; and the vast number of stars of every gradation of brilliancy scattered over its surface, which yet had the undefinable, but still convincing aspect of not being its components. It is estimated that above fifteen hundred stars are visible with the full aperture of the object glass within the limits of the nebula. With high powers, minute stars are discovered on the borders of the nucleus, but it has thus far yielded no evidence of resolution. Minute descriptions, accompanied with accurate drawings of both these nebulæ, have been recently given by the Messrs. Bond in the Memoirs of the American Academy, Vol. III.

On the whole, it appears that the increase in the power of our telescopes has added to the number of the clusters at the expense of the nebulæ properly so called; still, as Lord Rosse has remarked, it would be very unsafe to conclude that such will al- 
ways be the case, and thence to infer that all nebulosity is but the glare of stars too remote to be separated by the utmost power of our instruments. While Lord Rosse's telescope has shown certain nebulæ to contain an immense number of stars, it has also revealed to us new nebulous appendages of extreme faintness, which we must regard either as not composed of stars, or as composed of stars of very small absolute dimensions. 


\section{CHAPTER IV.}

PROGRESS OF ASTRONOMY IN THE UYITED STATES.

\section{SECTION I.}

HISTORY OF AMERICAN OBSERYATORIES.

IT is but a few years since practical astronomy began to be cultivated in the United States in an efficient and systematic manner. Until recently, the instruments in our possession were but few and small, and the observations which were made, seldom extended beyond the notice of the time of a solar or lunar eclipse, or the measurement of a comet's distance from neighboring stars with a sextant.

Probably the most important astronomical enterprise undertaken in this country during the last century, was the observation of the transit of $\mathrm{Ve}$ nus in June: 1769. The American Philosophical Society, in January, 1769, appointed a committee of thirteen to observe this rare phenomenon. The gentlemen thus nominated, were distributed into three committees for the purpose of making sepa- 
rate observations at three several places; viz., the city of Philadelphia; Mr. Rittenhouse's residence in Norriton, 17 miles north-rvest of Philadelphia; and the light-house, near Cape Henlopen on Delaware Bay. Dr. Ewing had the principal direction of the observatory in the city, Mr. Rittenhouse at Norriton, and Mr. O. Biddle at Cape Henlopen. Some money was appropriated by the Philosophical Society toward defraying the expenses of the observations; but this being found insufficient, aid was solicited and obtained from the Assembly. Temporary observatories were erected, tolerably well adapted to the purposes for which they were designed. A reflecting telescope with a Dollond micrometer, was purchased in London by $\mathrm{Dr}$. Franklin, with the money voted by the Assembly; another of the same character was presented by Thomas Penn, of London, and other instruments were supplied in sufficient number. The observations at the three stations were all successful, and an account of them is given in the first volume of the Transactions of the American Philosophical Society.

For more than half a century after the transit of Venus, very little, if any progress seemed to have been made toward the erection of a permanent ob- 
servatory, or toward the procuring of large instruments such as modern astronomy requires. This subject had indeed been repeatedly urged upon the attention of Congress, especially by the late John Quincy Adams, but entirely without success; and so late as the year 1832, in reviving an act for the continuance of the survey of the coast, Congress was careful to append the proviso, that "nothing in the act should be construed to authorize the construction or maintenance of a permanent astronomical observatory."

YALE COLLEGE OBSERVATORY.

A donation made to Yale College by Mr. Sheldon Clark, is believed to have contributed somewhat toward that impulse which astronomy has recently received. In 1828, Mr. Clark made a donation of twelve hundred dollars to Yale College for the purchase of a telescope. The telescope was ordered from Dollond, of London. It arrived in 1830, and was pronounced by the maker to be "perfect, and such an instrument as he was pleased to send as a specimen of his powers." This instrument has a focal length of ten feet, and an aperture of five inches. The object glass is almost perfectly 
achromatic. For objects that require a fine light, as the nebulæ and smaller stars, this instrument exhibits great superiority, and its defining power is equally good. It has a variety of eye-glasses, and a spider line micrometer of the best construction.

The mounting of this telescope is not equal to its optical character. It has an altitude and azimuth movement, without graduated circles, and is rolled about the room upon casters. The location of the instrument was peculiarly unfortunate. It was placed in the steeple of one of the college buildings, where the only view afforded of the heavens was through low windows, which effectually concealed every object as soon as it attained an altitude of thirty degrees above the horizon. Under these circumstances, the telescope has proved less serviceable to science than might otherwise have been anticipated. On one occasion, however, circumstances gave this telescope considerable celebrity. The return of Halley's comet in 1835 was anticipated with great anxiety. The most eminent astronomers of Europe had carefully computed the time of its appearance, and the results of their computations had been spread before the public in all the popular journals. Expectation therefore was stimulated to an unwonted degree. The comet 
was first observed in this country by Professors Olmsted and Loomis, with the Clark telescope, weeks before news arrived of its having been seen in Europe. This was the occasion of bringing prominently before the public the desirableness of having large telescopes, with all the instruments necessary for nice astronomical observations. It gave a new impulse to a plan which had already been conceived, of establishing a permanent observatory at Cambridge upon a liberal scale-a plan, however, which required the momentum of another and more splendid comet for its completion. It kindled anew the astronomical spirit of Philadelphia, and excited a desire for instruments superior to those which they then possessed. Indeed, the importance of systematic astronomical observations was beginning to be somewhat generally felt, as well as the necessity of superior instruments for this purpose, and many embryo plans were formed for the establishment of economical observatories.

WILLIAMS COLLEGE OBSERTATORY.

The first attempt of this kind was made by Prof. Albert Hopkins of Williams College, Mass. In 1836, Prof. Hopkins erected a small building: con- 
sisting of a center with two wings, the whole being 48 feet in length by 20 in breadth. The central apartment is surmounted by a revolving dome 13 feet in diameter, and each wing has an opening through the roof for meridian instruments. Under the dome has been placed an Herschelian telescope of 10 feet focus, mounted equatorially. The circle for Right Ascension is a foot in diameter; the Declination semicircle is thirty inches in diameter. Both were made by Mr. Phelps of Troy, N. Y., and read to minutes. In the east wing has been placed a transit instrument by Troughton, having a focus of 50 inches, and an aperture of three and a half inches. In the same room is a compensation clock by Molineux.

HUDSON (OHIO) OBSERVATORY.

The next experiment for an observatory was made in Ohio, in connection with the Western Reserve College. Having been elected to the Professorship of Mathematics and Astronomy in this institution, in the spring of 1836 , I was sent to Europe for the purchase of instruments and books, and returned in 1837 , with an equatorial telescope, a transit circle, and a clock. During the next season a 
building was erected, which, though quite moderate in dimensions, was well suited to the accommodation of the instruments. The entire length of the building is 37 feet, and its breadth 16 feet. The transit room is 10 feet by 12 upon the inside, having a sand-stone pier in its center. The pier is entirely detached from the building, and descends about six feet below the surface of the earth. The transit commands an unobstructed meridian from ninety degrees zenith distance on the south, to eighty-nine on the north.

The central room is occupied by the equatorial; it is fourteen feet square on the inside, and is surmounted by a revolving dome of nine feet internal diameter. The equatorial pier descends six feet below the surface, and, like the transit pier, has a slope of one inch to the foot.

The transit circle was made by Simms of London. It has a telescope of thirty inches focal length, with an aperture of nearly three inches. The circle is eighteen inches diameter, graduated on platina to five minutes; and there are three reading microscopes, each measuring single seconds.

The equatorial telescope, made also by Simms, is five and a half feet focal length, with an aperture of about four inches. The Right Ascension circle 
is twelve inches in diameter, graduated to single minutes, and reads by two verniers to single seconds of time. The Declination circle is also twelve inches in diameter, graduated to ten minutes, and reads by two verniers to ten seconds of arc.

The clock was made by Molineux, and has a mercurial pendulum. The instruments were first placed in the observatory, September, 1838, and during the whole time of my residence in Hudson, Ohio, I pursued a systematic course of observations, as far as my engagements in the College would permit, and without the advantage of an assistant. Among these observations may be mentioned, two hundred and sixty moon culminations for longitude, sixty-nine culminations of Polaris for latitude, sixteen occultations, five comets with sufficient accuracy to afford a determination of their orbits, beside a great variety of other objects, for regulating the clock, etc.

PHILADELPHIA OBSERVATORY.

The High School Observatory at Philadelphia was erected at about the same time with that of Western Reserve College, but the instruments were not received until the autumn of 1840 . In the year 
1838, the Comptrollers of the High School erected a tower"about forty-five feet high, in the rear of the building for the school. It was insulated ten feet below the surface of the earth. The brick walls were three feet thick at bottom, and two and a half feet thick at top, and the diameter of the tower was about twelve feet in the clear. It was surmounted by a dome eighteen feet in diameter, weighing about two tuns. The equatorial, by Merz and Mahler of Munich, is of eight feet focal length, and six inches aperture, moved by clock-work. It rested on two marble slabs, each weighing about a thousand pounds, which were supported by two strong castiron beams that reached from the north to the south brick wall, and thus bound the two walls together. 'This telescope is mounted like the celebrated telescope at Dorpat, and has a variety of powers to 480 , with micrometers. The hour circle reads to four seconds of time, and the Declination circle to ten seconds of arc.

In 1842, the iron girders which supported the equatorial were removed, and the tower was inclosed by walls separated from it by a space of about two feet, which walls serve to support the dome and the frame apartment containing the instruments. The marble slabs upon which the equatorial stands, were 
placed on the top of an arch springing from the four walls of the tower.

The meridian circle is by Ertel of Munich. It is mounted on marble pillars resting on the south wall of the tower. The telescope has an object glass of four and a half inches aperture and five feet focus, and is so constructed that the object glass and eye-glass may be made to change places. It has two circles, each graduated to read by the aid of four verniers to two seconds of arc. The clock is by Lukens, has a mercurial pendulum, and rests upon a marble pier which rises from the S.W. angle of the tower.

The erection of this observatory formed an epoch in the history of American astronomy, in consequence of the introduction of a superior class of instruments to any which had been hitherto imported. It introduced the instruments of Munich fairly to the notice of the American public; and their superiority to the English telescopes was felt to be so decided, that almost every large instrument which has been since imported has been from the same makers. In the hands of Messrs. Walker and Kendall this Observatory became celebrated, not only in America, but also in Europe. It has furnished numerous observations of comets, especially 
the great comet of 1843, and also a long list of observed occultations and moon culminating stars.

\section{WEST POINT OBSERVATORY.}

The West Point Observatory was erected about the same time with that at Philadelphia. In 1839, a large building was erected for the accommodation of the library and philosophical apparatus, with three towers for the reception of astronomical instruments. The central tower is surmounted by a traveling dome 27 feet in diameter, and about 17 feet high from the spring. It is pierced by five window openings near the curb, and an observing slit two feet wide, extending from a point four feet above the floor, to nearly two feet on the opposite side of the zenith. The dome rests on six twenty-four pound camnon-balls, which turn between two castiron annular grooves.

In the two flank towers, meridian observing slits are made about twenty inches in the clear. These begin about two and a half feet from the floor, and extend through the roof, thus affording an uninterrupted view of the celestial meridian from the southern to the northern point of the horizon.

In the year 1840, Prof. Bartlett visited all the 
principal observatories in England, Scotland, Ireland, France, Bavaria, and Belgium, and ordered the three large instruments which have been since received. These consist of an equatorial telescope, a transit instrument, and a mural circle.

The equatorial, which is erected in the central tower, was furnished by $\mathrm{Mr}$. Thomas Grubb, of Dublin. The telescope made by Lerebours, of Paris, is a refractor of eight feet focus and six inches aperture. It has a position micrometer furnished with an illuminating apparatus for bright lines and dark field. The hour circle is twelve inches in diameter, and reads, by the aid of three verniers, to a second of time. The declination circle is fifteen inches in diameter, and by means of two verniers, reads to fifteen seconds of space. The telescope is moved by clock-work, so that the object under examination is easily kept in the center of the field of view.

In the east tower is a transit telescope, by Ertel and Son of Munich. It has a clear aperture of $5 \frac{1}{4}$ inches, with a focal length of seven feet, and is supplied with all the appendages necessary to facilitate the making of observations. There is in this tower a fine sidereal clock by Hardy.

In the west tower is a mural circle by Simms, 
of London. It is cast in one entire piece of brass, instead of the usual mode of frame-work. Its diameter is five feet, and the graduations are upon two bands, one of gold, the other of palladium. The telescope has a clear aperture of 4 inches, and a focal length of 5 feet. It is provided with all the usual means of adjustment, together with a vertical collimating eye-piece, and an illuminating apparatus for dark field and bright lines. Professor Bartlett, the director of the observatory, has subjected this instrument to a severe trial, and finds the probable error in the measurement of an angle of $60^{\circ}$ to be but $0^{\prime \prime} \cdot 22$, exclusive of the error of reading. There is also a sidereal clock in the same tower.

Prof: Bartlett made a series of observations on the great comet of 1843 , which are published in the Transactions of the American Philosophical Society. He has also made a good many observations with the meridional instruments, which have not yet been published. $\mathrm{He}$ is at present engaged in a regular series of observations on the stars enumerated in the "Notes to the British Association Catalogue," and also upon the planet Neptune. 
NATIONAL OBSERVATORY.

Soon after the completion of the West Point Observatory, the National Observatory at Washington was commenced. The origin of this establishment may be ascribed in some measure to the United States Exploring Expedition of 1838-42. As it was obviously important to determine the longitude of places visited by the expedition, it was deemed necessary that a regular series of astronomical observations should be made in the United States. Accordingly Mr. Bond, of Boston, and Lieut. Gilliss, at Washington, were directed to observe the moon culminating stars of the Nautical Almanac, and also occultations of stars by the moon whenever it was practicable. These observations were made with great regularity at Washington, from Nov. 1838 to June 1842, with a five feet transit instrument belonging to the coast survey, in a small building on Capitol Hill.

On his return from Europe, in 1840, Professor Bartlett made a report to the Engineer Department at Washington, on the Observatories of Europe. In this report, he embodied most, if not all of the modern improvements in the construction of instruments, as well as the erection of observatories. 
Soon after he prepared a plan and estimates for an observatory at Washington for Mr. Poinsett, then Secretary of War.

A law authorizing the erection of a dépôt of charts and instruments for the navy, was passed by Congress during the session of 1841-2, the expense being limited to twenty-five thousand dollars. Lieut. Gilliss was instructed by the Secretary of the Navy to present a plan of a building, after consultation with the principal astronomers of the United States. The plan thus prepared was afterward submitted to the most eminent astronomers of Europe, and the model finally adopted, embraced all the improvements upon the original plan recommended by them. 'The observatory consists of a central building of brick, with wings upon the east, west, and south sides. The central building is 50 feet square, two stories and a basement high, surmounted by a revolving dome 23 feet in diameter. Directly under the dome is the great pier, whose diameter at the base is $\mathbf{1 5}$ feet, and tapers gradually to the top, upon which rests the great equatorial. On the east and west sides of this building are wings, each 21 by 26 feet, and 18 feet high. The wing on the south side is 21 by 36 feet, in two apartments. In the west wing is the meridian transit instrument; 
in the east wing is a meridian circle and a mural circle; in the first apartment of the south wing is the transit in the prime vertical, and in the second apartment is the new refraction circle. There is also a clock belonging to each wing.

The great refractor was made by Merz and Mahler, of Munich. The object glass is $9 \frac{6}{10}$ inches in diameter, with a focal length of 15 feet 3 inches. The finder has an object glass $2 \frac{6}{10}$ inches clear aperture, and a focal length of $\mathbf{3 2}$ inches. This telescope is equatorially mounted, and furnished with clock-work. It has a repeating filar micrometer, with eight eye-pieces, magnifying from 100 to 1000 times. The cost of this telescope was $\$ 6,000$; its object glass alone being valued at $\$ 3,600$.

The transit instrument has an object glass with a clear aperture of $5 \frac{1}{2}$ inches, and a focal length of 88 inches, obtained from Merz and Mahler, and the instrument was constructed by Ertel and Son, of Munich. The axis is of red metal, 42 inches long between its bearing points. The cost of this instrument was $\$ 1,480$; the object glass alone cost $\$ 320$.

The mural circle was made by Mr. William Simms of London. It is of five feet diameter, made of brass, and cast in a single piece. It is divided into spaces of five minutes each, upon a band of 
gold inlaid on the rim, or perpendicular to the plane of the circle. The object glass of the telescope has a clear aperture of four inches, and a focal length of five feet. At its focus, are seven vertical wires and a horizontal stationary one, with a micrometer wire movable in altitude. Placed at equal distances round the circle, are six micrometer microscopes, with an acute cross of wires at their foci, for reading angles less than five minutes. Five revolutions of the micrometer are designed to measure five minutes upon the circle. The heads being divided into sixty equal parts, each division represents one second of arc. The telescope has four extra eye-pieces of different magnifying powers. The cost of the mural circle was $\$ 3,550$.

The meridian circle was made by Ertel and Son of Munich. Its object glass has an aperture of $3 \cdot 8$ inches, with a focal distance of 59 inches. This instrument is provided with a 30 inch circle, divided into arcs of three minutes, and reads to seconds and tenths of a second by four microscopes. The clock in the east wing has a mercurial pendulum, and was made by Charles Frodsham.

The transit in the prime vertical was made by Pistor and Martins of Berlin. The object glass of the telescope has a clear aperture of $\mathbf{5}$ inches, with 
a focal length of 78 inches. The eye-tube carries a system of two horizontal and fifteen vertical stationary wires, with one movable vertical wire. This instrument is mounted at one end of its axis, and outside of its supports. It is reversed from one side to the other twice during every observation; and though it weighs upward of 1000 pounds, so perfect is its system of counterpoises and the reversing apparatus, that a child can lift it from its $Y_{s}$, reverse and replace it in them, in less than one minute. The clock has a gridiron pendulum, made by Charles Frodsham. The cost of the Transit was $\$ 1,750$.

The refraction circle was made by Ertel and Son, from plans and drawings furnished by Lieut. Maury. The telescope is $8 \frac{1}{2}$ feet long, with a clear aperture of 7 inches. It is supported in the middle of the axis, between two piers; and it has two circles of four feet diameter, one on each end of the axis, divided on gold into arcs of two minutes. Each circle is provided with six reading microscopes. The telescope has two micrometers, one moving in azimuth, the other in altitude. It is so contrived that the wires, and not the field, are illuminated; and every eye-piece, even of the highest powers, just as it is used, and without alteration 
of any kind, becomes a collimating eye-piece, by simply turning the telescope down upon a basin of mercury.

The comet seeker was made by Merz and Mahler. It has an object glass $3 \frac{2}{10}$ inches in diameter, and a focal length of 32 inches, with which low magnifying powers are used, that it may embrace a large field, and collect the greatest possible quantity of light. The hour circle is five inches in diameter, reading by two verniers to four seconds of time; and the declination circle, which is of the same diameter, reads to minutes of arc. The cost of this instrument was $\$ 280$.

In the fall of 1844 , the duties assigned to Lieut. Gilliss by the Navy Department being terminated, Lieut. Maury was directed to take charge of the new "Dépôt of Charts and Instruments." Lieut. Maury commenced a regular and systematic series of observations upon the sun and moon, the planets, and a list of fundamental stars, comprising those of the greatest magnitude, and of the most favorable positions to be used as standard stars. He also undertook observations for a most extensive catalogue of stars. This work contemplates a regular and systematic examination of every point of space in the heavens that is visible to us, and of assigning 
position, color, and magnitude, to every star that the instruments are capable of reaching. Lieut. Maury's plan of sweeping is as follows: The telescope of the mural circle is set in altitude, and all the microscopes carefully read and recorded, and the eye-piece is moved up and down so as to cover a belt of from 40 to 50 minutes broad in declination. The micrometer diaphragm is provided with a number of parallel wires, the intervals of which have been carefully determined. Thus in whatever part of the field a star appears, a micrometer wire is close at hand, and the star is bisected by the nearest wire, while the time at which it passes the several vertical wires is also noted. The number of the bisecting wire and the reading of the micrometer being now entered, the observation is complete.

The observer thus keeps his eye at the telescope for hours at a time, and under favorable circumstances, can observe with ease two or three hundred stars during the night. The meridian circle in the same way occupies the belt below this; while the transit instrument, by means of a micrometer moving in altitude, is converted into a difference of declination instrument, and occupies the belt above, each instrument overlapping the belt of the other by four or five minutes. The next night, the 
instruments change places, and go over the same ground, i. e., the meridian circle covers the same belt to-night which on the former night was swept by the mural. Supposing the two nights equally favorable, which is seldom the case, all the stars that were seen in the first sweep by the mural, should be observed in the second by the meridian circle. The two lists are immediately compared, and should there be any discrepancies between them, the large equatorial is put in pursuit of the stars in question.

This great work contemplates the examination of every star down to the tenth magnitude in the entire heavens; and while it looks to the discovery of new planets and unknown stars, it also aims to detect the disappearance of any stars found in existing catalogues.

The observatory commenced its operations early in 1845. The first volume, a quarto of 550 pages, containing the observations of 1845 , has been published, and has elicited high commendation both at home and abroad. The volume furnishes 3200 observations with the meridian transit instrument; 2100 observations with the mural circle, and 425 observations with the prime vertical transit instrument. This volume has at once placed our na- 
tional observatory in the front rank with the oldest and best institutions of the kind in Europe. The volume for 1846 is now in press. The catalogue for that year will number some 12 or 15,000 stars, most of them unknown to any existing catalogues; the whole work will form a quarto volume of not less than 1000 pages, and will be the largest work of the kind ever published by any observatory as the result of a single year's labor.

\section{GEORGETOWN OBSERVATORY.}

The erection of the Georgetown Observatory was nearly cotemporaneous with that of the National Observatory. A donation for this purpose was made to the college at Georgetown, in Dec. 1841. The building was erected in 1843, and finished in the spring of 1844 .

The central part is thirty feet square on the outside; with connecting wings both on the east and west sides, each of them being 27 feet by 15 , making the entire length of the observatory 60 feet. The central room is surmounted by a dome of nineteen feet internal diameter, which works on twenty cast-iron rollers 8 inches in diameter. From the cellar, through all the floors of this part of the build- 
ing, the masonry pier, 41 feet high, 11 at base, and 6 at top, enters into the dome room, and upon it rests the equatorial, lately received from Simms of London. This telescope has an object-glass of $4 \cdot 8$ inches clear aperture, and 90 inches focus, mounted with clock-work. The hour circle is 16 inches in diameter, reading by two verniers to one second of time; the declination circle is 24 inches in diameter, reading by verniers to five seconds of space. Cost $\$ 2,000$.

In the west room is mounted a transit instrument made by Ertel and Son, of Munich, in 1843 and 1844. The object glass is $4 \cdot 6$ inches clear aperture, and 76 inches focal length. It has a reversing stand by which the instrument can be reversed in a minute and a half. This instrument cost $\$ 1,180$, besides the expenses of transportation from Munich.

In the east room is mounted a 45 inch meridian circle, made by William Simms, of London, with a telescope five feet long and a four inch object glass. The circle is graduated to five minutes, and there are four micrometers fixed to the eastern pier, reading to one second of arc. When the instrument is reversed, the readings are made by a second set of microscopes, which are attached to the western pier. In the eye-tube are seven fixed and 
one movable R. A. wire; and one fixed and one movable declination wire. The lowest eye-piece is used for a collimating eye-piece, by which the nadir point is determined by reflection from a trough of mercury. The cost of this instrument was $\$ 2,050$. In the transit room there is a sidereal clock, by Molyneux, of London, and also another in the east room.

This observatory is under the direction of the Rev. Mr. Curley, who commenced a series of transit observations in 1846. During the autumn of the same year, he made some observations of circumpolar stars with the meridian circle, for determining the latitude of the observatory. During the year 1848, M. Sestini, of Rome, was added to this observatory, and it was expected that the celebrated comet-hunter, M. De Vico, of Rome, would be associated with Mr. Curley. But these expectations were suddenly disappointed by the death of De Vico, which took place at London on the 15 th of November, 1848. 
CINCINNATI OBSERVATORY.

The Cincinnati Observatory owes its existence to the labors of Prof. O. M. Mitchell. In the years 1841 and 1842, a society was organized in Cincinnati, called the Cincinnati Astronomical Society, the object of which was to furnish the city with an observatory. Eleven thousand dollars were subscribed in shares of twenty-five dollars; and a site for the observatory was given by Nicholas Longworth, Esq. It consists of four acres of ground, on one of the highest hills on the eastern side of the town. In June, 1842, the society being fully organized, Professor Mitchell visited Europe to purchase a telescope. At Munich, he found an object glass of twelve inches aperture, which had been tested by Dr. Lamont, and pronounced one of the best ever manufactured. This was subsequently ordered to be mounted, and was purchased for $\$ 9,437$. The instrument arrived in Cincinnati in February, 1845. In November, 1843, the cornerstone of the observatory was laid by the venerable John Quincy Adams. The building is eighty feet long and thirty feet broad. Its front presents a basement and two stories; while in the center, the 
building rises three stories in height. The pier is built of stone, and is grouted from its foundation on the rock to the top. The equatorial room is $\mathbf{2 5}$ feet square, and is surmounted by a roof so arranged as to be removed entirely during the time of observations.

The object glass of the telescope has an aperture of twelve inches, and a focal length of 17 feet. The hour circle is 16 inches in diameter, and reads by two verniers to two seconds. The declination circle is 26 inches in diameter, and divided on silver to five minutes, reading by verniers to four seconds. The instrument has five common eye-pieces and nine micrometrical, with powers varying from 100 to 1,400 .

Quite recently, through the kindness of Dr. Bache, the superintendent of the U. S. Coast Survey, this observatory has been furnished with a five feet transit instrument, which is now mounted and in active use. A new sidereal clock has recently been presented to this observatory.

Prof. Mitchell has hitherto devoted his time chiefly to the remeasurement of Struve's double stars south of the equator. This work was undertaken at the special request of that distinguished astronomer. Quite a number of interesting discov- 
eries have been made in the course of this review: Stars which Struve marked as oblong, have been divided and measured; others marked double, have been again subdivided and found to be triple; while a comparison of the recent measures of distance and position with those of Struve, has demonstrated the physical connection of the components of many of these southern stars.

CAMIBRIDGE OBSERVATORY.

The project of erecting an observatory in the neighborhood of Boston upon a scale corresponding with the importance and dignity of astronomy, had for a long period been the object of conversation among the friends of science. This was a favorite scheme with the late Dr. Bowditch, and various plans had been proposed for carrying it into execution. It did not, however, appear practicable to raise a sum of money sufficient to carry out the plan upon the liberal scale which was desired. Something was needed to give a stronger impulse to the subject of Practical Astronomy. This impulse was given by the unexpected appearance of the splendid comet of 1843 . In the month of March of that year, a comet with a magnificent train hav- 
ing made its appearance, the Boston public natually looked to the astronomers of Cambridge for information respecting its movements. The astronomers replied that they weie entirely destitute of instruments adapted to nice cometary observations. The fact thus brought distinctly to the notice of the public, together with the knowledge of the existence of good instruments in other parts of the United States, aroused a general determination to supply at once the deficiency.

Early in the month of March, 1843, an informal meeting of three or four individuals interested in the subject, was held at the office of the American Insurance Company in Boston. The proceedings of this meeting were cordially seconded by the American Academy of Arts and Sciences, and in consequence, a regular meeting of merchants and other citizens of Boston was held at the hall of the Marine Society, to consider the expediency of procuring a telescope of the first class for astronomical observations. At this meeting the question was decided in the affirmative, and a subscription to the amount of twenty thousand dollars recommended to defray the expense. This amount was immediately furnished. Mr. David Sears of Boston gave five thousand dollars for the erection of an observa- 
tory, besides five hundred dollars toward the telescope. Another gentleman of Boston gave one thousand dollars for the same object; eight other gentlemen of Boston and its vicinity gave five hundred dollars each; there were eighteen subscribers of two hundred dollars, and thirty of one hundred dollars each, besides many smaller sums. The American Academy of Arts and Sciences made a donation of three thousand dollars; the Society for the Diffusion of Useful Knowledge gave one thousand dollars; the American, Merchants, and National Insurance Companies, and Humane Society, gave five hundred dollars each; two other companies gave three hundred dollars each; and one gave two hundred and fifty, and another gave two hundred dollars.

The Corporation of Harvard University purchased an excellent site for the erection of an observatory. The position is elevated about fifty feet above the general plain on which are the buildings of the University, and it commands, in every direction, a clear horizon, without any danger of obstruction from trees, houses, smoke, or other causes. Upon this, which is known as Summer House Hill, the Sears Tower was erected, for the accommodation of the large telescope, with wings for other in- 
struments, and a house for the observer. The Sears Tower is a square building of thirty-two feet on a side. The walls are of brick, resting on a granite foundation. The corners of the tower are arched toward the center, in such a manner as gradually to bring the interior into a circular form of thirtyone feet diameter, surmounted by a granite circle, on which is laid an iron rail of ten inches width, hollowed in the middle, to serve as a track for the eight inch iron balls on which the dome revolves. The dome is thirty feet interior diameter, with an opening five feet wide, extending beyond the zenith. The shutters to this opening are raised and closed by means of endless chains working in toothed pulleys, and are easily managed by a winch and pinions geared into wheels of one foot diameter. They are perfectly weather-proof. To the lower edge of the dome is affixed a grooved iron rail, similar to the one laid on the granite cap of the walls. Eight iron balls, which had been smoothly and truly turned, were placed at equal distances round the circle, and the dome gradually let down to rest upon them. Although this dome is estimated to weigh about fourteen tuns, yet it can be turned through a whole revolution by a single individual, without any very great exertion, in thirty-five seconds. 
The central pier for the support of the telescope is of granite, and is in the form of a frustrum of a cone, twenty-two feet in diameter at the base, and ten feet at the top. It is forty feet high, and rests on a wide foundation of grouting composed of hydraulic cement and coarse gravel, twenty-six feet below the natural surface of the ground, and is entirely detached from every other part of the building. Upon the top of the pier is laid a circular cap-stone, ten feet in diameter and two feet thick; on which stands, by three bearings, the granite block, ten feet in height, to which the metallic bed-plate of the instrument is firmly attached by bolts and screws, without any cement whatever. Five hundred tuns of granite were employed in the construction of the entire pier.

Upon the east side of this tower is a small wing for the accommodation of the transit circle and clock; and on the north side is a similar wing, designed for a transit in the prime vertical. The house for the accommodation of the observer is connected with the east wing.

The "Grand Refractor" was made by Messrs. Merz and Mahler, of Munich, Bavaria. They bound themselves by contract to make two object glasses of the clear aperture of fifteen inches, to be 
at least equal to that furnished to the noble instrument now mounted at the Russian Observatory of Pulkova. On being notified of the completion of these object glasses, the agent of the University, $\mathrm{Mr}$. Cranch, of London, accompanied by the instrument-maker, Mr. Simms, proceeded to Munich, and after careful trial and examination, made the required selection. The selected object glass was received at Cambridge on the 4 th of December, 1846 ; the great tube and its parallactic mounting did not arrive until the 11th of June, 1847. The process of erection was commenced on the morning of the 23d of June; and on the evening of the next day, the telescope was directed upon celestial objects. The object glass of the telescope is fifteen inches in diameter, and has twenty-two feet six inches focal length. Some of the eye-pieces are six inches long, making the entire length twenty-three feet English. There are eighteen different powers, ranging from 180 to 2000 . The declination circle is twenty-six inches in diameter, divided on silver, and reads by four verniers to four seconds of arc. The hour circle is eighteen inches in diameter, divided on silver, reading by two verniers to one second of time. The movable portion of the telescope and machinery is estimated to weigh about three 
tuns. It is, however, so well counterpoised in every position of the telescope, and the effects of friction are so nearly obviated by an ingenious arrangement of rollers and balance weights, that the observer can direct the instrument to any part of the heavens by a slight pressure of the hand upon the ends of the balance rods. While observing, a sidereal motion is given to the telescope by clock-work, regulated by centrifugal balls. This telescope cost $\$ 19,842$.

The optical character of this instrument has given entire satisfaction. The components of the star Gamma Coronæ, which Struve, with the Pulkova refractor, pronounces most difficult to separate, being distant from each other less than half a second, are seen in the Cambridge telescope distinct and round, the dark space between them clearly defined. The same distinctness attends the separation of Gammar Andromedæ, the individuals of which are distant from each other less than half a second. The companion of Antares, estimated to be of the tenth magnitude, and which was discovered by Prof. Mitchell with the Cincinnati refractor, is quite conspicuous with a power of 700. It was with this instrment $\mathrm{Mr}$. Bond discovered the eighth satellite of Saturn, two days before it was discov- 
ered by Mr. Lassell, of Liverpool, with his Newtonian reflector of 21 inches aperture. He has also made satisfactory micrometric measurements of the satellite of Neptune, which is not known to have been done with any other instruments except $\mathrm{Mr}$. Lassell's telescope and the Pulkova refractor. The minutest double stars in the neighborhood of the ring nebula of Lyra, mentioned by Lord Rosse as difficult objects with his twenty-seven feet reflector, are seen in the Cambridge telescope. It has also partially resolved the great nebula in Orion, and shows a great number of stars within the limits of the nebula of Andromeda.

A transit circle, made by Simms of London, has recently been received and erected in the east wing. It has two circles, each of four feet diameter, graduated on silver to five minutes, and reads to single seconds by means of eight microscopes cemented to the granite piers-four microscopes belonging to each circle. The aperture of the object glass is four and one eighth inches, with a focal length of five feet. The length of the axis between the shoulders of the pivots is two feet two inches. The pivots are of steel, two and a half inches in diameter. Two sets of friction wheels, supported by strong spiral springs, relieve the pressure of the 
pivots on the Ys. There are two different modes of illumination, one through the axis as usual, and the other at the eye-piece, showing bright wires on a dark field. There are two micrometers attached to the eye-piece for measures in altitude and in azimuth. A single division of the micrometer is equal to three tenths of a second.

There is also belonging to the observatory a fine comet-seeker of four and a quarter inches aperture, besides several other instruments.

The wing on the north side of the tower is designed hereafter to receive a transit for the prime vertical, but this instrument has not yet been ordered.

Mr. William C. Bond and his son George P. Bond, give their undivided attention to the objects of the observatory. They do not propose to undertake a catalogue of stars, nor the usual meridional observations which are made at Greenwich and most of the European observatories; but they design to give their whole strength to that class of observations for which their grand refractor affords peculiar advantages. The following are of this kind:-observations of new planets; the satellites of Saturn, Uranus, and Neptune; double stars, especially those. which have considerable proper 
motion; together with a general review of the most remarkable nebulæ. They have recently published in the Memoirs of the American Academy, a description of the Great Nebula in Orion and that of Andromeda, accompanied with drawings of the most careful and elaborate execution. It is proposed to prosecute the study of other nebulæ in a similar manner, confining their attention to a few objects, and striving to produce a perfect picture of every nebula examined, so that future astronomers may be able to decide whether time has wrought any changes in their constitution or figure. The younger Bond maintains a constant and systematic search for comets. With the comet-seeker he sweeps over the entire heavens at least once a month, and whenever he discovers any nebulous body with which he is not familiar, it is subjected to a special examination. For two or three years he has pursued this system of observation, and has thus been the independent discoverer of seven comets-but unfortunately it subsequently appeared that each of these, save one, had been seen some days earlier in Europe. Mr. Schumacher has stated that Mr. Bond would have received the gold medal for the comet first seen by him as a nebulous object on the 18th of February, 1846, if his obser- 
vations made at that time had been communicated, according to the regulations of the King of Denmark, to the trustees of the medal.

SHARON OBSERVATORY.

Sharon Observatory is a private establishment belonging to $\mathrm{Mr}$. John Jackson, situated near Darby, about seven miles west of Philadelphia. It was erected in 1845, is seventeen feet square on the outside, and rises to the height of thirty-four feet. At five feet from the top, two strong beams are placed across the building, and support a circular platform of five feet diameter, on which the equatorial stands. The tower is surmounted by a conical dome, covered with tin and lined with cloth. The dome rests on four iron balls revolving on a circular railway. The opening in the dome is eighteen inches wide, and has three doors which slide over each other and are moved by cords passing over pulleys.

The equatorial was made by Merz and Son, of Munich. It was ordered in 1842, and arrived in 1846. The object glass has a clear aperture of six and a third inches, and its focal length nearly nine feet. It has five eye-pieces, magnifying from 85 to 456 times, and an annular micrometer. The Right 
Ascension circle is nine inches in diameter, and reads by two verniers to four seconds. The declination circle is 13 inches in diameter, graduated to ten minutes, and reads by verniers to ten seconds. Clock-work is attached to the polar axis, giving to the telescope a uniform motion, and keeping a star apparently at rest in the field of view. The entire expense of this instrument was $\$ 1,833$.

This observatory is also furnished with a meridian circle made by Young, of Philadelphia; the object glass having been procured from Merz and Son, of Munich.

It is mounted on marble columns resting on solid masonry, in the south wall of the tower. The object glass is three and a quarter inches in diameter, and has a focal length of four feet. One end of the axis carries a circle twenty inches in diameter, which is graduated to four minutes, and reads by four verniers to three seconds. The price of this instrument was $\$ 800$. A sidereal clock is firmly fixed on a marble column near the transit instrument. It has a mercurial pendulum, and was made by Gropengiesser, of Philadelphia. 
TUSCALOOSA (ALABAMa) OBSERvatory.

The Tuscaloosa Observatory was erected in the year 1843, and has been partially furnished with instruments for observation of a superior order. The building is fifty-four feet in length, by twentytwo in breadth in the center. The central apartment is surmounted by a revolving dome of eighteen feet internal diameter, under which it is proposed to place an equatorial telescope of about fourteen feet focus. The west wing is occupied by a transit circle, constructed by Simms of London, having a telescope of five feet focal length, with an object glass of four inches clear aperture. The limb is three feet in diameter, divided to five minutes, and reads by four microscopes to single seconds. In the same room is a clock with mercurial compensation, by Molineux of London. This observatory is under the direction of Prof. F. A. P. Barnard.

MR. RUTHERFORD'S OBSERVATORY.

There is a private observatory erected in the upper part of the city of New York, corner of Second Avenue and Eleventh street, belonging to Lewis 
M. Rutherford, Esq. It is furnished with a refracting telescope made by Henry Fitz of New York, from glass imported from Paris. The aperture of the object glass is six inches, and focal length eight feet. It was mounted equatorially, like the Dorpat telescope by Messrs. Gregg and Rupp of New York, but without clock-work. The Right Ascension circle is eight inches in diameter, and reads by verniers to two seconds of time; the declination circle is eleven inches in diameter, and reads by verniers to one minute of arc. The telescope has four eye-pieces, the highest magnifying 400 times. The performance of this telescope is remarkably good, dividing epsilon Arietis, under favorable cirstances, with a power of 220 , the distance of the component parts being about one second; and showing the sixth star in the trapezium of Orion, which star Captain Smyth pronounces " a very intensiva of vision."

This telescope rests upon a brick column, surmounted by a revolving dome of twelve feet diameter. Mr. Rutherford has been employed for several years in a series of observations upon the double stars. He has made repeated and careful measurements of many close stars, and intends to prosecute them as far as his professional engagements will 
permit. Connected with this observatory is a small building containing a transit instrument by Simms, belonging to Columbia College. The telescope has an aperture of nearly three inches, and a focal length of four feet. It is mounted upon two stone columns resting upon a solid foundation of sandstone. An opening in the roof affords a view of about 160 degrees of the meridian. In a small wing of this building is a stone column, upon which is placed an altitude and azimuth instrument by Simms, also belonging to Columbia College. The horizontal and vertical circles are each fifteen inches in diameter, graduated to five minutes, and reading by two microscopes to one second of arc. The telescope has an aperture of two inches, and a focal length of twenty-four inches.

This observatory was employed by the Coast Survey, during the summer of 1848 , as a station for determining the difference of longitude between Cambridge and New York, by means of the magnetic telegraph.

DARTMOUTH COLLEGE OBSERVATORY.

It is proposed to erect an observatory in connection with Dartmouth College, New Hampshire. The building is not yet commenced, but an equatorial 
telescope has been ordered and received. This telescope was made by Merz and Son of Munich, and has a clear aperture of six inches, with a focal length of eight feet French measure. It is furnished with one terrestrial eye-piece; seven negative eye-pieces, magnifying from 36 to 600 times; a single lens magnifying 940 times; one positive eye-piece for the ring micrometer, and five others for the filar micrometer. The hour circle is nine and a half inches in diameter, and reads by two verniers to four seconds of time ; the declination circle is thirteen inches in diameter, and reads to ten seconds of arc. The filax micrometer has six fixed threads at right angles to the two movable ones, and may be illuminated in either a dark or bright field at pleasure. The circular micrometer has two rings, and may be used with or without illumination. The telescope is moved by a centrifugal adjustable clock.

The sidereal clock is furnished with Mahler's compensation pendulum, and runs a month without winding.

It is proposed to erect a building surmounted by a dome for the accommodation of the equatorial; also a wing for a meridian transit instrument; another for a prime vertical transit; and a third wing for a computing room. 
AMHERST COLLEGE OBSERVATORY.

A small building for astronomical observations has recently been erected in connection with Amherst College, Massachusetts. 'This building consists of an octagonal tower, fifty feet high and seventeen feet in diameter, with a revolving dome and a central pedestal on which to place a telescope when ever it shall be obtained. On the east side of the tower is attached a transit room, 13 by 15 feet, with a sliding roof. Here is a transit circle made by Gambey of Paris, the telescope having a focal length of about three feet, and an aperture of two and a half inches. The circle is fifteen inches in diameter, graduated to five minutes, and is furnished with four verniers reading to three seconds. The clock was made by Breguet, and has a gridiron pendulum.

\section{BROOKLYN OBSERVATORY.}

During the past five years, several plans have been proposed for erecting in the vicinity of $\mathrm{New}$ York an astronomical observatory of the first class, and furnishing it with the best instruments which art can supply; but hitherto all these plans have failed 
for want of the requisite funds. Another project has recently been started under more favorable auspices, and it is hoped may prove successful. Last March an astronomical society was organized in Brooklyn, with a view to the erection of an observatory. The stock is distributed in shares of $\$ 25$ each; each share having one vote, and entitling the holder to admission to the observatory. The subscriptions are to be paid in two instalments, the first to be payable when the sum of twenty thousand dollars shall have been subscribed. Over sixteen thousand dollars are already pledged, and several sites for the building have been offered without expense to the society. It is proposed to procure a first-class refracting telescope, a meridian circle, a clock, and various smaller instruments. It can scarcely be believed that this plan will be allowed to fail for want of the additional sum of about three thousand dollars.

From the preceding sketch, it must be apparent that within ten years rapid progress has been made toward supplying our country with the means of astronomical observations. We now have instruments which permit us to engage in astronomical researches upon a footing of equality with the oldest 
establishments of Europe; while the number of observers, and the taste for astronomical studies, has kept pace with the increase of our instruments. Astronomy may now claim to be the most popular of the sciences, with, perhaps, a single exception; and we anticipate a brilliant career of discovery for American astronomers. 


\section{SECTION II.}

ASTRONOMICAL EXPEDITION TO CHILT.

In the year 1847, Dr. Gerling, of Marburgh, suggested the importance of a new determination of the sun's parallax by observations upon Venus, at and near her stationary periods. The determination of the dimensions of the solar. system rests entirely upon the assumed value of the sun's parallax. The value now generally received, viz. $8^{\prime \prime} \cdot 57$, rests upon the observations of the transit of Venus in 1769. Transits of Venus over the sun's disc, afford the best method of determining this parallax, but these phenomena are of very rare occurrence, there being not a single transit visible in any part of the world, from 1769 to 1874 . Now, although the observations of the transit of $\mathbf{1 7 6 9}$ are believed to have afforded a very accurate value of the sun's parallax, yet it is much to be regretted that the results obtained by combining the observations at different stations two and two, differ among themselves 
by an entire second. It is therefore very desirable that this result should be verified by independent methods. Such methods are found in simultaneous observations of either Venus or Mars, from two remote points of the globe. If an astronomer in a high northern latitude observes the position of one of these bodies when upon his meridian, and another astronomer in a high southern latitude does the same, a comparison of these two observations will give the parallax of the planet, from which we can compute its distance from the earth. The most favorable time for observing Mars, is when it is nearest the earth-that is, at its opposition; and the most favorable time for observing Venus is when it is stationary, or near its inferior conjunction. The two places of observation must be in opposite hemispheres, as remote as possible from each other, and it is desirable that they should both be under the same meridian.

In 1848, the American Philosophical Society and the American Academy of Arts and Sciences, recommended that an astronomical expedition be sent to Chili for the purpose of making observations upon Dr. Gerling's plan, in connection with the National Observatory at Washington; and in August, 1848, Congress authorized the fitting out of the expedition 
under direction of the Secretary of the Navy. Lieut Gilliss, of the United States Navy, was appointed to take charge of the expedition, and passed midshipmen A. McRae and Henry C. Hunter were appointed as assistants. Suitable wooden buildings, to serve as an observatory in Chili, were prepared in Washington, and shipped to Valparaiso in the summer of 1849.

The principal astronomical instruments for the expedition are two telescopes equatorially mounted, a meridian circle, a clock, and three chronometers.

The larger telescope is the eight feet refractor described on page 254. It was fitted with clockwork by Wm. Young, of Philadelphia, and by him provided with a micrometer adapted both for differential measurements, and for measurements of position and distance.

The other telescope is a five feet achromatic, by Fraunhofer. It was also equatorially mounted, and fitted with a micrometer by Young, of Philadelphia.

The meridian circle is by Pistor and Martins, of Berlin. The object glass of the telescope has a clear aperture of four and a third inches, with a focal length of six feet. The circles are thirty-six inches diameter, minutely divided, and provided each with two reading microscopes. 
The series of astronomical observations, especially contemplated, consists of differential measurements during certain portions of the years 1849, 1850, 1851, and 1852, upon Venus and Mars, with certain stars along their paths.

The observations of Venus chiefly depended upon, are observations near the inferior conjunctions of 1850 and 1852. The principal observations of Mars are near the times of opposition of that planet in 1849 and 1852.

To facilitate the observations and to secure concert of action, so that observers in every part of the world may use the same stars of comparison, Lieut. Gilliss prepared an ephemeris of these planets and suitable stars of comparison during the critcal periods.

The expedition set sail last season, and arrived safely at Valparaiso. The observatory was located at Santiago, the capital of Chili, where observations have already been commenced under favorable auspices.

Numerous astronomical observations were made by the officers of the United States exploring expedition, under Capt. Wilkes, during the years 18391844, but they have not yet been published. 


\section{SECTION III.}

ASTRONOMICAL RESULTS OF PUBLIC SURVEYS.

VERY extensive surveys have been undertaken, at the expense of the general government, and some by state governments, which have indirectly contributed very much to the science of astronomy. Of these, the survey of the coast of the United States is the most important.

The survey of the coast was proposed by $\mathrm{Mr}$. Jefferson, and was authorized by Congress in 1807 . Mr. Gallatin, then Secretary of the Treasury, sketched the plan of a magnificent geodetic work, in which the principal headlands of the coast should be fixed by astronomical observations. In consequence of the unsettled state of the country, no active steps were taken toward carrying this plan into execution until 1811, when Mr. Hassler was placed in charge of the work, and was sent to Europe to procure the requisite instruments. He did not return with the instruments until the fall of 1815 . In 1816 
he commenced the survey; and in 1818, Congress not being satisfied with the progress of the work, it was stopped.

In 1832, the work was revived by an Act of Congress, and placed under the direction of Mr. Hassler, in whose hands it made steady progress until his death in 1844. Prof. A. D. Bache was then appointed to take charge of the survey, and has continued it to the present time.

The astronomical part of this survey consists in determining the latitude and longitude of the stations, and the direction of the sides of the triangles with reference to a meridian.

Professor Bache has undertaken to determine the difference of longitude between Greenwich and the most important points upon our coast, with the greatest possible precision. For this purpose he has availed himself of all the astronomical observations previously on record, and has instituted new observations, including those of occultations and eclipses, moon culminations, and the exchange of chronometers. Numerous observations have been made in Cambridge and its vicinity, in the neighborhood of New York, Philadelphia, Washington, and other places. The difference of longitude between these several places has been determined by means 
of the electric telegraph, so that observations at any of these places are equally available for determining the longitude of each of them from Greenwich.

Advantage has been taken of the frequent passage of steamers between Boston and Liverpool, to make a thorough comparison of the times of those ports by means of chronometers. For this purpose, as soon as a steamer arrives in Boston, its chronometers are taken to Cambridge Observatory for comparison, where they remain until the steamer is ready to return. Upon arriving in Liverpool, the chronometers are taken to the Liverpool Observatory, and their errors determined. This method of comparison has been systematically pursued since 1844 . During the year 1846 , forty-two such comparisons were made. In 1848 the longitude of the Cambridge Observatory from Greenwich was determined by $\mathrm{Mr}$. Bond, from the transportation of 116 chronometers, in thirty-four voyages of the Cunard steamers from Liverpool to Boston, to be $4^{\mathrm{h}} 44^{\mathrm{m}} 30^{\cdot} 5^{\mathrm{s}}$. The longitude deduced from lunar occultations and solar eclipses is $4^{\mathrm{h}} 44^{\mathrm{m}} 31 \cdot 9^{\mathrm{s}}$. During the year 1849, eighty-seven additional comparisons were made, the results of which differ nearly two seconds of time from those previously obtained by astronomical observations. 
The results of the coast survey must furnish additional materials for determining the figure and dimensions of the earth. The Atlantic coast embraces more than twenty degrees of latitude, and its survey will virtually furnish a measured arc of the meridian of that extent. In several places the survey will furnish long continuous arcs upon the same meridian. Thus from Nantucket northward we shall obtain an arc of over three degrees; from Cape Lookout, northward along the shore of Chesapeake Bay, we shall obtain an arc of over five degrees; and the Florida coast will furnish us a continuous arc of more than seven degrees.

The survey of the boundary between the United States and Texas, in the year 1840, and the survey of the north-eastern boundary of Maine between the years 1840 and 1844, furnished the occasion for the determination of the latitude and longitude of numerous points, chiefly by Major J. D. Graham of the corps of Topographical Engineers.

In the summer of 1835 , Captain Talcott was employed by the government of the United States, to make a series of observations near the southern line of Michigan, to settle the disputed question of boundary between that territory and Ohio. In this 
expedition the latitude and longitude of several places was determined with great precision.

The most important astronomical survey hitherto undertaken by any state government was that commenced by the state of Massachusetts in 1830 , and completed in 1838. This survey was founded upon a base of $7 \cdot 39$ miles in length, measured on the banks of the Connecticut river, from which a net-work of triangles commenced and spread over the entire state. The latitude and longitude of twenty-seven places were determined independently by Mr. R. T. Paine; and the results of the two surveys agree remarkably with each other.

A topographical survey of the state of Maryland has recently been executed, under the direction of Mr. J. H. Alexander. 


\section{SECTION IV.}

DETERMINATION OF LONGITUDE BY MEANS OF THE ELECTRIC TELEGRAPH.

THE first attempt to determine difference of longitude by means of the electric telegraph was made by Captain Wilkes, in 1844, between Washington and Baltimore. Two chronometers, previously rated by astronomical observations in the vicinity, were brought to the telegraph offices, and were compared together by means of the ear, without coincidence of beats. This method will furnish difference of longitude with a precision probably greater than any method heretofore known; but it is susceptible of great improvements.

In the year 1845, a plan was adopted by Prof. Bache, superintendent of the coast survey, to apply this method, in an improved form, to the determination of the difference of longitude of the principal stations of the survey; and in 1846, measures were taken to connect in this manner Washington, Phil- 
adelphia, and New York. An arrangement was made with the Telegraph Company to allow the use of their line for scientific purposes, after the usual business operations had closed for the day. A line of wires was extended from the General Post Office in Washington to the Naval Observatory; a wire was carried from the main line through the High School Observatory at Philadelphia; and a short wire was carried from the office in Jersey City to a station fitted up as a temporary observatory, and furnished with a five feet transit telescope and an astronomical clock. The observations at Washington were made by Prof. Keith, those at Philadelphia by Prof. Kendall, and those at Jersey City by Prof. Loomis, the whole being under the direction of $\mathrm{Mr}$. S. C. Walker. Each station was furnished with a telegraph key and a receiving magnet.

Washington, Philadelphia, and Jersey City were thus put in telegraphic connection; instruments for obtaining time were provided; and to determine the difference of longitude of the stations, required simply the means of producing an instantaneous effect observable at all the stations. This was to be obtained by the motion of the keepers of electromagnets, which had been previously adjusted by 
Mr. Saxton, so as to secure their simultaneous striking on the transmission of the galvanic current. The first trials which were made for the transmission of signals were unsuccessful. The observers were not provided with the means of communicating by the ordinary mode of telegraphing; and if every thing was not arranged exactly as had been previously agreed upon, it was impossible to correspond for the purpose of discovering the source of the difficulty. Communication between Philadelphia and Washington was however effected on the 10th of October, and the difference of longitude approximately obtained. Signals for time by the clock were transmitted, and the instant of transit of a star over the wires of the transit instrument was telegraphed. These observations gave for the difference of longitude between the two places, 7 minutes and 34 seconds in time.

The experience of a few nights showed the necessity of complete registering apparatus, such as is ordinarily employed by the telegraph companies; and this was accordingly ordered, but was not received in season for use during the year 1846 .

In the summer of 1847 the experiments were resumed with more complete apparatus. After 10 o'clock, P.s., the three stations at Washington, Phil- 
adelphia and Jersey City, opposite New York, were converted into temporary telegraph offices, as well as astronomical stations. The astronomical observations for clock corrections and personal equations, were arranged by Mr. S. C. Walker, on the model of Struve's celebrated chronometer expedition between Pulkova and Altona.

The mode of transmitting the telegraph signals was as follows:-A mean solar chronometer was compared by coincidence of beats with the sidereal transit clock, before and after telegraph signals. Then the party giving signals having previously broken the circuit; restored it by striking on his signal key, at intervals of even ten seconds, for a period of about ten minutes, so as to insure at least one coincidence of beats. The party at the other station who received the signals, was notified of each signal beat by hearing his own armature beat. The apparatus was adjusted so that the receiving armature beat should be nearly as loud as the clock beat. The times of the armature beat were compared with those of the receiving sidereal clock beat by the ear alone, and the time so recorded. On some nights, only twenty signals were given, at intervals of ten seconds upon the sidereal clock. But this method only repeats on the receiving clock the 
same fraction of a second, and does not furnish the same precision as the method of coincidence of beats.

It was found that signals could be given in coincidence with the clock beats, with such precision, that it was useless to attempt any correction of the signal times by the ear of the listener. But where the method of coincidence of beats of a mean solar and sidereal clock was dispensed with, and the fraction of a second was required to be estimated entirely by the ear, the error in the estimates was quite appreciable. It was found that observers, on the average, estimate the fraction of a second too small when using the ear alone, unassisted by the eye. This error is greatest at the middle date between two clock beats, and was found to vary from 0.06 to 0.18 of a second with different observers. This plainly indicated the necessity of relying solely on the method of coincidences of a mean solar and sidereal clock or chronometer. It was found that for the distance of 250 miles, embraced in these experiments, the electric current took no sensible time to propagate itself, and that two clocks at this distance could be compared with the same degree of precision as if they were placed side by side. 
The following is the result of this summer's campaign :-

DIFFERENCE OF LONGITUDE BETWEEN

Philadelphia and Philadelphia and Washington and Washington. Jersey City. Jersey City.

1847. July $19,7^{\mathrm{m}^{-}} 32^{\mathrm{s} \cdot} \cdot 969 \quad 4^{\mathrm{m}} 30^{\mathrm{s} \cdot} 440$

\begin{tabular}{rrrr}
21, & $33 \cdot 195$ & & \\
24, & $33 \cdot 058$ & $30 \cdot 305$ & \\
27, & & $30 \cdot 425$ & \\
28, & & $30 \cdot 470$ & \\
29, & $33 \cdot 050$ & $30 \cdot 407$ & $12^{\mathrm{m}} 3^{\mathrm{s} \cdot 552}$ \\
Aug. 3, & $33 \cdot 134$ & $30 \cdot 386$ & $3 \cdot 452$ \\
10, & & $30 \cdot 439$ & \\
11, & & $30 \cdot 303$ & \\
\hline Means,_-7m $33 \cdot 079$ & $4^{\mathrm{m}} 30 \cdot 397$ & $12^{\mathrm{m}} 3_{\mathrm{s}} \cdot 504$
\end{tabular}

These experiments seem to authorize the conclusion, that the electric telegraph affords the best means for the determination of terrestrial longitude between places in telegraphic connection with each other; and it is believed that the difference of longitude between two stations may be determined by this method, with the same degree of precision as the difference of latitude.

During the summer of 1848 , similar experiments were made to determine the difference of longitude 
between New York and Cambridge. A wire was extended from the Cambridge Observatory to connect with the New York and Boston line, near Brighton; and another wire was carried from the same line to Mr. Rutherford's observatory in the upper part of New York city. Thus the observatories at New York and Cambridge were in telegraphic communication. At New York, a new forty-five inch transit instrument, by Simms of London, belonging to the Coast Survey, was used for local time, and a sidereal clock with chronometers for comparisons. At Cambridge a similar transit was used, with numerous chronometers carefully compared. The comparisons of time were made both by the method of coincidences, and by telegraphing the transit of the same star over both meridians.

The method of coincidences was practiced in the following manner:-The observer at Cambridge, $\mathrm{Mr}$. Bond, with a solar chronometer before him, strikes the key of his register coincidently with the beat of his chronometer. The observer at New York, Prof. Loomis, hears the click of his magnet, and compares the instant with the beat of his own clock, which indicates sidereal time. The two sounds probably do not exactly coincide; but the 
Cambridge observer continuing to beat seconds upon the key of his register, the clicks heard at New York grow later and later as compared with the beats of the New York clock, and ultimately coincide. The New York observer records the instant of coincidence. The Cambridge observer continues to beat seconds for fifteen minutes, during which time the New York observer obtains two, and perhaps three coincidences of beats. The observer at New York now commences beating seconds in a similar manner, coincidently with the ticking of his clock, and continues it for fifteen minutes. The Cambridge astronomer compares the click of his magnet with the beats of his chronometer, and during the fifteen minutes, obtains four, and perhaps five coincidences, his chronometer beating half-seconds. The comparison of the two time-keepers thus made, is almost perfect. The other method of comparison was by telegraphing transits of stars. A list of zenith stars was selected beforehand, and furnished to each observer. The Cambridge astronomer points his telescope upon one of these stars as it is passing his meridian, and strikes the key of his register at the instant the star appears to coincide with the first wire of his transit. He makes a record of the time, by his own chronometer, and 
the New York astronomer, hearing the click of his magnet, records the time by his own clock. As the star passes over the second wire of the transit instrument, the Cambridge astronomer again strikes the key of his register, and the time is recorded both at Cambridge and New York. The same operation is repeated for each of the other wires. The Cambridge astronomer now points his telescope upon the next star of the list, which culminates after an interval of five or six minutes, and telegraphs its transit in the same manner. In about twelve minutes from the former observation, the first star passes the meridian of New York, when the New York astronomer points his transit instrument upon the same star, and strikes the key of his register at the instant the star passes each wire of his transit. The times are recorded both at New York and Cambridge. The second star is telegraphed in a similar manner. The Cambridge astronomer now selects a second pair of stars, and repeats the same series of operations, and is followed by the astronomer at New York, when the star comes upon his own meridian. By this comparison, the difference of time between the two stations is obtained independently of the tabular places of the stars.

On seven nights in July and August, these meth- 
ods were practiced, during which time 12,000 signals were exchanged between the observatories at New York and Cambridge.

The personal equations for the clock corrections of the different observers, were obtained by a very extensive series of comparisons, 894 in number, the transit of the same star over alternate wires of the telescope being noted by different observers.

The preliminary computations give an approximate result for longitude, differing only a small fraction of a second of time from that based on the observations of moon culminations and the transportation of chronometers, viz., 11 minutes and 27 seconds.

During the month of October, 1848, the difference of longitude between the Cincinnati Observatory and the High School Observatory, in Philadelphia, was also determined by telegraph for the use of the United States Coast Survey. A wire was carried from the Cincinnati Observatory to the Philadelphia line, thus putting the observatories of Philadelphia and Cincinnati in telegraphic communication. The series of observations made was substantially the same as had been practiced two months before between New York and Cambridge. A sidereal clock in Philadelphia was compared with a solar 
chronometer in Cincinnati, by beating seconds upon the key of the telegraph register for fifteen minutes, and noting the instants of coincident beats. Transits of the same stars over both meridians were also telegraphed, as had been practiced between Cambridge and New York. These comparisons were made on six different nights. The observations are not yet fully reduced, but the difference of longitude between the two observatories is found to be 37 minutes 21 seconds nearly.

During the months of July and August, 1849, a telegraphic comparison was made between the observatories of Philadelphia and Hudson, Ohio; and during the winter of 1849-50, a similar comparison was made between Washington and Charleston, S. C.

In the course of the comparisons for longitude by telegraph, which have now been mentioned, many thousand signals were transmitted, and all by the hands of a human operator. But it is impossible for human fingers to move with the precision of machinery; and after the first successful trial of the telegraph for longitude, it became evident that an important advantage would be secured if the clock could be made to transmit its own signals; and in August, 1847, I urged this subject upon the notice 
of the Superintendent of the Coast Survey, in a written communication.

The desideratum was to make an astronomical clock break the galvanic circuit every second, so that practically it might be said that its beats could be heard along the entire line of telegraphic communication, and in such a manner as not to affect the rate of the clock.

In the summer of 1848, Prof. Bond proposed a method of accomplishing this object, by insulating certain parts of the clock, and making the escapement itself the break circuit key of the telegraph wires. He made a drawing of his plan, and Prof. Bache, after satisfying himself of its practicability, engaged him to prepare a clock on this plan for the use of the survey.

Dr. Locke, of Cincinnati, in the autumn of 1848 , invented an attachment which may be applied to a common clock, and which fulfills every desirable requisite. He employs a wheel with sixty teeth attached to the axis of the escapement wheel. Each tooth, when horizontal, strikes against the handle of a platinum tilt-hammer, A B C, weighing about two grains, and knocks up the hammer, which almost immediately falls to a state of rest on a bed of platinum. The fulcrum B, of the tilt-hammer, and the 


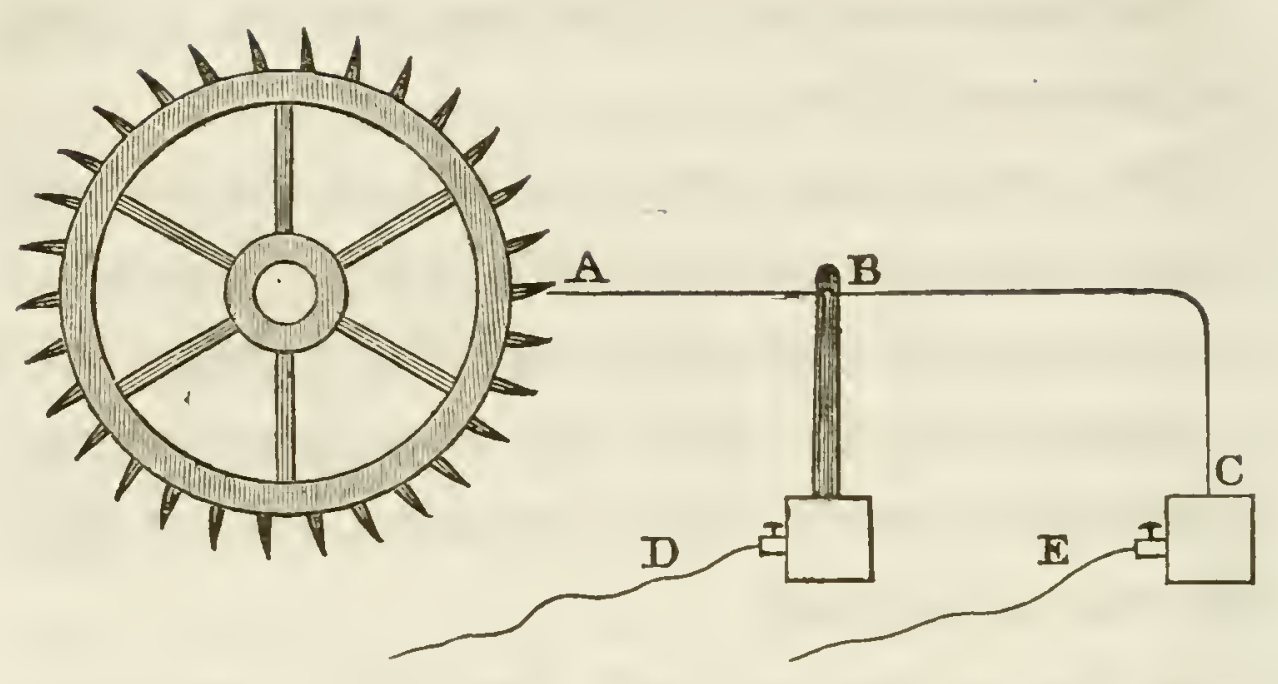

platinum bed, rest severally on a small block of wood. Each is connected by wires $\mathrm{D}$ and $\mathrm{E}$, with a pole of the galvanic circuit, and the circuit is alternately broken and completed, by the rising and falling of the hammer. The latter operation takes about one tenth of a second of time.

This arrangement was first tested on the 17th of November, 1848, on the Cincinnati and Pittsburgh line, about four hundred miles in length. The circuit was broken every second by the motion of the clock; and the fillet of paper being allowed to run off from the reel of the telegraph register, it was graduated into equal portions, consisting of an indented line about nine tenths of an inch in length, followed by a blank space of about one tenth of an inch. The two correspond to one second of time, commencing with the beginning of the 
line. The appearance of the graduated paper was as follows :

This experiment was continued for two hours, during which time the seconds by the Cincinnati clock were registered on the running fillet of paper at all the offices along the line. In order to distinguish the hours and minutes upon this graduated paper, Doctor Locke proposes to make the beginning of the ordinary minutes omit one blank space, the beginning of five minutes omit two, of ten minutes, three, and of an hour, ornit four consecutive blank spaces. Thus ordinary beginnings of minutes have continuous lines of two seconds, fives three, tens four, and hours five seconds.

The mode of using the register for marking the date of any event, is to tap on a break circuit key simultaneously with the event. The beginning of the short blank space thus registered in the midst of the indented line of the register, fixes, by a permanent printed record, the date of the event. Thus A represents such a register printed upon the graduated paper.

A

In this arrangement, it is important that the fillet of paper should run off from the reel with entire $\mathrm{R}^{*}$ 
uniformity. For this purpose more accurate clockwork is needed than is employed in ordinary telegraphing. One hundred inches of paper should be made to run off as nearly as possible in one hundred seconds of time. The fraction of a second of any event recorded upon the paper, may then be determined with a proportional scale, or dividers within one or two hundredths of a second. This clock may be easily employed in registering transits of stars over the meridian. It is only necessary for the observer to tap on the key, at the instant a star appears to pass each wire of his transit, and the observation is permanently recorded on paper with almost mathematical precision.

In the month of January, 1849, a clock upon Dr. Locke's construction was employed for printing transits of stars over different meridians for the determination of longitude. The observatories at Cambridge, New York, and Philadelphia were all put in communication with each other and with Washington city. The clock which was to be employed, was set up in Philadelphia, and connected with the telegraph line. Simultaneously with the beats of this clock, a click was heard of the magnets at Cambridge, New York, and Washington. The paper being allowed to run off from the reel, it 
was graduated into parts corresponding to the beats of the Philadelphia clock. The astronomer at Cambridge now selects a convenient star for observation, and announces it by name to each of the other stations. He strikes the key of his register as the star passes successively each wire of his transit instrument, and the dates are printed not only upon his own roll of paper, but also upon those at New York, Philadelphia, and Washington. When the same star comes over the meridian of New York, the observer there goes through the same operation, and his observations are printed upon all four of the papers. The Philadelphia observer does the same when the star comes upon his own meridian. Thus we have four long rolls of paper, one at Cambridge, a second at New York, a third at Philadelphia, and a fourth at Washington, all graduated into equal parts by the ticking of the Philadelphia clock, and upon these we have printed the instants at which the star was seen to pass each wire of the transits at Cambridge, New York, and Philadelphia. The position of each mark thus printed, shows not only the second of occurrence, but also the fraction of a second, which may be measured with scale and dividers. 'Thus, if we suppose the transit instruments to be all adjusted to the meridian, and the rate of 
the clock to be correct, we have obtained the difference of longitude of the stations compared, independently of the tabular place of the star employed, and also independently of the absolute error of the clock. The observers now read their levels and reverse their transit instruments. The Cambridge astronomer selects a second star, which is telegraphed in the same manner with the first. Thus the error of collimation of all the telescopes is corrected. The other errors of the instruments must be determined by separate observations in the usual manner. Subsequently a third and a fourth star were selected by the Cambridge astronomer, and telegraphed in the same manner, as they passed in succession over the different meridians. These experiments were made on the $23 \mathrm{~d}$ of January, 1849 , and occupied most of the night. The results are most wonderful, and open an entirely new field of investigation. Hitherto in transit observations, astronomers have been accustomed to estimate fractions of a second entirely by the ear, with only such assistance from the eye, as can be derived from the rapid motion of the star through the field of the telescope. The error of such an observation even with practiced observers, frequently amounts to a quarter of a second. But in this new mode of ob- 
servation, the observer has no use for his ears. The astronomer might in future be made without ears. It is only necessary for him to move his finger, at the instant the star is seen to pass each wire of his telescope, and his observation is recorded in a permanent form, and may be subsequently examined at his leisure.

This method is equally applicable to all observations with the transit instrument, and its advantages are such, that it promises entirely to supersede the old mode of observation. It not only possesses the advantage of precision, but also of performing vastly more work in a given time. Fifteen seconds is the ordinary equatorial interval for the wires of a transit instrument, and it was the opinion of Bessel, that five wires with this interval, are better than seven wires compressed into the same space. By using the method of imprinting the dates of the bisections of these wires on paper, where the use of the ear, and the counting of beats, and the manual labor of writing down these dates, are all dispensed with, the equatorial intervals may be reduced from fifteen to two seconds, or even to one and a half. Thus the number of bisections in a single culmination of a star, may be multiplied seven fold. The value of a night's work with the transit instrument is pro- 
portionally increased, so that a single year will furnish the same precision of results as many years of observation by the old method. In order to secure these advantages, it is important that the paper should be made to run off from the reel with entire uniformity. This may doubtless be effected by employing clock-work of sufficient strength and delicacy; such, for example, as is used to give motion to the Munich equatorials.

Dr. Locke's invention is not the first which has been published for breaking the galvanic circuit by clock-work. The honor of the first invention appears to be due to Prof. Steinheil of Munich, who, previous to September, 1839, had perfected a method for causing any number of clocks to indicate exactly the same time. This was accomplished by means of an arrangement which enabled the regulating clock, at the end of every hour, to advance or put back the hands of the subordinate clocks, so that all should indicate exactly the same time. This contrivance was as follows: One of the wheels in each clock carries a flat piece in the form of a spiral, which, during the hour, slowly raises a weight acting on a lever. The weight, when raised, is sustained like the trigger of a musket, and the spiral piece has a notch in which the lever may be caught. When 
the instant arrives for the standard clock to regulate all the others, an electro-magnet attracts its armature, and causes the arm of the lever to fall, carrying with it the spiral piece, with which the hands of the clock are connected. If during the preceding hour the clock has gained or lost time, the fall of the lever carries backward or forward the spiral piece, and with it the hands of the clock, so that on every dial the hands indicate exactly the same time. Thus all the clocks of a large city may be made to strike the hour at the same instant.

In the year $1840, \mathrm{Mr}$. Wheatstone invented a different method of accomplishing a similar object. The galvanic circuit in his clock is completed and broken, by the use of a circular disc of brass attached to the axis of the scapement wheel. This disc being divided on its circumference into sixty equal parts, each alternate division is cut out and filled with a piece of wood, so that the circumference consists of thirty regular alternations of wood and metal. The disc is insulated and connected with one pole of a galvanic battery. A delicate brass spring connected with the other pole, presses gently on this disc. Thus the circuit is closed and broken at alternate seconds. This mode enables the primitive clock to control the motion of any number of clocks in connection 
with it. Every time the circuit is broken or closed, any receiving clock-wheel with sixty teeth may be made to advance one second, and this wheel may, in the usual way, control the minute and hour wheel.

Mr. Bain's clock was patented in Great Britain in 1841, and has been successfully used for rail-road and other purposes. The circuit is closed and broken by a short brass bar, placed in a horizontal position near the middle of the pendulum, which slides back and forth about an inch, at each vibration of the pendulum.

In the year 1847, Mr. J. J. Speed of Detroit, Mich., conceived a plan for keeping the time of large cities uniform. He proposed to have all the clocks in the city connected with galvanic circuits, and operated from some central battery, the hands on the clocks moving only at given intervals, and at the instant the circuit should be closed. To close and break the circuit, he had a clock constructed with a tilt-hammer, which was lifted by a projecting tooth on one of the wheels of the clock. The credit of this part of the invention is conceded, however, to Mr. C. F. Johnson of Owego, N. Y., and was patented by him in 1846. The idea of applying the galvanic circuit to give motion to 
house clocks by means of the tilt-hammer, is claimed by Mr. Speed. His attention being soon after directed to other objects, Mr. Speed never carried his plan into execution; and the clock which he ordered to be constructed with the tilt-hammer arrangement, is now the property of the United States Coast Survey.

Mr. Speed's clock is similar in principle to that of Dr. Locke, although rude in its construction. Wheatstone's and Bain's clocks do not appear capable of being combined with the telegraph register in the same manner as Dr. Locke's, viz., to mark a continuous line upon paper, interrupted only for an extremely short interval at the beginning of each second. This is indispensable in the proposed application of the clock. If, for example, the circuit were complete for one second, and broken during each alternate second, as in Wheatstone's arrangement, then in attempting to record the instants of astronomical phenomena, as practiced with Dr. Locke's clock, one half of the phenomena would fail to be recorded, in consequence of their falling upon those seconds when the circuit was broken.

The Congress of the United States have, with unusual promptitude, expressed their conviction of the importance of this invention, by awarding the 
sum of ten thousand dollars to Dr. Locke for his invention, and directing that a clock upon this principle should be constructed for the use of the observatory at Washington. This clock has been completed, and is now set up for use at the observatory.

Professor Mitchell of Cincinnati has invented a method of breaking the galvanic circuit, by means of a delicate fiber attached to the pendulum, which acts upon a cruciform lever, and thus, in every double vibration of the pendulum, allows a metallic point to dip into a cup of mercury, which completes the circuit. Thus in his register, the clock dots are made at every two seconds.

Several different methods of registering the signals have been proposed. Dr. Locke uses a long fillet of paper, as is customary in the common Morse telegraph. Another method is the chemical method of registering with the main circuit. This method has some inconveniences arising from the irregularity of the action of the circuit, and the indistinctness of the marks. Prof. Mitchell causes a circular metallic disc to revolve with a uniform motion, by means of a Fraunhofer regulator, upon which disc the impressions of a pen or style form a dotted circle; then at the end of each revolution, a tooth 
upon the axis of the disc takes hold of a fixed rack and moves the traveling frame, which carries the center of the disc through a small space, so that the traces of the succeeding circle are prevented from mixing with those of the preceding one.

A fourth form of register is the invention of $\mathrm{Mr}$. Saxton of Washington. Mr. Saxton employs a cylinder covered with a sheet of paper, which turns upon a screw axis, so that the traces are made upon a perpetual spiral. This appears to be the most convenient arrangement of any yet proposed. One sheet filled on both sides will contain an ordinary night's work. A year's work will make a book of some three hundred pages, on the margin of which may be entered remarks relative to the state of the level and meteorological instruments, names of stars observed, and instrumental deviations.

The experiments of Jan. 23, 1849, between Cambridge, Philadelphia, and Washington, have afforded an approximate determination of the velocity of the electric fluid. If the fluid required no time for its transmission, then the star signals given at Cambridge ought to be similarly printed at all the places; and the fraction of a second registered upon the Cambridge scale, should be identically the same as upon the Philadelphia scale. But if the fluid re- 
quires time for its transmission, these fractions will be different; and the difference will be twice the time required for the fluid to travel from Cambridge to Philadelphia. In the observations of Jan. 1849, a difference in the registers of the papers at the several stations was detected, and it indicated a velocity of the electric wave of about nineteen thousand miles per second. Prof. Mitchell, by an entirely different process, has deduced a velocity of about twenty-eight thousand miles per second. In the month of October, 1849, similar experiments were repeated between Washington and Cincinnati, indicating a velocity of only sixteen thousand miles per second.

These results are materially less than that generally received upon the authority of Prof. Wheatstone. It is, however, by no means unphilosophical to suppose that the velocity of electricity is a variable quantity, depending upon its tension, as well as upon the dimensions and quality of the conducting medium. 


\section{SECTION V.}

ASTRONOMICAL PUBLICATIONS.

Anong astronomical publications in this country, the translation of La Place's Mécanique Celeste by Bowditch, deservedly holds the first rank. Although in name merely a translation of a foreign book, with a commentary, it has many claims to the character of an original work. Bowditch has probably done more for the improvement of physical astronomy, than all other Americans combined.

Of astronomical observations, the only ones which have appeared in separate volumes, are those of Lieut. Gilliss, at Washington, from 1838 to 1842 ; and those at the Naval Observatory for 1845. The former constitutes an octavo volume of 672 pages, the latter, a quarto volume of 550 pages, with 13 plates.

With the preceding exceptions, the American contributions to astronomical science are to be found in periodicals and the transactions of scientific socie- 
ties. The Transactions of the Royal Society of London contain some observations by American astronomers before the Revolution. The Transactions of the American Philosophical Society contain valuable papers from Rittenhouse, Ewing, Smith, Ellicott, Dunbar, Lambert, Adrain, Hassler, Gummere, Talcott, Courtenay, Loomis, Mason, Nicollet, Walker, Kendall, Bartlett, Gilliss, and several others. Among the subjects of these communications may be enumerated the Transit of Venus in $\mathbf{1 7 6 9}$; the Transit of Mercury in 1769; the Comets of 1770,1807 , 1842, 1843, and 1844; the Solar Eclipses of 1791, 1803, 1806, 1831, 1834, 1836, 1838 ; Numerous Occultations of Stars; Moon Culminations; Observations of Nebulæ; Observations and Computations for the Latitude and Longitude of numerous Places in this Country.

The Memoirs and Proceedings of the American Academy contain important papers from Willard, Williams, Winthrop, Webber, Dean, Bowditch, Fisher, Paine, W. C. Bond, G. P. Bond, and Graham. Among the subjects of these papers may be enumerated, Observations of the Transits of Mercury in 1782, 1789, and 1845; the Comets of 1807, 1811 , 1819, 1845, 1846, and 1847; the Solar Eclipses of $1780,1781,1782,1791,1806,1811,1845$, and 1846 ; 
Various Occultations of Stars; Observations of Nebulæ; and Observations and Computations for the Latitude and Longitude of various Places in the United States.

The Memoirs of the Connecticut Academy contain Observations of the Comets of 1807 and 1811, by Mansfield and Day, and the Calculation of the Longitude of Yale College.

The Transactions of the Albany Institute contain a Notice of the Solar Eclipse of 1806, by Simeon De Witt, and Observations of the Solar Eclipses of 1831 and 1832, by Prof. S. Alexander.

The American Journal of Science contains some original observations of Comets and Eclipses, and has been the vehicle for the diffusion of much valuable information respecting subjects of passing interest.

The American Almanac, which has been published regularly since 1830 , has given each year very full computations of all visible eclipses, and the elements for the calculation of occultations of stars by the moon. These computations were made by Mr. R. T. Paine until the year 1841, and since that time by Prof. Pierce.

The United States Almanac, which only continued for three year's, gave, in addition to the usual 
astronomical articles, a great variety of tables useful to computers.

The computation of the occultations of all stars down to the sixth magnitude, for nearly twenty years, has been made by Messrs. Walker, Downes, Paine, and Gibbes. Mr. Downes' computations for the years 1848, 1849, and 1850, have been published by the Smithsonian Institution. They contain the times of all the Occultations visible at Washington, and elements for facilitating a similar computation for any part of North America.

During the session of 1849 , Congress made an appropriation of $\$ 6,000$ for the commencement of an American Nautical Almanac. Lieut. Charles H. Davis was appointed superintendent, and the preparation of different parts of the work has been assigned to a corps of computers. Lieut. Davis asks for an appropriation of $\$ 13,000$ to defray the expenses of the work during the current year. $\mathrm{He}$ has secured the valuable services of Prof. Peirce, whose reputation can not fail to inspire confidence in the character of the work. In the first volume, which can not be published until about 1852 , the ephemerides of some of the planets will be based upon new theories, which will make them much more reliable than any heretofore published. 
The first periodical undertaken in this country devoted exclusively to astronomy, was the Sidereal Messenger, edited by Prof. Mitchell. This was designed to exhibit in a popular form the recent discoveries in astronomy, and by this means to cultivate a more general taste for astronomical science. The work was commenced in July, 1846, and continued for a little over two years, when it was abandoned for want of patronage.

At the meeting of the American Association for the Advancement of Science, at Cambridge, in August, 1849 , it was decided that a journal was needed in this country, devoted exclusively to the publication of original researches and observations. They proposed as their model the Astronomische Nachrichten of Professor Schumacher; the numbers to appear at irregular intervals, as matter accumulates, or important information is received.

The services of Mr. B. A. Gould have been secured as editor, and the first number of the "Astronomical Journal" was issued in November, 1849. The tenth number was issued in June, 1850, making somewhat more than one number a month. This journal has already attained a high reputation, and can not fail to impart a fresh impulse to the cause of science in the United States. 


\section{SECTION VI.}

THE MANUFACTURE OF TELESCOPES IN THE UNILED STATES.

VARIous attempts have been made in this country to manufacture both reflecting and refracting telescopes. I shall speak of each of them in succession.

REFLECTING TELESCOPES.

A great many reflecting telescopes have been constructed by amateur astronomers in different parts of the country; but for the most part, these attempts have been but moderately successful, and have contributed but little, if any thing, to the progress of science. The most important exception to this remark was in the case of a telescope manufactured in 1838, by Messrs. Smith, Mason, and Bradley, the two former gentlemen being at that time students of Yale College. This telescope had an aperture of twelve inches, and a focal length of fourteen feet. The mirror was cast, ground, and polished by their own hands. Stars of less than 
one second's distance, were separated by this instrument; the faint star, "debilissima," near \& Lyræ, was easily shown; and the nebula in Hercules, between $\eta$ and $\zeta$, was resolved into an immense number of small stars. With this instrument, $\mathrm{Mr}$. Mason made some very accurate observations of three nebulæ, of which an account is given in the Transactions of the American Philosophical Society. This paper affords but a foretaste of what might have been anticipated from the talents of Mr. Mason, had not his course been arrested by his premature death, which occurred Dec. 26th, 1840.

Several mechanics have undertaken the manufacture of reflecting telescopes for sale, but the only one who has pursued this business to any great extent is Mr. Amasa Holcomb, of Southwich, Massachusetts. Mr. Holcomb first attempted the grinding and polishing lenses about the year 1826. He then proceeded to the manufacture of refracting telescopes, but being discouraged by the difficulty of obtaining suitable glass, he turned his attention to reflectors. In this he succeeded remarkably well, and now his telescopes are found in almost every state of the Union, and some have been ordered for foreign countries. Mr. Holcomb now manufactures four sizes of instruments. 
The first size is 14 feet long and 10 inches aperture, with six eye-pieces, magnifying from 100 to 1000 times.

The second size is 10 feet long and 8 inches aperture, with six eye-pieces, magnifying from 60 to 800 times.

The third size is $7 \frac{1}{2}$ feet long and 6 inches aperture, with five eye-pieces, magnifying from 40 to 600 times.

The fourth size is 5 feet long and 4 inches aperture, with four eye-pieces, magnifying from 40 to 300 times.

These telescopes are of the Herschelian form, and have received medals from the American Institute of New York, and the Franklin Institute of Philadelphia, after a most thorough and severe examination. With a telescope of the second size, the double stars, $\xi$ Libræ, and $\zeta$ Bootis, the components of which are distant from each other but little more than one second, have been easily separated, and Saturn's ring seen double nearly throughout its visible portion. Mr. Holcomb has sold five telescopes of his first size, and as many of the second, with a much larger number of the smaller sizes. 


\section{REFRACTING TELESCOPES.}

The experiments which have been made in this country in the manufacture of refracting telescopes, may be divided into two classes; namely, those which have employed American glass, and those which have employed foreign glass.

Several telescopes of small dimensions have been made of American glass, which have performed quite satisfactorily; but the attempts to make large telescopes with American glass, so far as the results have been laid before the public, have invariably proved failures. At several establishments in this country, glass is manufactured, which answers perfectly all the ordinary purposes of the arts, and for transparency, compares well with foreign glass; but it has been found impossible to obtain large specimens possessing that entire homogeneity and freedom from veins which are demanded in a lens, in order that it may produce a perfect image.

Mr. Alvan Clark of Boston has made two telescopes of East Cambridge flint glass, having an aperture of five inches, which will show the division of the close pair in Zeta Cancri and Zeta Bootis, whose distance is about one second. He has, however, expressed his determination to make 
no more telescopes of American glass until he can find it better. It may safely be asserted, notwithstanding some pretensions to the contrary, that no good telescope of large dimensions has yet been manufactured of American glass.

Ever since the invention of the achromatic telescope by Dollond, nearly a century ago, one of the greatest obstacles to the construction of large telescopes, has been the difficulty of obtaining large discs of glass of uniform density, and free from veins. It has been said that the glass employed by Dollond in the manufacture of his best telescopes was all made at the same time; and the largest achromatic object glasses constructed in England, until recently, did not exceed five inches in diameter. More than half a century ago, the English Board of Longitude offered a considerable reward for bringing the art of making flint glass for optical purposes to the requisite perfection, but it led to no important discoveries. Upon the continent of Europe, experiments of this kind have been more successful. M. Guinand of Switzerland, and M. Fraunhofer of Bavaria, successively devoted their minds to the subject of manufacturing glass for optical purposes, and with astonishing success.

Guinand was born at Brenets, near Neufchatel, 
and was by trade a mechanic. Having been permitted to inspect an achromatic telescope, he determined to make one for himself, but could find no glass suitable for this purpose in Switzerland. He obtained some flint glass from England, but this was not always perfectly pure. He melted it anew, but did not obtain satisfactory glass. He then erected, on the river Doubs, near Brenets, an establishment, in which he constructed, with his own hands, a very large furnace, and commenced the manufacture of glass, and finally succeeded in obtaining pieces large enough for telescopes. He visited Paris in 1798, and exhibited discs of from four to six inches diameter. He afterward discovered a method of softening pieces of perfectly pure glass, for the purpose of giving them the form of a disc. In the year 1805, Guinand was invited by Reichenbach to assist him in his optical establishment which he had founded at Benedictburn, about 40 miles from Munich. Here he remained nine years, but always in a subordinate capacity. In 1814 he returned to Brenets, and established a separate manufactory, where he made telescopes, and furnished both flint and crown glass. In 1823 he was able to produce a disc of a foot and a half in diameter. In 1824 he exhibited 
a grand achromatic object glass at the exposition of industry at Paris, which excited the admiration of the king, who solicited the son of Guinand, then present, to invite his father to take up his residence at Paris. Unfortunately the optician was not in a condition to remove. He died in 1825, at the advanced age of nearly 80 years.

Another individual who contributed to the reputation of the establishment of Reichenbach, perhaps even more than Guinand, was the illustrious Fraunhofer. Fraunhofer was born at Straubing in Bavaria, in 1787, and at twenty years of age (in 1807) was received into the manufactory of Reichenbach. He here exhibited the most extrordinary talents, and introduced many improvements into the manufacture of glass, as well as in the art of polishing the spherical surfaces of large object glasses. His crowning glory was the manufacture of a telescope of nearly ten inches aperture, which was purchased for the observatory of Dorpat in Russia.

It has been asserted that the object glass of the Dorpat telescope was made from glass cast by Guinand; but this hàs been positively denied by Ut. schneider, who states that the glass for the Dorpat telescope was cast by Fraunhofer, after Guinand left the establishment at Benedictburn; and he also 
states that the glass which Guinand made was not equal in quality to that which Fraunhofer made at a later period. There can, however, be little doubt that much of the reputation of the Munich telescopes has resulted from Guinand's experiments in the manufacture of glass. The art of making this glass is kept as a secret. Many particulars of this manufacture therefore can only be conjectured. Faraday found the specific gravity of Guinand's flint glass to be about $3 \cdot 616$, and that its composition was silica $44 \cdot 3$, oxide of lead $43 \cdot 05$, and potash 11.75. It is said that Guinand's original practice was to saw the blocks of glass which he obtained at one casting, into horizontal sections, supposing that every part of the same horizontal section would have the same density. A fortunate accident conducted him to a better process. While his men were one day carrying a block of this glass on a hand-barrow to a saw-mill, the mass slipped from its bearers, and rolling down a declivity was broken to pieces. Guinand selected those fragments which appeared perfectly homogeneous, and softened them in circular molds in such a manner, that on cooling he obtained discs that were afterward fit for working. To this method he adhered, and contriv. ed a way of cleaving his glass while cooling, so that 
the fractures should follow the most faulty parts. When flaws occur in the large masses, they are removed by cleaving the pieces with wedges, then softening them again in molds which give them the form of discs.

It will be remembered that glass softens so as to be readily molded into any required shape, at a temperature much below that of complete fusion; and it appears to be requisite in this second operation of forming the glass into discs, to stop short of the melting point. If the glass be completely melted, bubbles of air rise through the glass, and are found caught in the glass after it is cooled, diminishing its transparency, and perhaps causing even worse defects. Many discs are spoiled in this manner. The advantage of allowing the glass to cool before it is cast into discs, is, that it affords an opportunity to inspect the casting, and select such portions as appear least faulty. It is supposed that the glass in the first instance is cooled pretty suddenly, so that it cracks under the operation; and that these fissures are determined by the want of homogeneity in the glass; so that the individual fragments may each be regarded as tolerably homogeneous. Each fragment is then put into a separate crucible or mold, having a diameter such as it is proposed to give to 
the disc, and softened by heat until it accommodates itself perfectly to the mold; and some discs bear marks of having been pressed down into the molds by a weight upon the top. It is then annealed by slow cooling in the manner of ordinary glass ware.

The son of P. L. Guinand has been for many years engaged in the manufacture of glass, with great success. His establishment is at Paris, and the following are the prices at which he furnishes discs of either crown or flint glass of the first quality for telescopes :-

\begin{tabular}{rrrr}
4 & \multicolumn{2}{c}{60 francs. } \\
5 & " & \\
5 & " & 100 & " \\
6 & 200 & " \\
7 & " & 250 & " \\
8 & 400 & " \\
9 & " & 450 & " \\
10 & " & 500 & " \\
11 & " & 550 & " \\
12 & 600 & " \\
14 & " & 1000 & " \\
16 & 2000 & " & 5000
\end{tabular}

Discs of glass for the manufacture of telescopes may be obtained from Merz and Mahler, successors of Reichenbach and Fraunhofer, but it has been 
complained that they only sell second rate glass, and reserve the best for their own use. It is probable, therefore, that the best glass for optical purposes which is now offered to the public, is that from the manufactory of the younger Guinand at Paris; and this glass certainly possesses a high degree of excellence.

While then experiments made in this country with American glass have generally proved failures, experiments with the aid of foreign glass have been more successful. Mr. Alvan Clark, of Boston, has. made two telescopes of Guinand glass, of about five inches aperture, and has nearly completed a third of the same dimensions. One of these, which was sold to Mr. Wells, of Newburyport, separates the close pair in the triple star Gamma Andromedx, whose distance is one third of a second, and shows the sixth star in the trapezium of Orion at intervals, though with difficulty. The other shows, clearly both the fifth and sixth stars in the trapezium of Orion, and separates Gamma Coronæ, the close pairs in the triple stars Chi Aquilæ and Gamma Andromedæ.

Professor Young, of Dartmouth College, examined this telescope last August, and says-"With a power of 500, Zeta Herculis appeared to me to be 
most exquisitely defined, the components (whose distance is but little over one second) finely separated, and the black intervening space beautifully distinct. Eta Herculis appeared to me to be wedge-shaped, but not divided; (the distance of the components is only one third of a second.) Indeed, without a previous knowledge of its duplicity, I should have pronounced it doubtful. The object glass of this telescope appeared to me to be one of great excellence, indicating a high degree of finish in respect to the correction of both the chromatic and spherical aberrations."

The principal manufacturer of refracting telescopes in this country is Mr. Henry Fitz, of New York city. Mr. Fitz has completed large telescopes of four different sizes.

No. 1, has a focal length of thirteen feet, and an aperture of eight inches. It has four eye-pieces, the highest magnifying 624 times. This is now on Inand for sale.

No. 2, has a focal length of eight feet, and an aperture of six inches. Highest magnifying power, 50.0 times. He has made three of this size; one was purchased by $\mathrm{Mr}$. Lewis $\mathrm{M}$. Rutherford; another by the U. S. government, for the Chilian expedition; and the third is on hand for sale. 
No. 3, has a focal length of seven feet, and an aperture of five inches. Highest magnifying power, 400 times. He has made four of this size; one for Mr. Rutherford, one for Mr. Longstreth, of Philadelphia, one for Erskine College, S. C., and the fourth for Mr. Robert Vanarsdale, of Newark, N. J.

No. 4, has a focal length of five feet, and an aperture of four inches. Highest magnifying power, 250 times. He has made and sold three telescopes of this size.

Several of these instruments have been subjected to a very thorough trial before they were purchased. The instrument for the Chilian expedition was procured under the following circumstances:- $\mathrm{Mr}$. Fitz volunteered to make an object glass from Guinand's discs, of the same dimensions as that of the High School Observatory in Philadelphia, which should be compared with that instrument, and if pronounced equal to it, he should charge for it only the cost of a similar lens at Munich. In May, 1849, Professor Kendall, of the High School Observatory, made trial of the Fitz object glass upon the moon, Jupiter, and several double stars, and after careful comparison with his Fraunhofer, declared himself unable to pronounce which was the better glass. Several other competent judges assisted at the trial, 
and concurred with Professor Kendall in his opinion. The glass was therefore purchased by the government, according to the contract. Lieut. Gilliss, after thorough trial, pronounced this telescope perfectly satisfactory, and says that it readily shows the sixth star in the trapezium of Orion, and the daily variations in the colored portion of Mars.

The other telescope, No. 2, sold to Mr. Rutherford, has also been fully tested. Mr. Rutherford says of it, "Its light is sufficient to show plainly, under favorable circumstances, the stars called by Capt. Smyth, in the Bedford Catalogue, of the 16th magnitude. It renders the companion of \& Lyræ and the fifth star in the trapezium of Orion visible under sufficient illumination for micrometric measurement, and it shows the sixth star in the trapezium without illumination; it enables me to see the rugged cliffs and volcanic chasms of the moon most beautifully; it has shown me the disc of Jupiter covered with small belts, in addition to the two usually seen, while two of his satellites were plainly seen projected upon the planet's disc, followed by their shadows, which were as distinct as black wafers upon white paper, the difference in their magnitude being easily seen without measurement; it very much elongates $\eta$ Coronæ, and enables me 
readily to measure the position and distance of the close pair of the triplet of $\zeta$ Cancri (distance one second) with a power of $200 . "$

One of Fitz's telescopes, No. 4, formerly belonging to Mr. Rutherford, performs remarkably well, considering its dimensions. The planet Saturn, as seen through it, appears of a beautiful white light, without any sensible prismatic dispersion, and with a perfectly sharp outline. The shadow of the ring cast upon the body of the planet, and the shadow of the planet cast upon the ring, are both beautifully seen, and also the belted appearance of the planet. It shows distinctly five satellites. The planet Mars is seen perfectly sharp, with an irregular stripe of a dark shade across the middle of the disc. The star "debilissima," near Epsilon Lyræ, can be seen in it with comparative ease, and the companion of the Pole star is visible in an illumined field.

One of Mr. Fitz's object glasses of $3 \frac{3}{4}$ inches aperture, has shown distinctly the fifth star in the trapezium of Orion.

The preceding evidence shows conclusively that Mr. Fitz has succeeded in producing lenses of great excellence. The following table will show that his prices are quite moderate. Cost of an achromatic object glass of 


$\begin{array}{lll}3 \text { inches aperture, } & \$ 50 \\ 4 & \text { " } & 120 \\ 5 & \text { " } & 250 \\ 6 & \text { " } & 500 \\ 7 & \text { " } & 600 \\ 8 & \text { " } & 800\end{array}$

The cost of a telescope completely mounted, wili of course depend upon the style of mounting. The telescope No. 3, sold to Erskine College, was furnished with clock-work ard micrometer complete, after the model of the Munich instruments, and cost $\$ 1050$. 'The telescope of the same size, purchased by Mr. Vanarsdale, was similarly mounted, but without the clock-work or micrometer, and sold for $\$ 750$. These prices are considerably less than those of the Munich instruments. 


\title{
poputar Works
}

\section{RELATING TO THE ARTS, SCIENCES, ETC.,}

\author{
PUBLISHED BY
}

HARPER \& BROTHERS, NEW YORE.

Bell's Mechanism of the Hand,

And its Vital Endowments, as evincing Design. With Engravings. $12 \mathrm{mo}$, Muslin, 60 cents.

Beck's Botany of the United States,

North of Virginia; comprising Descriptions of the Flowernng and Fern-like Plants hitherto found in those States, arranged according to the Natural System. With a Synopsis of the Genera according to the Linnæan System, a Sketch of the Rudiments of Botany, \&c. 12mo, Muslin, \$1 25 ; Sheep extra, \$1 50 .

Bigelow's Useful Arts,

Considered in connection with the Applications of Science.

With numerous Engravings. 2 vols. 12mo, Muslin, \$1 50.

Brewster's Letters on Natural Magic,

Addressed to Sir Walter Scott. With Engravings. 18mo, Muslin, 45 cents.

Chaptal's Chemistry applied to Agriculture.

With a preliminary Chapter on the Organization, Stricture, \&e., of Plants, by Sir Humphrey Davy. An Essay on the Use of Lime as a Manure, by M. Puvis; with introductory Observations to the same, by Prof. REvwick. Translated and edited by Rev. William P. Page. I8mo, half Sheep, 50 cents.

Browne's Trees of America,

Native and Foreign, Pictorially and Botanically Delineated, and Scientifically and Popularly Described; being considered principally with reference to their Geography and History; Soil and Situation; Propagation and Culture ; Accidents and Diseases ; Properties and Uses: Economy in the Arts; Introduction into Commerce; and their Application in Useful and Ornamental Plantations. Illustrated by numerous Engravings. 8vo, Mus. lin, $\$ 500$. 
2 Works Relating to the Arts, Sciences, \&.c.

Brande's Encyclopedia of Science, \&c.

A Dictionary of Science, Literature, and Art : comprising the History, Description, and Scientific Principles of every Branch of Human Knowledge ; with the Derivation and Definition of all the Terms in general Use. Edited by W. T. BRANDE, F.R.S.L. and E., assisted by JosePh CAUvin, Esq. The various Departments by eminent Literary and Scientific Gentlemen. With numerous Engravings on Wood. 8vo, Sheep extra, \$4 00.

Boucharlat's Elementary Treatise on Mechanics. Translated from the French, with Additions and Emendations, by Professor E. H. Courtenay. With Plates. 8vo, Sheep extra, \$2 25 .

Combe's Principles of Physiology,

Applied to the Preservation of Health, and the Improvement of Physical and Mental Education. With Questions. Engravings. $18 \mathrm{mo}$, Muslin, 45 cents ; half Sheep, 50 cents.

Daniell's Illustrations of Natural Philosophy. Selected principally from Daniell's Chemical Philosophy, by JAMES RENwick, LL.D. With Engravings. 18mo, Muslin, $68 \frac{3}{4}$ cents.

\section{Dick's Celestial Scenery;}

Or, the Wonders of the Planetary System displayed; illustrating the Perfections of Deity, and a Plurality of Worlds. With Engravings. $18 \mathrm{mo}$, Muslin, 45 cents.

\section{Dick's Sidereal Heavens,}

And other Subjects connected with Astronomy, as illustrative of the Character of the Deity, and of an Infinity of Worlds With Engravings. 18mo, Muslin, 45 cents.

Dick's Practical Astronomer,

Comprising Illustrations of Light and Colors, practical Descriptions of all kinds of Telescopes, the Use of the Equatorial-transit, Circular, and other Astronomical Instruments, a particular Account of the Earl of Rosse's large Telescopes, and other Topics connected with Astronomy. Illustrated with 100 Engravings. $12 \mathrm{mo}$, Muslin, 50 cents.

Draper's Text-book of Chemistry. With nearly 300 Illustrations. 12mo, Sheep extra, 75 cents.

Draper's Text-book of Natural Philosophy. With nearly 400 Illustrations. 12mo, Sheep extra, 75 cents.

\section{Draper's Chemical Organization of Plants.} With an Appendix, containing several Memoirs on Capillary Attraction, Electricity, and the Chemical Action of Light. With Engravings. 4to, Muslin, \$2 50 . 
Worlss Relating to the Arts, Sciences, \&c.

Brougham's Pleasures and Advantages of Science. By Lord Broughair, Prof. Sedgwick, Dr. Verplanck, and Aroízo Pctrer, D.D. 18mo, Muslin, 45 cents.

\section{Dyeing, Calico-printing, \&c.}

A practical Treatise on Dyeing and Calico-printing; including the latest Inventions and Improvements; also, a Description of the Origin, Manufacture, Uses, and Chemical Properties of the various Animal, Vegetable, and Mineral Substances employed in these Arts. With an Appendix, comprising Definitions of Chemical Terms; with Tables of Weights, Measures, Thermometers, Hydrometers, \&c. By an experienced Dyer, assisted by several scientific Gentlemen. Illustrated with Engravings on Steel and Wood. 8vo, Muslin, \$3 50.

Griscom's Animal Mechanism and Physiology. Being a plain and familiar Exposition of the Structure and Functions of the Human System. With Engravings. 18mo, Muslin, 45 cents; half Sheep, 50 cents.

\section{Natural History of Birds.}

Their Architecture, Habits, and Faculties. By James Rennie.

With Engravings. 18mo, Muslin, 45 cents.

\section{Olmstead's Letters on Astronomy,}

Addressed to a Lady. With numerous Engravings. 12mo, Muslin, 75 cents.

\section{Renwick's First Principles of Chemistry.}

With Questions. Numerous Engravings. 18mo, half Sheep, 75 cents.

Renwick's Science of Mechanics applied to Practical Purposes. With numerous Engravings. 18mo, half Roan, 90 cents.

Renwick's First Principles of Natural Philosophy. With Questions. Numerous Engravings. 18mo, half Roan, 75 cents.

\section{Stansbury's Interest Tables at Seven Per Cent.} Calculated by Months and Days, and by current Days at the rates of 360 and 365 to the Year. Decimally arranged under the head of Time. Each Period less than a Year, having a separate Table by Months and Days, and Days as 360 ths, contained on the third of a Page; a Table for a Year being repeated on each two Pages under observation at the same time. Each Day up to 146 having also a separate Table, at 365 to the Year; with a Table of 146 Days, repeated like the Year Table. Together with Factors for calculating Rebate or Discount; and also convenient Time Tables. Royal $8 \mathrm{vo}$, half bound, $\$ 150$. 
4 Works Relating to the Arls, Sciences, \&.c.

Gove's (Mrs.) Lectures to Women on Anatomy and Physiology, with an Appendix on Water Cure. 18mo, Muslin, 75 cents.

Smith's Elementary Treatise on Mechanics. Embracing the Theory of Statics and Dynamics, and its Application to Solids and Fluids. With Illustrations. 8vo, Muslin, $\$ 150$; Sheep extra, $\$ 175$.

\section{Wyatt's Manual of Conchology,}

According to the System laid down by Lamarck, with the late Improvements by De Blainville. Exemplified and arranged for the Use of Students, by Thomas WVATT, M.A. Illustrated with 36 Plates, containing more than 200 Types drawn from the Natural Shell. 8vo, Muslin, \$2 75 ; colored Plates, $\$ 800$.

Hutton's Book of Nature laid Open.

Revised and improved by J. L. Bцаке, D.D. With Questions for Schools. $18 \mathrm{mo}$, Muslin, $37 \frac{1}{2}$ cents.

The Physical Condition of the Earth.

The Earth: its Physical Condition and most remarkable Phe. nomena. By TV. M. Higgiss. With Engravings. 18mo, Mus. lin, 45 cents.

Moseley's Illustrations of Mechanics.

Edited by James Revwick, LL.D. With Engravings. 18mn. Muslin, 45 cents.

The Parlor Book of Flowers ;

Or, Boudoir Botany. Comprising the History, Description, and Colored Engravings of 24 Exotic Flowers, 24 Wild Flowers of America, and 12 Trees with Fruits. With an Introduction to the Science of Botany. By Jons B. Newnas, M.D. Illustrated with 250 Engravings. 8vo, Morocco, gilt edges, \$5 00 .

Euler's Letters on Natural Philosophy.

Letters of Euler on different Subjects of Natural Philosophy : addressed to a German Princess. Translated by Hunter. With Notes and a Life of Euler, by Sir David Brewster; and additional Notes, by Joris Griscom, LL.D. With Engravings. 2 vols. $18 \mathrm{mo}$, Muslin, 90 cents.

Popular Guide to the Observation of Nature

Or, Hints of Inducement to the Study of Natural Production: and Appearances in their Connections and Relations. By Rов err Mudie. With Engravings. 18mo, Muslin, 45 cents.

Herschel on the Study of Natural Philosophy $12 \mathrm{mo}$, Muslin, 60 cents.

Natural History of Insects.

With Engravings. 2 vols. 18mro, Muslin, $90 \mathrm{cents}$. 
Works Relating to the Arts, Sciences, \&c. 5

Haswell's Engineers' and Mechanics' Pocket. book, containing United States and Foreign Weights and Measures; Tables of Areas and Circumferences of Circles, Circular Segments, and Zones of a Circle; Squares and Cubes, Square and Cube Roots; Lengths of Circular and Semi-elliptic Ares; and Rules of Arithmetic. Mensuration of Surfaces and Solids; the Mechanical Powers: Geometry, Trigonometry, Gravity, Strength of Materials, Water Wheels, Hydraulics, Hydrostatics, Pneumatics, Statics, Dynamics, Gunnery, Heat, Winding Engines, Tonnage, Shot, Shells, \&c. Steam and the Steamengine; Combustion, Water, Cables and Anchors, Fuel, Air, Guns, \&c. Tables of the Weights of Metals, Pipes, \&c. Miscellaneous Notes, and Exercises, \&c. 12mo, Pocket-book form, \$1 25.

\section{Natural History of the Elephant.}

As he exists in a Wild State, and as he has been made subservient, in Peace and in War, to the Purposes of Man. By James Rexie. With Engravings. 18mo, Muslin, 45 cents.

The Principles of Science applied to the Domestic and Mechanic Arts, and to Manufactures and Agricul. ture. By A. Potter, D.D. With illustrative Cuts. 12mo, Muslin, 75 cents.

Natural History of Quadrupeds.

By James Rennie. With Engravings. 18mo, Muslin, 45 cents.

Scott's Infantry Tactics;

Or. Rules for the Exercise and Manœuvers of the United States Infantry. With Plates. 3 vols. 24mo, Muslin, \$2 50. (Published by authority.)

Somerville's (Mary) Connection of the Physical Sciences. From the recently revised Edition. 12mo, Muslin, 50 cents.

Whewell's Astronomy and General Physics, Considered with reference to Natural Theology. 12mo, Muslin, 50 cents.

Uncle Philip's American Forest;

Or, Conversations with the Children about the Trees of America. With Engravings. 18mo, Muslin, 35 cents.

\section{Uncle Philip's Natural History;}

Or, Conversations with the Children about Tools and Trades among the Inferior Animals. With Engravings. 18mo, Muslin, 35 cents. 
Worlis Relating to the Arts, Sctences, \&.c.

Kane's Elements of Chemistry:

Including the most recent Discoveries, and Applications of the

Science to Medicine and Pharmacy, and to the Arts. Edited by John W. Draper, M.D. With about 250 Wood-cuts. 8vo, Muslin, \$2 00 ; Sheep extra, \$2 25.

Lee's Elements of Geology for Popular Use.

Containing a Description of the Geological Formations and Mineral Resources of the United States. With numerous Engravings. $18 \mathrm{mo}$, half Sheep, 50 cents.

White's Natural History of Selborne.

With Engravings. 18mo, Muslin, 45 cents.

Salverte's Philosophy of Magic,

Including Prodigies, Apparent Miracles, and other Occult Sciences. Translated from the French, with Notes, Illustrative, Explanatory, and Critical, by A. Todp Thomson, M.D. 2 vols. $12 \mathrm{mo}$, Muslin, $\$ 100$.

Loomis's Treatise on Algebra.

8vo, Sheep extra, $\$ 100$.

Loomis's Elements of Geometry and Conic Sections. 8vo, Sheep extra, $\$ 100$.

Loomis's Elements of Plane and Spherical Trigonometry, with their Application to Mensuration, Surveying, and Navigation. To which is added, a full Series of Tables of Logarithnus of Numbers, and of Sines and Tangents for every Ten Seconds of the Quadrant. With other useful Tables. 8vo, Sheep extra, $\$ 150$.

Loomis's Tables of Logarithms of Numbers;

And of Sines and Tangents for every Ten Seconds of the Quadrant. With other useful Tables. 8vo, Sheep extra, \$1 00.

Hackley's Treatise on Algebra.

Containing the latest Improvements. $8 \mathrm{vo}$, Sheep extra, $\$ 150$.

Hackley's Elementary Course of Geometry. $12 \mathrm{mo}$, Sheep extra, 75 cents.

Clark's Elements of Algebra.

Embracing, also, the Theory and Application of Logarithms: together with an Appendix, containing Infinite Series, the general Theory of Equations, and the most approved Methods of resolving the higher Equations. 8vo, Sheep extra, \$1 00.

Hazen's Popular Technology;

Or, Professions and Trades. Illustrated with 81 Engravings.

$18 \mathrm{mo}$, half Sheep, 75 cents. 
(1)

.

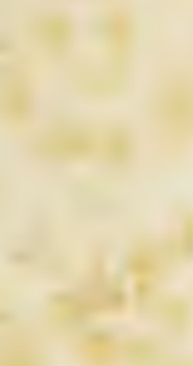

(1)

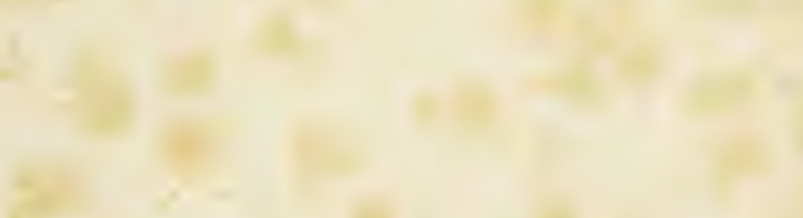

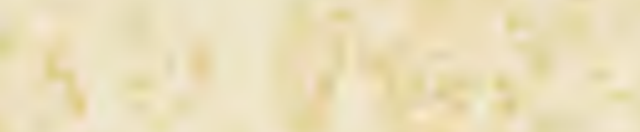

10 +

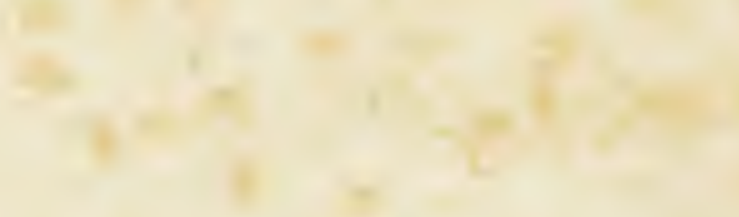

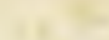

cos

$\sqrt{2}+x^{2}$

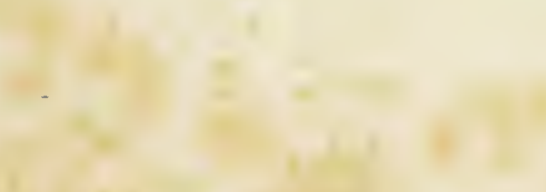

$+1+2=1-2$

.

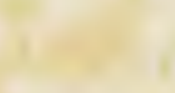

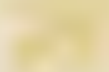

4 10 


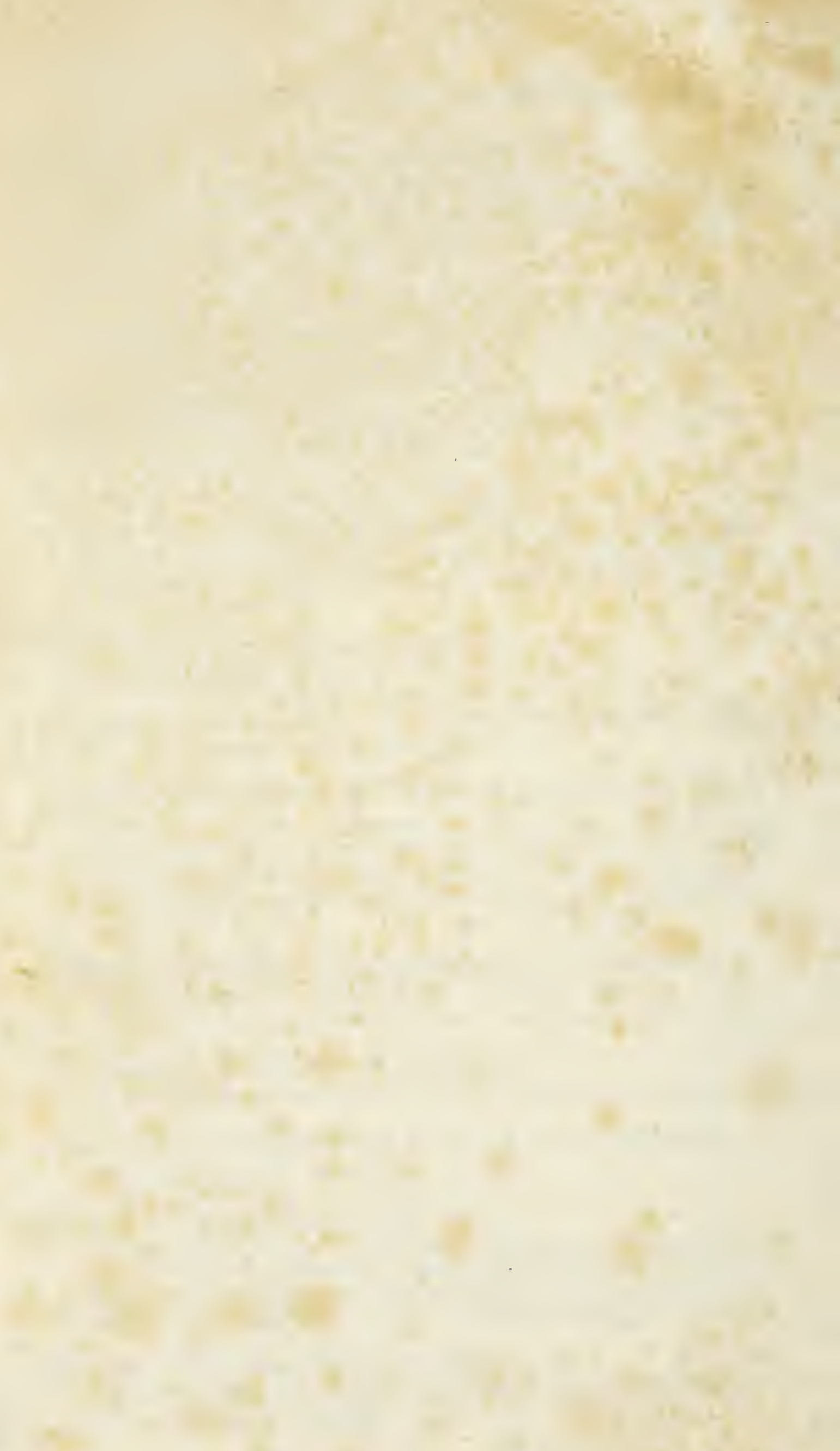




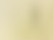

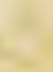

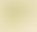

西

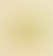

(n)

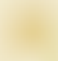

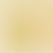





35002002630395

Loomis, Elias

The recent progrss of astronomy; especia

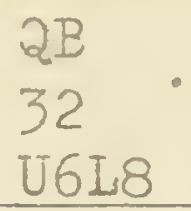

AUTHOR

Loomis $\quad 5122$

TITLE

ilecent orooress of astronomy

Istroromy Library

QB

32

U6I8 
